\title{
A DISAGGREGATE ANALYSIS OF URBAN TRAVEL BEHAVIOR
}

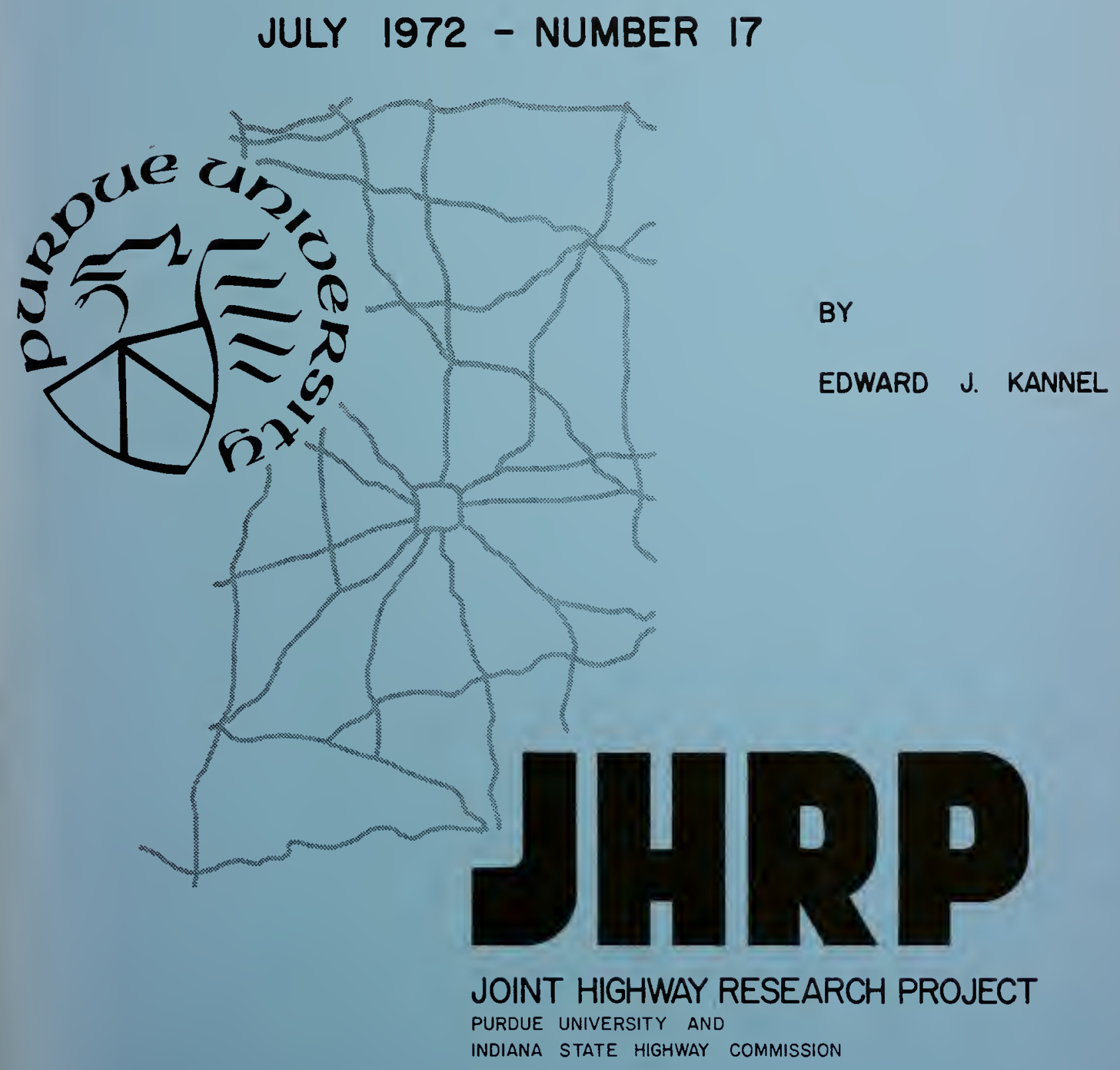



A DISAGGREGATE ANALYSIS OF URBAN TRAVEL BEHAVIOR

TO: J.F. McLaughlin, Director

Joint Highway Research Project

FROM: H. L. Michael, Associate Director Joint Highway Research Project

\author{
July 26, 1972 \\ Project: C-36-69I
}

File: $\quad 3-7-9$

The attached Final Report titled "A Disaggregate Analysis of Urban Travel Behavior" is submitted as fulfillment of the objectives of Phase I of the HPR Part I Study titled "A MicroAnalys is of the Effects of Household Socio-Economic Characteristics and Individual Attitudes on Trip Generation". The research was conducted and the report prepared by Edward $\mathrm{J}$. Kannel, Graduate Instructor in Research, under the direction of Professor $K$. W. Heathington.

This research evaluated the stability of household trip generation models over a seven year period. A sample of 357 families interviewed in the Indianapolis Transportation Study of 1964 were reinterviewed in 1971. Disaggregate trip generation models from the 1964 and 1971 data from these families were equally successful in estimating total zonal travel and provide the benefit of reduced sample size requirements for estimation of model parameters.

The Report is presented for acceptance and will also be forwarded for review, comment and acceptance by the ISHC and FHWA.

HLM : ms

Respectfully submitted,

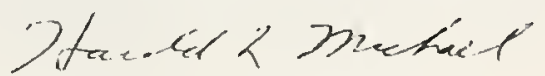

Harold L. Michael

Associate Director
CC: W. L. Dolch
R. H. Harre11
C. F. Scholer
R. L. Eskew
M. L. Hayes
W. H. Goetz
C. W. Love 11
M. B. Scott
W. L. Grecco
G. W. Marks
J. A. Spooner
M. J. Gutzwiller
R. D. Miles
N. W. Steinkamp
G. K. Hallock
J. W. Miller
H. R. J. Walsh
E. J. Yoder 
Digitized by the Internet Archive in 2011 with funding from

LYRASIS members and Sloan Foundation; Indiana Department of Transportation 


\title{
Final Report
}

A DISAGGREGATE ANALYSIS OF URBAN TRAVEL BEHAVIOR

$$
\text { by }
$$

Edward J. Kannel

Graduate Instructor in Research

Joint Highway Research Project

$$
\text { Project No.: C-36-69I }
$$

File No.: 3-7-9

\author{
Prepared as Part of an Investigation \\ Conducted by \\ Joint Highway Research Project \\ Engineering Experiment Station \\ Purdue University \\ In cooperation with the \\ Indiana State Highway Commission \\ and the \\ U.S. Department of Transportation \\ Federal Highway Administration
}

The opinions, findings and conclusions expressed in this publication are those of the authors and not necessarily those of the Federal Highway Administration. 


\section{ACKNOWLEDGMENTS}

The author wishes to express his appreciation to Professor Kenneth $w$. Heathington for his encouragement and guidance in the conception and execution of this research and for his critical review of the manuscript.

The assistance of Professor Virgil L. Anderson in review of the statistical analysis of the manuscript was very much appreciated. Thanks are also due to professor William I. Grecco and Professor Gilbert T. Satterly for their review of the manuscript.

The author is grateful to the Automotive Safety Foundation and the Joint Highway Research Project for their financial assistance and to his fellow workers for their assistance and encouragement.

Thanks are also due to $\mathrm{Mr}$. Gene Hatheway and other personnel of the Indianapolis Department of Transportation for their assistance during the data collection phase of this research.

Greatest appreciation is extended to the author's wife for her encouragement and assistance and to his sons for their inspiration. 
TABLE OF CONTENTS

Page

IIST OF TABLES........................... vi

LIST OF FIGURES.......................... ix

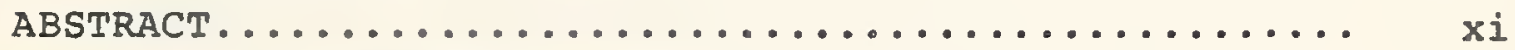

CHAPTER 1. INTRODUCTION........................ 1

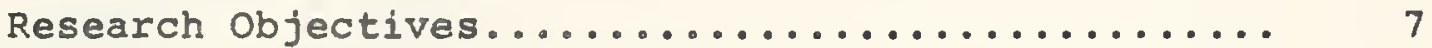

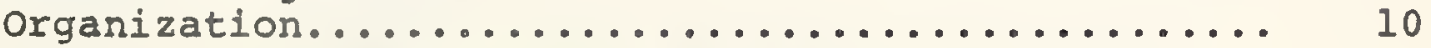

CHAPTER 2. MODELING CONCEPTS FOR EVALUATING TRAVEL

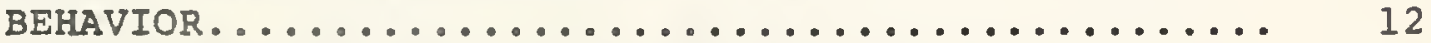

Aggregate Modeling Procedures and Assumptions...... 12

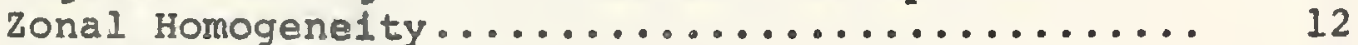

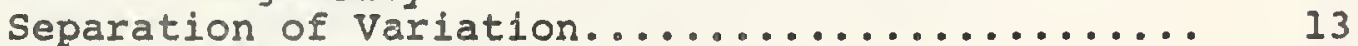

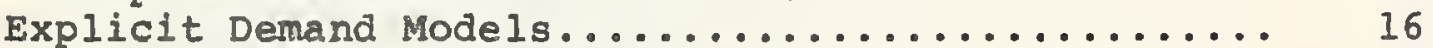

Disaggregate Trip Generation Analysis............ 19

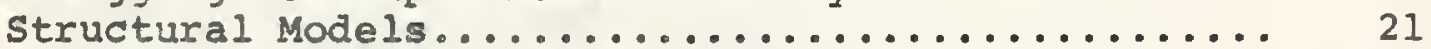

Structural Model Development and Application.... 23

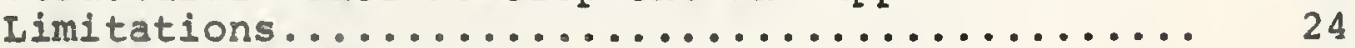

Individual Perceptions of Travel Decisions........ 25

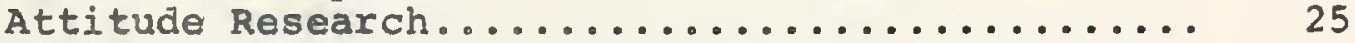

CHAPTER 3. STUDY DESIGN....................... 28

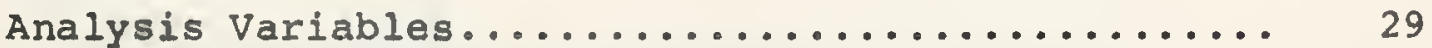

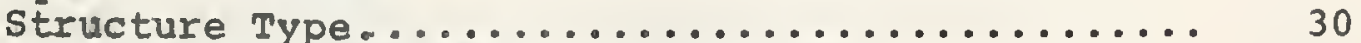

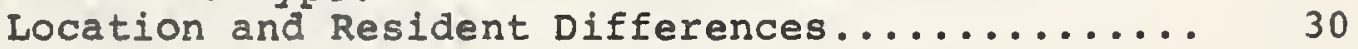

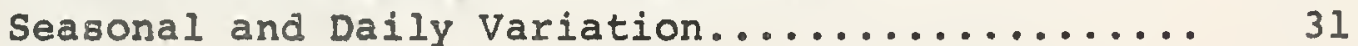

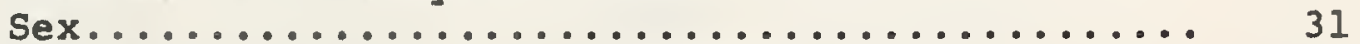

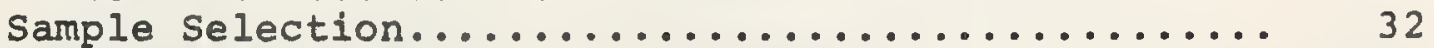

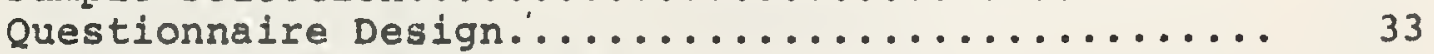

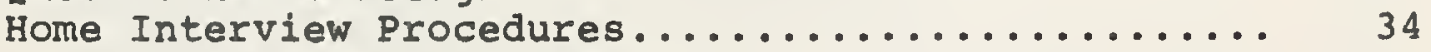

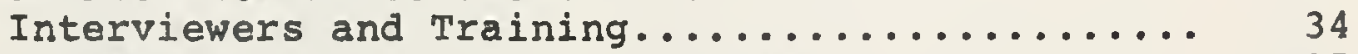

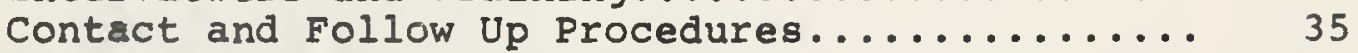

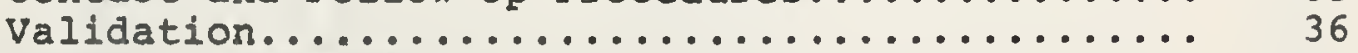

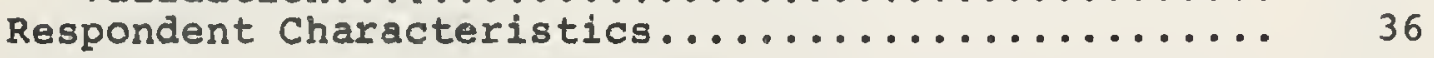


TABLE OF CONTENTS (continued)

Page

CHAPTER 4. INDIVIDUAL PERCEPTIONS OF TRAVEL CHOICE

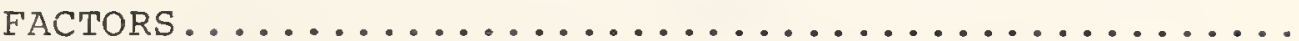

An Evaluation of Factors Important in Mode Choice...

Critique of the Successive Category Rating

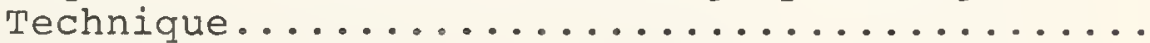

Evaluation of Mode Choice Factors by Subgroups...

An Analysis of Driver Preferences for Route Choice

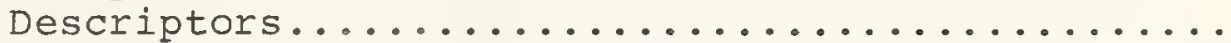

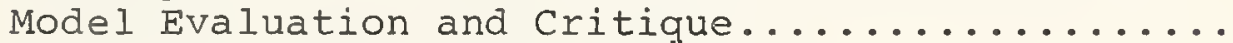

Analysis of Route Choice Descriptors by Subgroups

Analysis of Factors Related to Choice of Trip

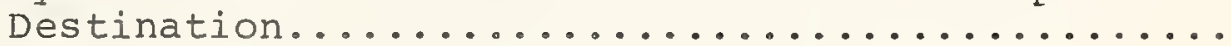

Analysis of Preferences for Shopping Trip

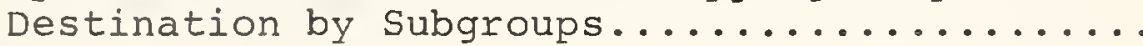

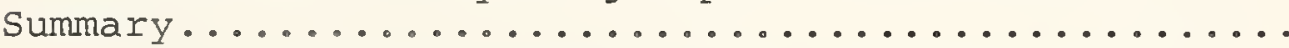

CHAPTER 5. HOUSEHOLD TRAVEI CHARACTERISTICS AND

TRIP GENERATION EQUATIONS..................

Household Travel Characteristics.................

Household Trip Prediction Equations for Estimating

Trips from Single Family Dwelling Units.........

Test of Assumptions of Household Model Trip

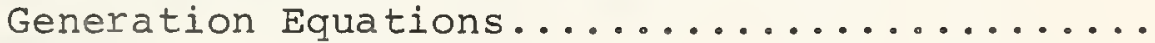

Estimating 1971 Home Based Trip Productions......

Expansion of Disaggregate Single Family Dwelling

Unit Equations to Obtain Zonal Trips...........

Expansion of Disaggregate Equations from All

Dwelling Units to Obtain Zonal Trips............

Potential for Data Reduction in Continuing Study.... Comparison of Model Parameters in Different

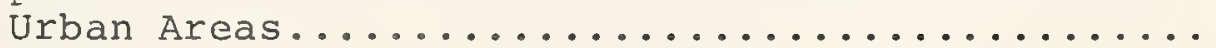

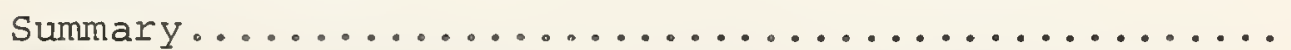

CHAPTER 6. EVALUATION OF ADDITIONAL VARIABLES IN

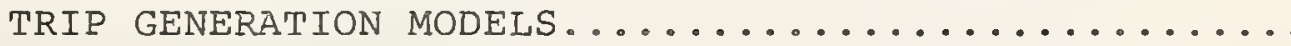

Individual Perceptions of Factors Influencing

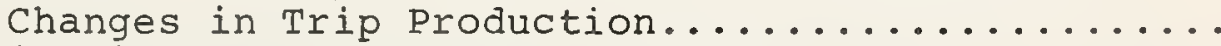

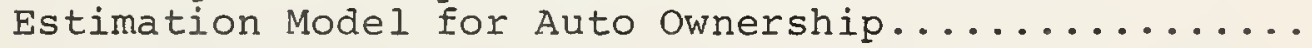

Other Factors Considered in Trip Generation Analysis

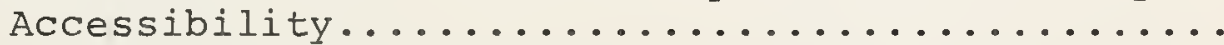

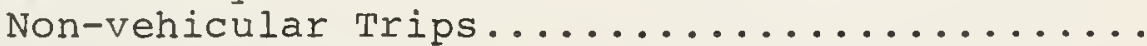

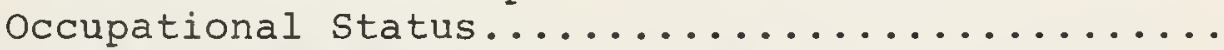

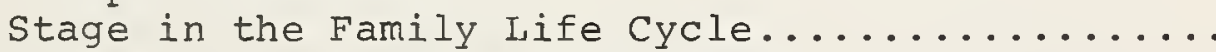

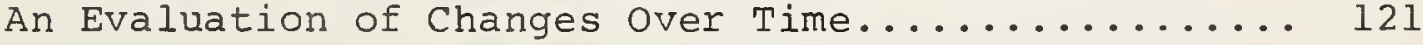

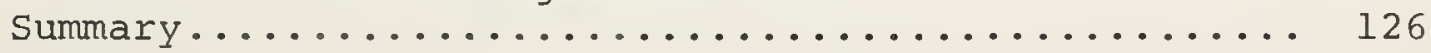


TABLE OF CONTENTS (continued)

Page

CHAPTER 7. ANALYSIS OF THE STRUCTURAL RELATIONSHIPS AMONG SELECTED VARIABLES IMPORTANT TO TRIP

GENERATION

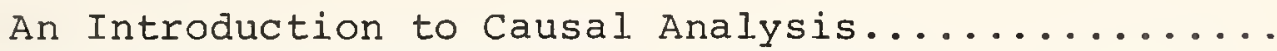

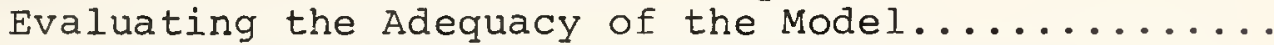

A Summary of the Structural Model Assumptions...

An Evaluation of a Simplified Causal Model........

An Evaluation of an Integrated Causal Model for

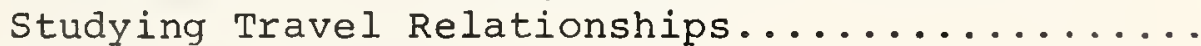

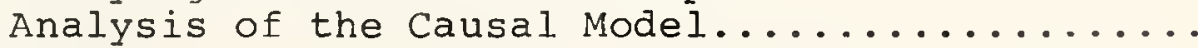

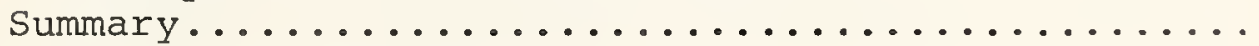

CHAPTER 8. CONCLUSIONS...................... 151

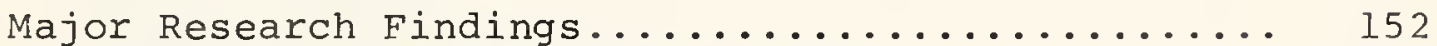

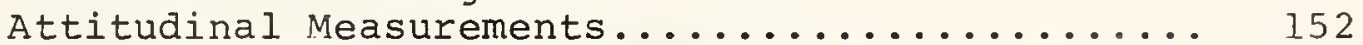

Household Trip Generation Analysis............ 153

Estimation of Zonal Travel from Disaggregate

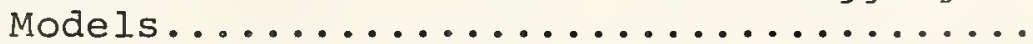

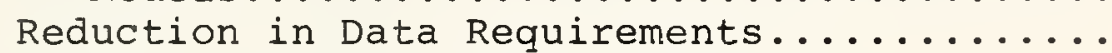

Causal Structure of Trip Generation

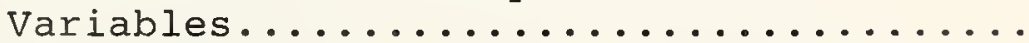

Application and Recommendations for Future

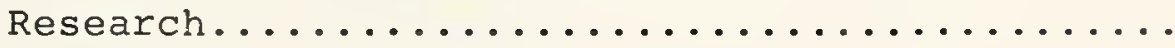

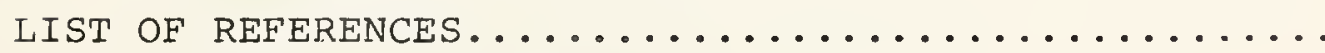

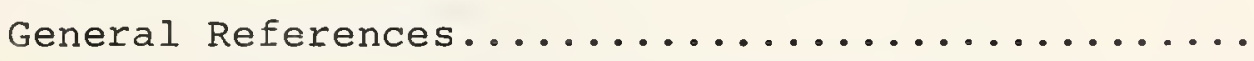

APPENDIX A. HOME INTERVIEW QUESTIONNAIRE AND RELATED

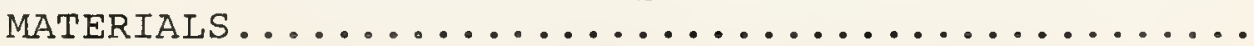

APPENDIX B. RESPONDENT CHARACTERISTICS AND HOUSEHOLD TRIP PRODUCTION RATES....................

APPENDIX C. CHARACTERISTICS OF WORK TRIP AND SHOPPING TRIP....................... 
LIST OF TABLES

Table

Page

2.1. The Affect of Aggregation on Within and

Between Sum of Squares for Four Levels of

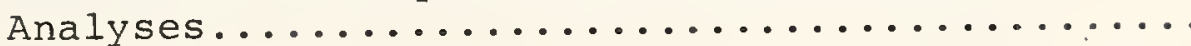

2.2. Statistical Comparison of Aggregate and Dis-

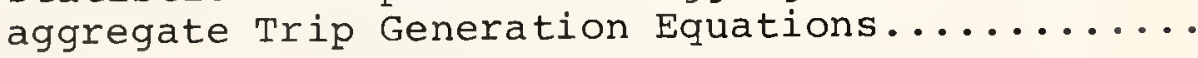

3.1. Average Household Income Distribution for

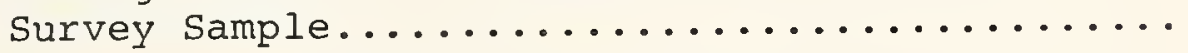

3.2. Occupation of Head of Household..............

4.1. Attitudinal Ratings of Mode Choice Factors in

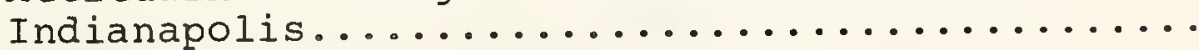

4.2. Attitudinal Ratings for Mode Choice Factors -

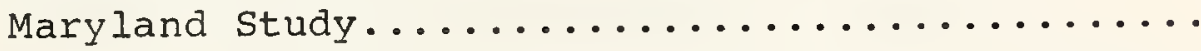

4.3. Kolmogorov-Smirnov Test for Difference in Mode Choice Preference, by Subgroups..............

4.4. Route Choice Descriptors Used in Paired

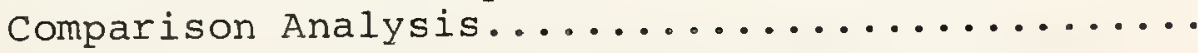

4.5. Observed Proportion Matrix for Evaluating Route Choice Preferences for Work Trip.........

4.6. Observed Proportion Matrix for Evaluating Route Choice Preferences for Shopping Trip.....

4.7. Attitudinal Ratings of Factors Important in Selection of a Shopping Trip Destination.......

4.8. Kolmogorov-Smirnov Test for Difference in Shopping Trip Destination Preferences, by

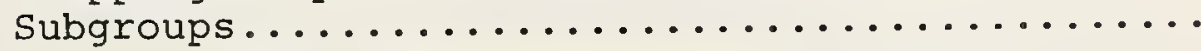

5.1. Average Household Socioeconomic and Trip Production Characteristics of Survey Sample..... 
LIST OF TABLES (continued)

Table

Page

5.2. Distribution of Variance in Household Travel

for Varying Family size Levels..............

5.3. Analysis of Variance for Home Based Trip

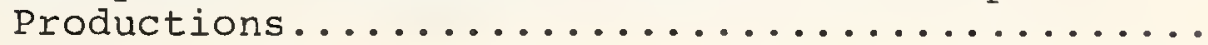

5.4. Household Prediction Equations for Home Based

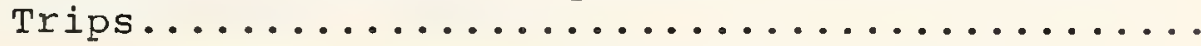

5.5. Lack of Fit Test of 1971 Household Linear

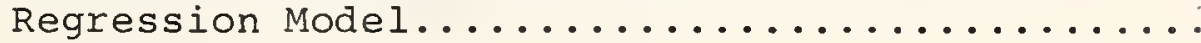

5.6. Summary Statistics of Single Family Household

Equations Expanded to Obtain Zonal Travel

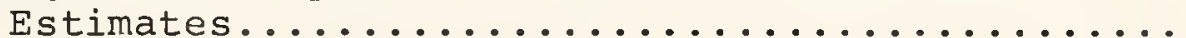

5.7. Zonal Home Based Trip Generation Models Developed by IRTADS....................

5.8. Expansion of Household Equations from All

Dwelling Units to Predict Total Zonal Travel....

5.9. Linear Regression Parameters for Household

Models Based on Entire 1964 Data Set..........

5.10. Comparison of Predictive Ability of Household Models Based on a Five Percent Sample and a

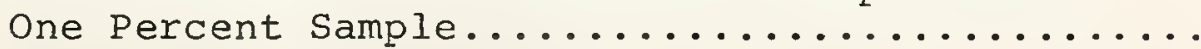

5.11. Aggregation Effects on Trip Generation Model

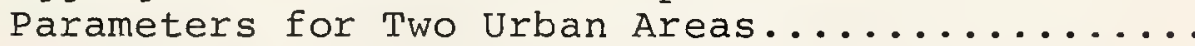

6.1. Respondents Perceptions of the Affects which Changing Household Characteristics and Urban Development Had on Trip Production from 1964

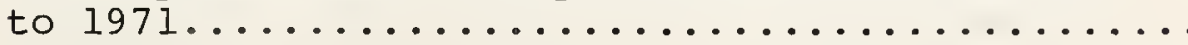

6.2. Home Based Trip Productions for Different Levels

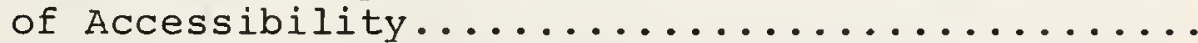

6.3. ANOVA Models for Evaluating the Effect of Accessibility on Home Based Travel............

6.4. ANOVA Models for Evaluating the Effect of

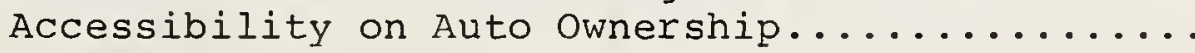


IJIST OF TABLES (continued)

Table

Page

7.1. Observed Correlation Matrix for Variables in

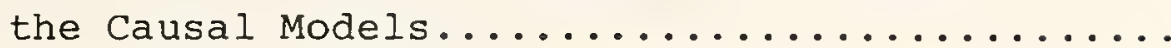

7.2. Differences Between Empirical and Reproduced Correlations - Model I.................... 144

7.3. Differences Between Empirical and Reproduced Correlations - Model II..................

7.4. Differences Between Observed and Reproduced Correlations - Model III..................

Appendix

Tables

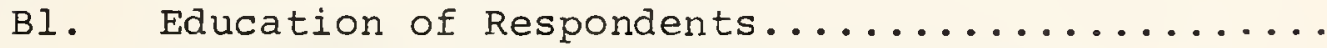

B2. Age Distribution of Head of Household, 1971...

B3. Family Status of Households in 1964 and 1971...

B4. Home Based Trip Production Rates for Family

Size and Auto Ownership Classes.............

B5. Home Based Trip Production Rates for Income

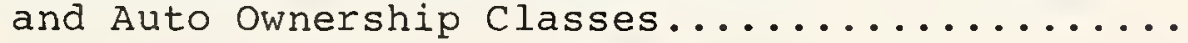

B6. Home Based Trip Production Rates for Income

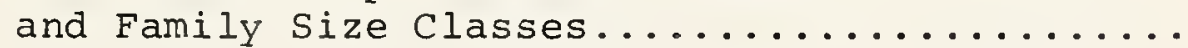

C1. Distance to Bus Stop for Survey Households....

C2. Average Work Trip Length for Occupation and

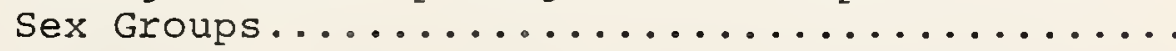

C3. Average Work Trip Length for Varying Levels

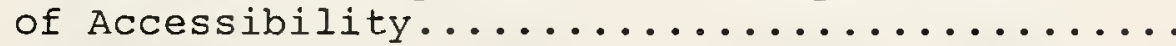

C4. Location of Shopping Trip Destination by Mode of Transportation and Sex of Respondent.......

C5. Reasons for Selecting Shopping Trip Destination

C6. Summated Rating Scale Analysis for Relating Individual Attitudes to Trip Production........ 
LIST OF FIGURES

Figure

4.1. Distribution of Response Rates of Successive Categories Scaling Technique for Work Trips....

4.2. Distribution of Response Rates of Successive Categories Scaling Technique for Shopping

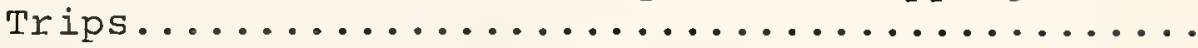

4.3. Relative Scales for Route Choice Descriptors....

4.4. Calculated Versus Observed Proportions for Route Choice Descriptors, Work Trip...........

4.5. Calculated Versus Observed Proportions for Route Choice Descriptors, Shopping Trip........

4.6. Relative Scales for Route Choice Descriptors for Work Trip, By Subgroups................

4.7. Relative Scales for Route Choice Descriptors for shopping Trip, By Subgroups.............

4.8. Distribution of the Trip Destination Opportunities Bypassed Before Selecting a Destination....

5.1. Household Travel Rates for Varying Levels of

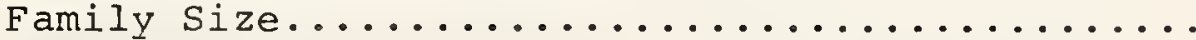

5.2. Household Travel Rates for Varying Levels of

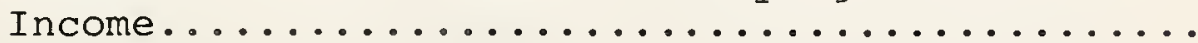

5.3. Household Travel Rates for Varying Levels of

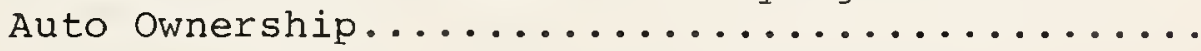

5.4. Home Based Trip Frequency Distribution........

5.5. Estimated Zonal Trip Productions from Household Model Versus Actual Zonal Trip Productions from IRTADS

5.6. Frequency Distribution of Zonal Residuals Determined from Expanded Household Equations.... 


\section{LIST OF FIGURES (continued)}

Figure

6.1. Average Household Income Related to Auto

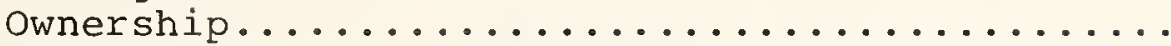

6.2. Effect of Accessibility on Household Trip

Production, Controlling for Income............

6.3. Effect of Accessibility on Household Trip Production, Controlling for Autos............

6.4. Effect of Accessibility on Auto Ownership,

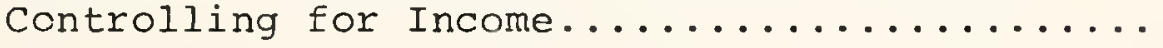

6.5. Effect of Accessibility on Non-vehicular

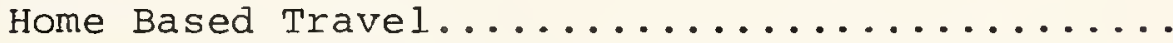

6.6. Changes in Trip Production Rate within the Household with Changes in Family Size........

6.7. Changes in Trip Production Rate Within the Household with Changes in Auto Ownership.......

6.8. Changes in Auto Ownership Within the Household with Changes in Family Income.......

7.1. An Example of a Four Variable Causal Model....

7.2. A Simplified Causal Model of Household Trip Generation Relationships.................

7.3. A Revised, Simplified Causal Model of Household Trip Generation Relationships.............

7.4. A Developed Causal Model of Household Travel

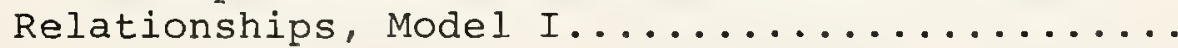

7.5. A Developed Causal Model of Household Travel

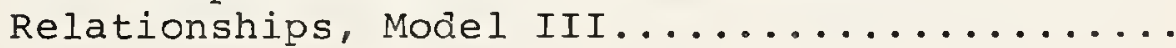


ABSTRACT

Kannel, Edward J. Ph.D., Purdue University, June, 1972. A DISAGGREGÁTE ANALYSIS OF URBAN TRAVEL BEHAVIOR. Major Professor: Kenneth W. Heathington.

This research was directed toward an evaluation of travel behavior at a disaggregate level of analysis. The objectives of the research were to develop trip generation models at the household level of analysis, to evaluate the stability of the relationships over time, to examine the causal structure of the variables found to be most significant in explaining trip production, and to examine individual's attitudes and perceptions of factors important in travel choice.

A quasi-laboratory experimental design was established to evaluate the stability of household trip generation models over a seven year period. A sample of 357 single family households was selected from the 1964 Indianapolis, Indiana transportation study. The identical families were reinterviewed in 1971. Disaggregate trip generation models from the two data sets were equally successful for estimating the zonal trips reported by all single family units from which the survey sample was drawn. Also, disaggregate models based on data from all dwelling unit types were comparable to aggregate models for estimating total zonal travel. The disaggregate models provide the additional benefit of reduced sample size requirements for estimation of model parameters.

Examination of the causal structure of the variables indicated that family size and auto ownership are the primary explanatory variables in household trip generation equations. Income, labor force and relative accessibility 
provide an indirect influence on trip production due to their effect on auto ownership levels.

Attitudinal responses indicated only minor differences among subgroups of the sample in regard to factors important in mode and route choice and in selection of a trip destination. Travel time and travel costs were not generally perceived as the important factors in the respondent's decision. 
CHAPTER 1. INTRODUCTION

Prior to the 1944 Federal Highway Act which allocated monies for use in urban area planning studies, very little consistent effort had been applied to obtain information about the complexities of travel in urban areas. In the years preceding allocation of Federal monies, the planning efforts for urban areas were primarily shaped by knowledge of the techniques which had been used to develop rural area highway plans or plans for isolated areas, such as sections of streets, within the urban area.

Those in charge of developing urban studies were, however, aware that the problem was much more complex. The data and procedures for studying rural area conditions were inadequate for obtaining an understanding of the travel characteristics within the cities. Although many urban planners felt the need for more detailed studies, they did not have sufficient technical background or data for evaluation of the entire transportation system. Resource limitations also played a vital role.

The need for a greater base from which planning decisions could be formed was recognized by the cities and the Public Roads Administration (later known as the Bureau of Public Roads and now, the Federal Highway Administration). The federal agency in 1946 in cooperation with participating local agencies, started to conduct what has become the most significant data base of urban travel, the origin and destination study. These studies have subsequently been conducted in over 200 urban areas using the same basic format and definitions.

By 1954 the acceptance of the art of urban transportation planning was exhibited by the formation of the National 
Committee on Urban Transportation (NCUT). This committee drew upon the experience of many of the leading authorities in traffic engineering, highway planning, transit operations and city planning. Their experiences and procedural recommendations were combined and published in a transportation planning guide and a series of seventeen procedural manuals (NCUT, 1958). These manuals, along with continuous advisory aid of the Bureau of Public Roads, helped cities to develop transportation plans for various study areas.

The need for uniform, accepted procedures for developing transportation planning studies was emphasized by the 1962 Federal Highway Act. This act required every urban area of over 50,000 population to have a continuing, comprehensive planning process on which to base their requests for Federal Aid monies. Because of the shortage of persons trained in transportation planning, personnel with limited backgrounds were utilized to perform the technical analyses in many of the smaller areas. To meet the basic requirements of the 1962 Act, the cities relied heavily on the model formulations and forecasting experience developed in other cities; and the guidelines and directives provided by the Bureau of Public Roads.

It is fair to say that the development of the urban transportation planning procedures has been formed through a lack of understanding of the complexities of urban travel, rather than in light of such knowledge. There has been, and still is, a lack of understanding of the entire decision process which controls urban travel behavior. The interrelationships among economic, social, and psychological factors which influence travel choice have not been integrated into a single theory of travel. Consequently, rather than attempting to model the complex behavior as a continuous decision process, the transportation planner has developed a four stage, sequential modeling process known as the Urban Transportation Planning (UTP) package. These models 
include trip generation, trip distribution, modal split, and trip assignment.

Each of the models of the UTP package is normally developed independently of the others without consideration of the interacting forces which occur in the travel decision process. At each stage in the modeling process, the differences between the estimated and the observed conditions are noted and "appropriate" adjustments are made to force the observed and estimated conditions to coincide before entering the next stage of the model sequence. Since the modeling approach is not based on an integrated theory of travel behavior, the analyst can not effectively determine the reason for the discrepancy. As a result the "appropriate" adjustment may simply be a ratio factor between the observed and predicted conditions.

The research reported in this dissertation does not develop a total theory of travel behavior, but the analysis approach is directed to a disaggregate analysis of the data so a better understanding of travel behavior at the decision level of travel can be attained. Analysis of the trip generation phase of transportation planning has been given primary consideration. In particular household travel relationships are examined.

The trip generation modeling concept used in traditional planning studies is referred to as a zonal analysis concept. The enormous body of data obtained in the home-interview portion of the origin and destination studies is aggregated and summarized in larger units of the total study area, the traffic zone. These zones are the smallest areas considered in all further analyses and projections. Through aggregation, large portions of the travel variability which exists within the households are averaged out. As a result, the aggregated relationships provide estimation equations which, on the surface, appear to be statistically more reliable than disaggregate models. Research on model 
formulations based on total zonal trips or average zonal trip rates, however, has shown that aggregation of the behavioral units to zonal averages masks the true relationships and the causal nature of the independent variables. The model parameters are found to be highly dependent on the size of the areal unit selected in the analysis. Further, the variables included in the aggregate model may not bear the same degree of significance if one had considered the collinear effect of other explanatory variables. For example, the distance of a zone from the central business district has been found to bear a significant relationship to trip production in some prediction models. other research indicates that this relationship is mainly spurious in nature (30); when household size and auto ownership rates are considered at a disaggregate level of analysis, the effect of distance from the central business district is not a major factor in explaining travel behavior.

Analysis of the aggregate data also ignores a second basic issue in model development. This issue is related to the measurement of changes. When the analyst is interested in measurement of changes, particular care must be exercised to carefully identify the explanatory variables of the model and the parameters associated with those variables. Since the aggregate models are based on large volumes of data which are averaged together, the models are not sensitive to subtle changes which occur at the basic decision level of travel. Further, the data measures habits for a single time frame; since it is financially infeasible to obtain large quantities of data which would be necessary to revise the zonal estimates, the relationships observed in the original time frame are assumed to be held constant throughout the planning period. Very little basic research to verify this assumption has been conducted. Worrall attempted to obtain a longitudinal data set to 
measure changes over time but the emphasis was on short term variations (43). Logic suggests that changes in social and cultural patterns, and changes in technical developments will have an effect on urban travel. To be sure, comparisons of aggregated relationships within an urban area have been made for different time periods, but as noted, these aggregated relationships are dependent upon the level of aggregation and the activity and composition of the areal units. Since the size of some zones or the level of activity within the zones may change over the study period, it is difficult to separate the influence due to changing area description from the influence due to the changing relationships of the variables in the model. The subtle changes in urban structure and individuals' status and life style cannot be detected at the macro level of analysis.

A second argument cited for aggregating to larger units for analysis is that forecasts of future socioeconomic or land use characteristics which are used in travel forecasting models are less reliable as the area of projection becomes smaller. Recognizing that travel projections could be no better than the forecasts for the independent variables which are in the model, there has been no attempt to understand the complex relationships which exist at the decision level of travel choice.

Again, the concern for forecasting the independent variables to a fine level of detail need not be a deterrent to analysis of the data at the behavioral level. If the variables are linear, forecast of the variables need not be different from the forecasts which are necessary for the zonal concept models. Analysis can be conducted at the disaggregate level and future travel estimates for any aggregate area may be possible because the disaggregate model parameters are not tied to a fixed areal boundary. This would be an advantage in the continuing phase of the transportation study as the size and shape of the area 
change. This greater flexibility in application would also allow the analyst to use data from other public records (e.g. census data) which are summarized in areal units which do not conform to the boundary scheme of the transportation study.

Finally, analysis of travel characteristics at the behavioral level of analysis is also important for developing an understanding of travel decisions which enter in the other phases of the urban transportation planning process. The disaggregate analysis unit provides a basis for inferring values that the individual places on the various characteristics of the transportation system. The individual's choice may be based on factors other than those which can be conveniently measured in the aggregate models. For example, mode choice models are based on some combination of socioeconomic characteristics such as income and auto ownership; service characteristics of the transportation system such as cost or time ratios of alternate modes; and/ or characteristics of the trip itself, such as trip purpose stratifications for work and non work trips. These models are almost always less than adequate for determining the actual modal split; but perhaps of greater significance is that they alone do not provide the planner with information which would reflect changes in facility usage due to changes in the characteristics of the system. This is true because the models only simulate habits which exist under the present operating system, and are not directed towards the general system factors which may be perceived to be more important to the individual. Recent research has been directed towards the evaluation of attitudes and perceptions of the trip maker to determine the importance of several factors such as cost, comfort, reliability, congestion, level of service, and convenience to the trip maker. These research efforts have attempted to define a set of variables 
which can be quantified to express the importance of factors which are not necessarily related to a specific mode or route selection, but are adaptable to the general decision process $(7,31,32)$. Such knowledge of system characteristics provides the planner with more viable data for evaluating the present system and introducing now concepts in design or operation. There is a need to continue this research and to extend beyond consideration of mode and route choice decision variables to include consideration of spatial distribution so that one can combine the "where" dimension with the "how" and the "why."

\section{Research Objectives}

The purpose of this study is to attain a better understanding of travel behavior by evaluating travel relationships at a disaggregate, behavioral level of analysis. The household is taken as the basic decision making unit for evaluating travel behavior. Housing needs and auto ownership levels are determined by the household as a unit. Although some travel decisions certainly are individual in nature, the household unit has travel demands which are also common in nature; satisfaction of the households' travel needs extends beyond the needs of a particular individual.

In this research a quasi-laboratory experimental design has been established to study changes in household socioeconomic characteristics and travel behavior over time. To evaluate possible changes, a sample of 357 households was selected from the original list of households interviewed in the 1964 Indianapolis, Indiana Transportation Study. A second home interview of these same families, was conducted in 1971 to provide data in another time frame. This unique sampling procedure allowed a high degree of control of the analysis units and allowed an evaluation of the stability of relationships over a seven year period. In particular, the sample was selected to include all possible combinations of 
family size, auto ownership and income levels. This simultaneously provided a wide range of other characteristics such as occupational status, education levels, and place of residence in the urban area. It was possible, however, to control some of the confounding influences from other sources. Recognizing that two families of similar size and with similar socioeconomic characteristics may have differing travel behavior due to differences in social or psychological attitudes, only those households were reinterviewed in which the same family which resided at the dwelling unit in 1964 was still living at that address in 1971. Further, the travel variation which might be a function of the type of dwelling unit in which the family resides, was controlled by interviewing only residents living in single family dwelling units.

Home based trip generation models are given prime consideration. The objective is to study relationships at the disaggregate analysis level to determine the stability of these relationships over time. It is hypothesized that relationships exhibited at the household level of analysis will be causally related to the system being modelled and that these relationships will remain more stable. The stability of household models is evaluated by comparing the model parameters developed from data for the two time periods.

In addition, the ability of household equations to estimate aggregate trip production necessary for other modeling stages used in current planning methodology is evaluated. The zonal estimates from the household models are compared with the estimates obtained from the aggregated model formulations used in the 1964 Indianapolis Regional Transportation and Development study (IRTADS). In this portion of the research the household models are confined to the consideration of the same variables as were used by IRTADS. The limits of successful use of behavioral models 
is not fully established, however, by the ability of the models to obtain zonal trip estimates. The behavioral models can be extended to obtain more complete knowledge of travel behavior by evaluating other variables which may have causal significance, even though these variables would be difficult to forecast and incorporate in an operational model. These variables include occupational and family life cycle variables.

A second major objective of this research is to examine the structure of interdependencies among the socioeconomic variables which are important to the estimation of trip production. Although the planner has generally confined the analysis of estimation models to the direct contribution of each of the independent variables on the dependent variable, there is also a need to understand the interrelationships among the independent variables since changes in these variables may ultimately affect the dependent variable. A systematic evaluation tool known as a structural or causal model is used to evaluate the contributing effects of each of the variables in the hypothesized structure. The technique provides a means of separating the direct contribution of each of the variables from the indirect contributions which occur due to correlations with other independent variables in the causal structure.

The third major objective is to examine individual's attitudes and perceptions which are important to decisions of mode and route choice and selection of trip destination. Travel is viewed as a form of human behavior to which sociological and psychological principles may be applied. Psychometric analysis techniques are used to examine individual's ratings of system characteristics. Analysis of individual attitudes can provide the planner with information which can not be attained at an aggregate analysis level, but may have greater causal significance and be more responsive to system evaluation. 
The route and mode choice attributes evaluated in this research have been identified in other previous research $(31,38)$. The objectives here are to evaluate the consistency of importance ratings for study populations exposed to different transportation operating characteristics and different socioeconomic background. The ultimate goal is to provide information which will allow the planner to develop models and operational facilities which are responsive to the needs and desires of the trip maker.

A second set of attributes is used to define further the importance of variables which are considered in the selection of trip destinations. These spatial distribution variables are related only to the shopping trip purpose. The objective is to obtain comparative measures of individuals' perceived importance of transportation related characteristics such as travel time, costs, or parking availability and consumer related characteristics such as goods selection and service provided at potential shopping destinations. Data collected in this portion of the home interview can be used to verify existing assumptions used in distribution models or suggest alternate approaches which would be more closely allied with individuals' perceptions of the important characteristics in selecting a destination.

\section{Organization}

In Chapter 2 the concepts for developing trip generation models are reviewed. In addition, causal modeling techniques and attitudinal research, as it pertains to this research, are discussed. The study design is presented in Chapter 3 .

In Chapter 4 attitude scaling techniques are used to determine the importance of system attributes in the choice of trip destination, mode of travel or route of travel. In the remaining chapters the research focuses on the evaluation of household socioeconomic characteristics and 
travel behavior. The household trip production models for evaluating parameter stability and forecasting ability are presented in Chapter 5. The strength and weaknesses of the household model are also discussed. Chapter 6 considers the more general models and evaluates alternative variable inputs which could be used in the household models. Finally, the method of structural model analysis is used to evaluate interdependencies among the household socioeconomic variables and trip production. 
CHAPTER 2. MODELING CONCEPTS FOR EVALUATING TRAVEL BEHAVIOR

\section{Aggregate Modeling Procedures and Assumptions}

The models which have become known as the Urban Transportation Planning Models (UTP) are based on aggregated relationships. The complex decision process of travel behavior is conveniently modeled in four stages, i.e., trip generation, trip distribution, modal split and trip assignment. The variables used and the parameters which are developed in calibration of the models are those which describe the habits of people as exhibited by the data from which the model was derived. The procedure allows that, where discrepancies exist at any individual stage of the modeling process, adjustments can be made to force the predicted results in the direction of the observed data before proceeding to the next phase. once the models have satisfied the criteria for reproducing the present conditions, forecasts are made of future conditions using the assumption that the gross relationships which have been found are the true causal relationships and that the parameters will remain stable over time.

The conventional modeling approach has several shortcomings which are due to assumptions used in the models. In this section the limitations of the aggregate model trip generation equations are discussed.

\section{Zonal Homogeneity}

Review of the assumptions nas shown that the zonal means are not adequately representative of the individual units, and the basis of aggregation does not result in homogeneous units of analysis $(10,25)$. Moreover, the model 
parameters developed from the aggregated units are a function of the unit size.

The degree to which an average value in a zone can be expected to describe the units is dependent upon the sample size and the amount of variation which exists within the zone. A basic premise in establishing zones is that the units within the zone are of like characteristics and the variation of units within the zone would be less than the variation which would occur if all units were taken together. McCarthy tested this assumption and concluded that the zone sample mean is not representative of all households in the zone (25). The reasons for inadequate representivity are that

a) zone sampling distributions are skewed rather than normal so the sample mean is not the central value; and

b) considerable heterogeneity exists within zones with respect to household travel characteristics and socioeconomic traits.

Separation of Variation

Fleet and Robertson concentrated on the effects of loss of information due to aggregation and how this aggregation can lead the analyst into spurious confidence in the results of his trip production model (10).

Using unexpanded dwelling unit data, an analysis of variance was conducted to break the total sum of squares of the dependent variable into its component parts. The total sum of squared deviations from the mean was partitioned into a between groups sum of squares which represents variation existing between zones; and a within groups sum of squares which represents variation within the zone. Mathematically, the total sum of squares is expressed by 


$$
\operatorname{TSS}=\sum_{j=1}^{k} \sum_{i=1}^{n_{j}}\left(x_{i j}-\bar{x}\right)^{2}
$$

where

$$
\begin{gathered}
\mathrm{x}_{i j}=\text { the ith observation on some variable }(\mathrm{x}) \\
\text { taken in the } j \text { th zone; } \\
\overline{\mathrm{x}}=\text { the grand mean of } \mathrm{x} \\
\overline{\mathrm{x}}=\frac{\sum_{j=1}^{k} \sum_{i} \mathrm{x}_{i j}}{\mathrm{~N}}
\end{gathered}
$$

$\mathrm{N} \quad=$ the grand total number of observations $=$

$$
\sum_{j=1}^{k} n_{j} ;
$$

$n_{j}=$ total number of observations in the $j$ th zone; and

$\mathrm{k}=$ number of zones

The sum of squares between zones (BSS) is the sum of squared deviations between the group means and the grand mean. The within group sum of squares (WSS) is the sum of the squared deviations among observations within the zone and the mean of that zone. Mathematically this can be expressed as:

$$
\text { TSS }=\sum_{j=1}^{k} n_{j}\left(\bar{x}_{j}-\bar{x}^{2}\right)+\sum_{j=1}^{k} \sum_{i=1}^{n_{j}}\left(x_{i j}-\bar{x}_{j}\right)^{2}
$$

(BSS)

(WSS)

Table 2.1 shows the portions of the total sum of squares for total trips which is within the analysis unit and the portion that is between analysis units. The table is based on data from Madison, Wisconsin (10). As the areal unit of aggregation becomes larger the between group sum of squares becomes smaller. This is particularly important because it is the between groups variation which is being explained when regression analysis is used to develop generation models. 


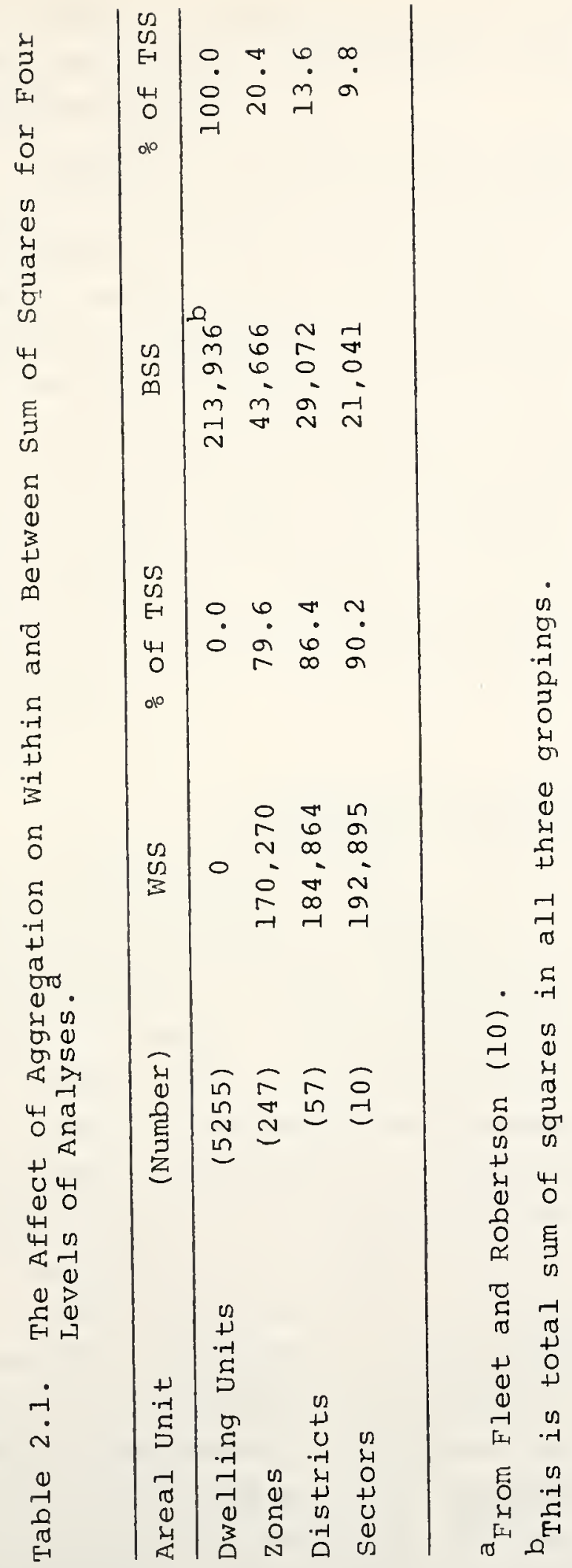


Since there is considerably less variation to explain in the model, the relationship appears stronger at the higher levels of aggregations.

Grouping of the data into area units may also result in specification errors in the model parameters. Robinson and others have shown that because of the differences in correlation which occur for different levels of aggregation, the parameters estimated for the aggregate models may not represent the true effects of variables in the models $(10,30,33)$. This has particularly important implications when models, which are calibrated with existing data, are used to project future traffic flows. For example, in trip generation analysis, projection of future trips will be biased by the differences between the calibrated parameter and the true parameter which would have been estimated at a more behavioral level of analysis.

\section{Explicit Demand Models}

Inconsistencies which are derived from the modeling approach used in the standard urban transportation planning models have provided the thrust for investigation of new model formulations. Two major criticisms of the conventional approach are that: (a) inconsistencies arise because the transportation system itself is not explicitly allowed to affect all stages of the model development; and (b) travel choices are highly interrelated and the segmented phases of traditional models do not adequately represent the continuous nature of consumers' choice.

Explicit demand models which combine the functions of generation, distribution, modal split and route assignment have been formulated in attempts to develop a theory of consumer travel demand. Although the research in this dissertation is not oriented toward development of explicit models, the approach is consistent with the concept of obtaining an understanding of the interrelationships of individual choice. The topic will therefore be briefly reviewed. 
Other researchers have pointed out that the most important aspect of criticism (a) above, occurs in formulation of trip generation models $(7,23,28)$. Traditional trip generation models imply that the number of trips generated is independent of level of service provided by the system. That is, while travel cost or time, or parking costs may affect modal split, it is assumed that changes in any of these conditions will not affect the total number of trips made.

Nakkash investigated trip generation formulations which recognized that the trips produced from, or attracted to an area may, indeed, be related to the relative accessibility of that area to other activity centers being considered (28). A total equilibrium model was not formulated, but interchange between different models was developed through the definition of accessibility variables used in trip generation models.

Relative accessibility variables were determined from the friction factors of the calibrated gravity model trip distribution models. The friction factors are a function of travel time and trip purpose. The relative accessibility of a zone was determined from the relationship:

$$
R A i k(l)=\frac{A_{i k}(l)}{\sum_{i=1} A_{i k}(l)} * 100
$$

where $\mathrm{RA}_{i k}(l)=$ relative accessibility of zone $i$ to activity $k$ for purpose $\ell$;

$i=$ zone under consideration;

$j=$ any zone in study area including zone $i$;

$\mathrm{k}$ = activity under consideration;

$\ell=$ trip purpose;

$\mathrm{A}_{i k(\ell)}=$ accessibility of zone $i$ to activity $k$ for purpose $\ell$; where

$$
A_{i k}(l)=\sum_{j=1}^{n} S_{j k} F_{i j(l)}
$$




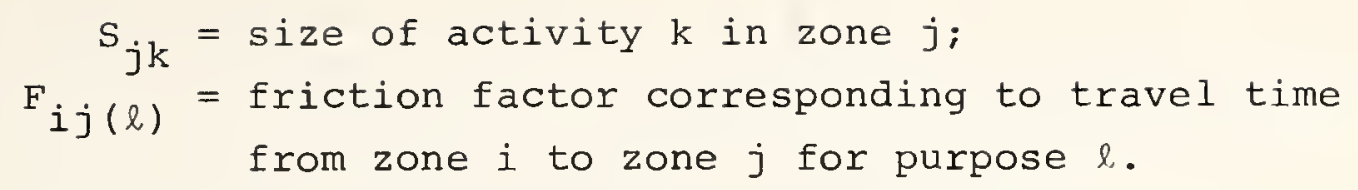

The hypothesis of the model is that the number of trips produced in a zone or attracted to a zone is a function of the relative ease in overcoming space between that zone and all other zones.

Nakkash developed zonal total trip generation models using accessibility variables for the Indianapolis transportation study area. Although accessibility variables did not appear to aid prediction for all trip purposes, the basic hypothesis was substantiated. In particular, accessibility measures were most significant in trip attraction equations.

Other researchers have attempted to formulate aggregate equilibrium models based on economic theory which would incorporate the traditional four phases of the Urban Transportation $\mathrm{Planning}$ process into a single equilibrium model $(7,23,32)$. These formulations have the general form;

$T_{i j k}=\propto A_{i}^{\propto 1} A_{j}^{\propto 2} S_{i}^{\propto 3} S_{j}^{\propto 4} L_{i j k}^{\propto 5}$; where

$T_{i j k}$ is an estimate of travel between nodes $i$ and $j$ by mode $k$;

$A_{i}, A_{j}$ are measures of activity of the nodes;

$S_{i}, S_{j}$ could be socioeconomic descriptors at each node;

$L_{i j k}$ is a measure of level of service between the zones; $i$ and $j$ by mode $k$; and the

$\propto$ 's are parameters of the model.

Any of the variables may be a vector of factors which are related to the travel choice.

Manheim has summarized the importance and the complexities in developing these models and has presented his own general model for deriving equilibrium flows (23). 
Since this research is primarily concerned with disaggregate, behavioral level analysis, the remainder of the chapter will concentrate on research efforts which have evaluated travel relationships at this level.

\section{Disaggregate Trip Generation Analysis}

In an effort to understand the relationships which exist at the household level of analysis, some researchers have analyzed the disaggregate data from available origin and destination studies. $O i$ and Shuldiner were perhaps the first to expose the fallacies of using aggregated data to produce estimates of urban travel (30). Their research broached the question of validity of established approaches and started the efforts for examining relationships which were meaningful at the household level of analysis. They found the two dominant explanatory factors to be household size and auto ownership. Of these, auto ownership was most important. The type of dwelling unit and the distance to the Central Business District had only negligible effects on trip rates. Income and occupation exhibited statistically significant associations, even when family size and autos were held constant, but their contribution to the response variable was negligible compared to family size and auto ownership.

A nationwide study of 30 cities conducted by the Survey Research Center of the University of Michigan also found family size and auto ownership to be the most important variables related to urban travel $(21,36)$. In addition, household trip production was sensitive to income, stage in the family life cycle, occupation of the head of household and density of the neighborhood.

Several researchers have statistically compared the results of trip generation equations based on zonal totals or zonal averages with models based on unaggregated household data $(8,10,19,25)$. Table 2.2 shows comparable 


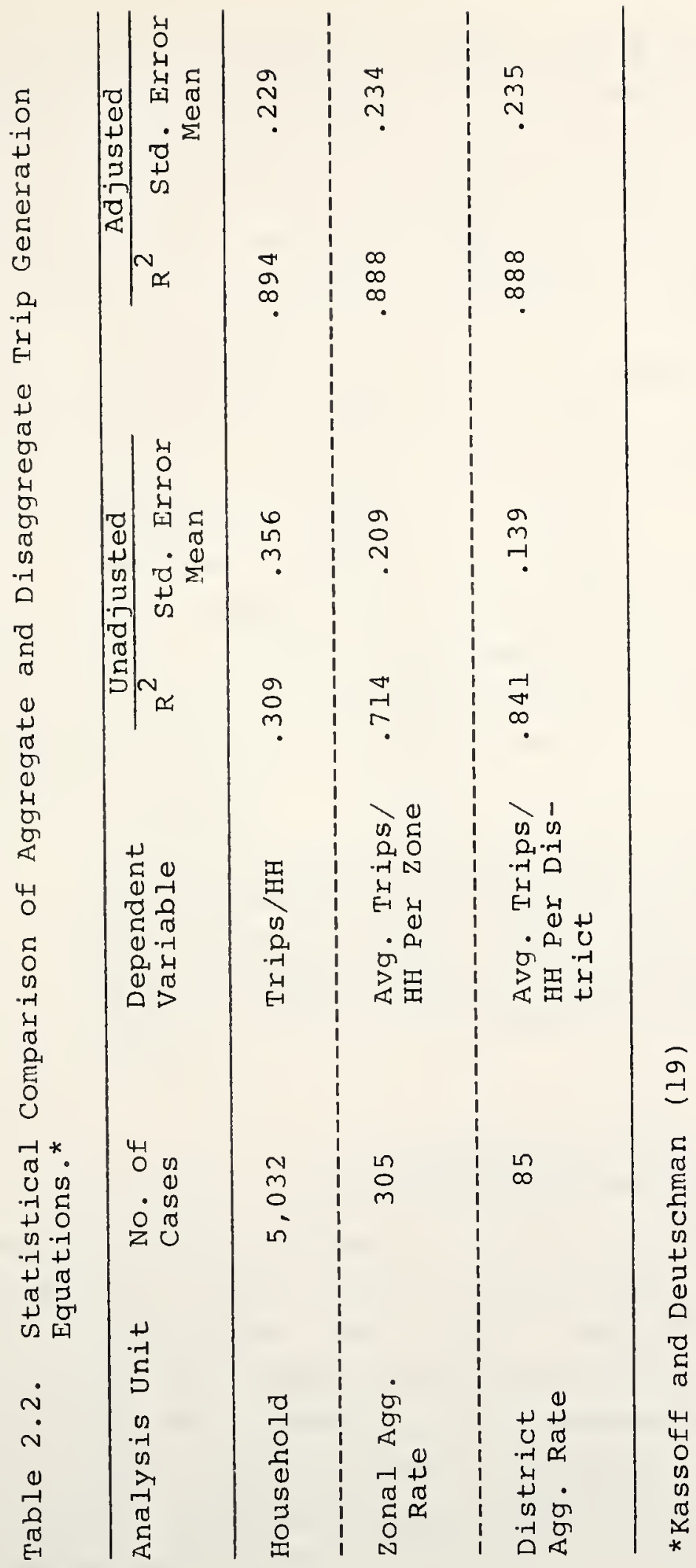


statistics presented by Kassoff and Deutschman (19). The statistical reliability of the household equation appears to be considerably lower than the zonal model when judged by the percent of the variation explained in regression analysis $\left(\mathrm{R}^{2}\right)$, and the percent standard error. However, it must be recalled that this model attempts to explain all of the variation in the data; the zonal model explains only the variation which exists between zones. After expansion of the household equation to estimate total area travel, it was noted that the dwelling unit equation was comparable to the zonal equation.

Fleet and Robertson noted that by analyzing the survey data before aggregation the analyst uses the data more completely to indicate the basic travel relationships (10). The benefits to be gained from the disaggregate analysis approach may best be summarized by the statement from their research:

In addition to allowing a more complete description of travel from the basic trip making unit (the household) as well as the relationship being more likely to remain stable over time, much more effective use is made of the sample data and thus the possibility exists in using small sample interviews as a means for updating in transportation studies.

\section{Structural Models}

The general availability of multiple linear regression computer programs has made this approach to model development very popular in operational studies. The user can handle large quantities of data and develop models with apparent statistical reliability without fully understanding the procedure or the assumptions of the regression model. The resultant variables and parameter estimates are often accepted for the final model without further concern for the nature of relationships which are developed. 
In this section it is not intended to argue about the degree to which the assumptions of regression are met, but rather to point out that the method does not allow the analyst to evaluate and describe all the interrelationships which occur among the independent and dependent variables. A complementary analysis technique is suggested to further examine variable relationships in the models. The analysis approach discussed has alternatively been referred to as causal models, structural models, path models and/or recursive models. In this section the model will be referred to as a structural model.

A structural model is a system of equations which allows the analyst to more fully evaluate the interrelationships which occur in a system of variables. To be sure, multiple regression analysis allows the analyst to observe the effects of several independent variables, either alone or in combinations, but this is possible only for the relationship with the response variable under immediate consideration. Although cross-product terms of selected independent variables may be included to show the effects of interaction among the independent variables, it is still not possible to evaluate the nature of this interaction, nor the relative contribution of the component parts. The structural model, on the other hand, seeks a set of equations which outlines the causal priorities of the variables and permits predictions of how a change in any one variable in the system affects the value of other intermediate variables in the system as well as the ultimate dependent variable of interest.

Examination of the components of a trip generation model may be cited as an example where it may be desireable to evaluate the relationships among a set of variables. A typical trip generation model may use auto ownership and average family size to forecast home based trip production. 
However, before auto ownership can be used, a forecast of this variable must be made. In this second model, average family size and income might be used to forecast auto ownership. The two separate models do not allow examination of the entire structure of the relationships which exist between family size, income, auto ownership and trip production. The structural model is suggested as an analysis method to determine the direct effect of income on trip production as well as the indirect influence due to the effect which income has on auto ownership rates.

Structural Model Development and Application

Pioneer work in the analysis of path coefficients which are the parameters of a structural model was done by Wright in the area of genetics $(45,46)$. Blalock, drawing upon the writings of simon and wold, provided the major thrust for the study of causal inferences in the non-experimental research of the social sciences (1, 35, 43). Duncan, Land, and Heise further described their work using causal models and made contributions to the study of causal models by outlining systematic approaches for interpretation of the model $(9,13,20)$.

Analysis of structurai models has also received attention in the development of transportation forecast models. Kain used a system of recursive equations to evaluate the interrelationships between variables which affect the length of work trip (18). He hypothesized a four stage recursive model in which the decision process was such that the worker first selects an environment in which he wishes to live (space preference). This choice may be shaped by such factors as sex, income, and housing prices. The first decision will then affect the choice of auto ownership, which in turn has an affect on the choice of mode of travel. Finally, all three of these 
affect the length of the work trip. In any of these equations additional varıables such as sex, age, income and housing price may contribute to the explanation of variation in the dependent variables, however, these variables were taken to be exogenous to the system and no attempt was made to define the interrelationships between exogenous variables.

The model developed by Kain is similar in concept to an explicit demand model in which the decision process is formulated in a single model rather than a series of models. The model in this form allows the analyst to make evaluations of direct and indirect effects on the decision variables in the model. The major advantage of this formulation is that all effects can be evaluated. If relationships are found to be only spurious in nature because of correlations with other variables, the variables may be considered to not have direct causal linkages with the dependent variable.

\section{Limitations}

Analysis of a structural model can be applied only to sets of relationships which are linear, additive and causal. The parameters of the model are usually developed using regression techniques, and so the analysis is confined to the data which meet the assumptions for regression.

It is recognized that the theory of causal structures may be applied and quite different causal models could be evolved from the same set of data. The different models could predict basically the same empirical relationships among the correlation coefficients. This means that the correctness of any given model cannot usually be established until other models have been eliminated, either theoretically or on empirical grounds $(e . g$, a knowledge of time sequence). However, the method can be used as an exploratory tool through which one notes those instances where theory 
fails to predict correctly, making successive changes until more adequate predictions have been obtained.

It has previously been noted that if one develops models and parameter estimates for variables which are causally related to the response variable, the relationships will tend to be more stable over time. A check on the correctness, or at least the stability of the causal model parameters can be obtained in this research by comparing the models with data sets from two points in time.

\section{Individual Perceptions of Travel Decisions}

Urban travel models have been developed by fitting observed socioeconomic and urban development characteristics to the travel behavior exhibited by individuals operating within the conistraints of the existing transportation system. The models which are developed strictly on the basis of simulating present conditions may not provide the analyst with a sensitive model which would indicate changes in travel due to changes in urban structure, social structure or changes in the transportation itself. From the planner's viewpoint, it is important to know how changes in policies such as parking price policies, transit service levels, street congestion, etc., will affect the consumers travel decisions. only recently have research efforts been directed towards consumer satisfaction or dissatisfaction with the transportation system $(21,26,27,31,40)$.

\section{Attitude Research}

In this dissertation, the study of individual's perception of factors important in travel choice is directed to mode and route choice preferences and to factors important in selection of a trip destination. The author did not attempt to formulate an original pool of possible factors which would be important in the choice of route or choice of mode. Instead, the reported results from other 
research were used as a basis for selecting the travel choice descriptors analyzed in this study $(31,40)$. These research efforts are briefly reviewed here.

Researchers at the Maryland University were specifical$l_{y}$ concerned with attitudes related to choice of mode (29, 31). The objectives of their research were:

1) to identify and assess the importance of attributes of an ideal transport system as conceived by the consumer; and

2) to determine the extert to which consumers consider existing systems to satisfy this ideal.

The researchers developed an exhaustive pool of factors thought to be important in modal choice decisions. pilot studies were conducted in Baltimore, Maryland and Philadelphia, Pennsylvania. Factor analysis was used to identify the important attitude groupings. Some of the principal factors indentified were reliability, travel time, convenience, protection from the weather, cost, condition of the vehicle, familiarity, congestion and self esteem. They reported little difference in the structure of the factor matrix for work and non-work trips; however, absolute differences in importance of the factors was apparent across trip types.

Wachs used an attitude scaling technique to evaluate route choice preferences for three trip purposes: work, shopping and trips to visit friends (33). Respondents for that study were residents of Evanston, Illinois; an uppermiddle class suburb of Chicago. Factor analysis was used to identify seven attitudinal factors which explained 67 percent of the variation in a list of 21 original variables. The factors, in order of important for explaining route choice preferences, were preferences for: 1) access controlled routes, 2) less congestion and strain, 3) safety, 4) the shortest route, 5) commercial development along a route, 6) pleasant scenery and 7) absence of commercial development. 
Wachs concluded that differences in attitudes existed for different subgroups of the population and that people tended to select routes which possess the characteristics which were preferred. Also he noted that the degree of importance of the factors did not vary greatly for different trip purposes. 
CHAPTER 3. STUDY DESIGN

The data used in this research were obtained from home-interview surveys in Indianapolis, Indiana. This metropolitan area of 300,000 population had conducted a basic transportation study with home interview data collection taking place during the fall of 1964. This data set was taken as the base year for the present study.

The Indianapolis Regional Transportation and Development study (IRTADS) was a typical example of the traditional transportation study. A five percent sample of households was selected for the home-interview portion of the study. A total of 10,532 interview forms were completed. The interview data were aggregated into the 395 zones defined for the study area and factored to represent total volumes for the area.

The trip generation modeling formulations were based on the zonal totals concept. A total of 19 equations were developed for home based and non-home based productions and attractions as stratified by four different trip purposes (16). Generally, the purpose stratifications were work, shop, school, and other trip purposes.

The gravity model was used for trip distributions and the final modal split models were basically diversion curves based on relative highway and transit travel times. Trip assignment was conducted using the standard package of programs developed by the Federal Highway Administration. 


\section{Analysis Variables}

A basic hypothesis of this research is that the relationships which exist between the socioeconomic and demographic variables and the travel patterns at the household level of analysis, will have greater causal significance and will tend to be more stable over time than the aggregate model analysis. The objectives are to study the variables which are significantly related to the travel habits and attempt to statistically evaluate the changes in travel as changes occur in the independent variables. To evaluate these relationships, a sample of households was selected from the 1964 IRTADS dwelling unit sample list to be reinterviewed in 1971.

Earlier research has suggested several variables of interest which could be evaluated at the household level of analysis. These include family size, auto ownership, stage in family life cycle, occupational status, income, dwelling unit type and location within the urban structure. For the purpose of this study, it would have been desireable to obtain data simultaneously on all levels of all important variables and to evaluate the effects of any one variable while controlling for all variables in the experimental design. However, if one were to establish a multi-variable design of this nature with say, just three levels of the seven variables mentioned, over twelve hundred households would have to be sampled to obtain one observation for each of the treatment combinations. Of course, considering the variability of the data, one observation would be insufficient to establish a meaningful average value for a subgroup.

In this study it was decided to select a sample which would as far as possible, represent all levels of three principal socioeconomic variables; family size, auto ownership and income. The other variables not specifically controlled in the experimental design will generally influence 
the response variable and add confounding effects in the analysis of the primary variables being considered. While in laboratory experiments it is often possible to control the environment to some degree, this is generally not possible when dealing with human behavior. However, where possible the confounding influence of other variables were controlled in this study as described below.

\section{Structure Type}

To control for differences in travel behavior which might be due to differences in life style of families living in different types of dwelling units and not due to changes in the principal variablus being considered, all units selected from the 1964 sample list lived in single family units. Further, data from the 1964 study indicated that residents living in single family units, but not owning the unit, reported different mean trip rates than home owners; therefore the 1971 survey considered only those families which were single family home owners.

\section{Location and Resident Differences}

From the 1964 survey list it was possible to identify the address and family which was living at that address. Since the intention of this study was to interview the identical families as were interviewed in the original survey to evaluate stability of relationships and effects of changes in socioeconomic variables of the families, it was necessary to determine where the family which occupied a selected dwelling unit in 1964, resided in 1971. A family was selected for interview only if they still resided at the same address as in 1964. In this way differences in travel behavior which may have been due to changes in the living environment, rather than changes in household characteristics, could be controlled to a greater degree. Of course, new transportation facilities, or new 
land use developments which affect travel for that household may have taken place, but these can not be controlled in the analysis. The effect of such changes on travel of the household are evaluated only by asking the respondents to indicate whether such changes increased, decreased or did not change the amount that the family travels by car and public transportation.

\section{Seasonal and Daily Variation}

The 1964 survey was conducted from mid-August to midDecember. Likewise, the 1971 survey was conducted in the fall over a five week period from mid-October to the end of November. Statistical tests of differences in week day trip rates indicated statistically significant differences $(\propto=0.25)$ in trip rates for days of the week. The 0.25 significance level was used because acceptance of the null hypothesis of no significant difference was desired to ease restrictions in survey scheduling. To guard against acceptance of the null hypothesis when a significant difference did in fact occur, the high alpha level was selected. Since daily differences were possible, the survey schedule was established so each household would record trips on the same day of the week as in 1964.

\section{Sex}

Several characteristics of the respondents such as occupation, auto availability, education, and sex may affect the response pattern for the attitudinal questions. of this group, it was possible to assure a distribution of responses from men and women respondents. In the survey design, the principal respondent was assigned as either the head of the household or spouse of head. The interviewer was to make an appointment at a time when the indicated principal respondent would be available. Any additional members of the household which were available 
were also asked to respond to the attitudinal questions.

\section{Sample Selection}

Restricting the list of potential households to single family home owners reduced the sample size from 10,532 to about 6,600. Approximately one third of all households did not report income in 1964; therefore, before drawing a sample from this list, a further reduction was made to eliminate all households which had not provided complete information. This resulted in a final list of 4,300 households.

The sampling procedure used a systematic, one in four, sampling rate to obtain a basic list. Each family in this list was checked against the listings of the 1971 telephone directory to ascertain if the family still resided at the address shown in 1964. The objective was to obtain a list of potential households which would provide about 400 completed interviews.

The basic design for selecting the households for this survey was to establish a three variable classification matrix for family size, auto ownership and income. Income was divided into three categories: less than $\$ 5000, \$ 5,000$ to 7,999 and greater than $\$ 8,000$; Auto ownership was divided into three categories: 0 cars, 1 car and 2 or more cars per household; and family size was generally considered in four classes: $1,2,3$ and 4 or more members per household, although distribution in the last category was also desired to get an adequate representation of larger family sizes.

In order to obtain as much information as possible about all combinations of family size, auto ownership and income it was necessary to make special efforts to obtain households with some of the less frequent variable combinations. For example, households with higher incomes and larger family size seldom have the joint occurrence of not 
owning an automobile. In these instances the entire list of 4300 units was searched to obtain a listing of households with combinations of socioeconomic characteristics which occurred less frequently in the population. From this secondary list, random selections were made to fill empty or near empty cells in the three variable classification matrix. Even this effort could not fill all cells of the matrix because there were some combinations which did not exist in the source list (e.g., a one member household with income greater than $\$ 8000$, who did not own a car). An initial sample of 400 households was selected to be interviewed in the study. A list of additional households was also established to replace refusals from households in the original list. For all household types IRTADS found an overall non-response rate of approximately 15\%, but in research studies which do not have the advantage of being publicized in local news media, the refusal rate may be substantially higher. In this study, the response rate was 65 percent. Approximately 8\% of the nonresponses were due to families moving from the household between the time of selection and the actual survey. Another $9 \%$ were attributed to vacant households due to vacations, sickness or death.

\section{Questionnaire Design}

A questionnaire was developed to obtain the information for the two general areas of interest, i.e. origin-destination travel data and individual attitude data. The procedures and definitions used in the 1964 study were carefully reviewed for development of the origin-destination study $(14,15)$. All efforts were made to use the same definitions and recording procedures to assure the acquisition of a comparable, consistent data set.

In the study design stage, experts in the fields of social science and psychology were consulted to evaluate 
alternate techniques for obtaining the attudinal data. since it was necessary to collect the trip data on a household to household basis it was decided to use attitude measuring techniques which could be used in the same way.

A questionnaire was developed which contained structured responses in the form of paired comparisons and successive categories attitude measuring techniques, as well as unstructured questions which were directed to obtaining information on the "why" of travel decisions. Gentrally, the unstructured questions were presented to the respondent before the structured questions which contained a specific list of items to be evaluated. This was to reduce the possibility that the answers given in the unstructured questions would be influenced by the list of variables considered by the researchers in the attitude survey.

The questionnaixe was pretested at 10 households in the Indianapolis area and some changes were made. The revised questionnaire was checked again, but since the revisions were not related to pecularities of the study area, the second pretest was conducted in Lafayette, Indiana. This second version was accepted as the survey instrument to be used. A copy of the questionnaire appears in Appendix A. The average time for administering the questionnaire was forty minutes.

\section{Home Interview Procedures \\ Interviewers and Training}

Six female and two male interviewers were selected for conducting the survey. The interviewers were of exceptional quality in that seven of them held college degrees. Two of the interviewers had previous interviewing experience. Since other research indicated that it might be useful to have members of particular ethnic groups being interviewed by members of their own group, two minority group interviewers were assigned to general areas where the 
black population was larger.

The interviewers were given a two day training session before beginning the survey. The first day was used to thoroughly acquaint the interviewers with the purpose of the survey, the procedures to be used, and the questionnaire and related materials. The second day was devoted to reviewing each of the questions and all of the definitions of trip purpose, modes of travel to be considered, household members, etc.

After completion of the training sessions, each interviewer was given one household to contact. Upon completion of the interview, each interviewer returned to the central office to review all portions of the questionnaire before other interviews were assigned.

Contact and Follow Up Procedures

Initial contact with prospective respondents was made by sending a letter explaining the purpose of the study and asking for their cooperation. Forms for recording trips on the travel date were also sent in this letter. A copy of the letter and forms appear in Appendix A.

Each week the interviewers were provided a list containing the name, address and principal respondent (head or spouse of head) of all households to be interviewed in the following week. On the day before "Travel Date" of a household, the interviewers called the residence to answer any questions about filling out the travel form and to arrange a mutually convenient time for conducting the remaining portions of the interview. Call back procedures were established in the event that the respondent could not be immediately contacted by telephone. In the event that the respondent refused to cooperate in the study when contacted by phone, the interviewer notified the study office. Initially the interviewers were asked to try and 
make personal contact with all households who had declined to set up an interview when contacted by phone. Although this procedure had some success in obtaining interviews from these households, this procedural requirement was relaxed so that personal contact was attempted only if the family seemed to be reasonably receptive to the interview. When an interview could not be conducted, attempts were made to replace the sample household with another with the same characteristics.

\section{Validation}

Twice each week the interviewers were required to deliver all interviews to the study office. At that time the questionnaires were reviewed and problems were discussed. Additional validation checks were conducted by randomly selecting returned questionnaires and recontacting the sample household to check the validity of the reported data. All checks made indicated the interviewers were asking the appropriate sections of the questionnaire and were spending the amount of time in the household indicated on the questionnaire.

\section{Respondent Characteristics}

A total of 357 questionnaires were completed for analysis in this study. The principal respondent was a male in 162 households and female in 195 households. The households were located throughout the Indianapolis study area and represented a mixture of educational levels and occupational status, as well as the other control variables discussed.

The average age of the head of household was 52 years with a median education of 11.8 years. The breakdown of family income and head of household occupational groups for 1964 and 1971 are shown in Tables 3.1 and 3.2. Other household characteristics are provided in Appendix $B$ along 
with the average home based trip production for the family size, auto ownership and income stratifications.

It should be noted that the sample selected for this study is not a representation of the total population of all single family, home owning residents in 1971. Each household is assumed to be a random sample from all households with the same socioeconomic characteristics as reported in 1964. However, the sample may not be representative of all single family units today since the families interviewed have remained in the same household at least seven years. It is possible that families who change residence location may have different characteristics than those that remain located at the same address. Nearly 65 of all families in the single family units checked did change location during this period.

The sample is now generally older than the total population and has a larger percentage of the household heads who are retired or unemployed. 


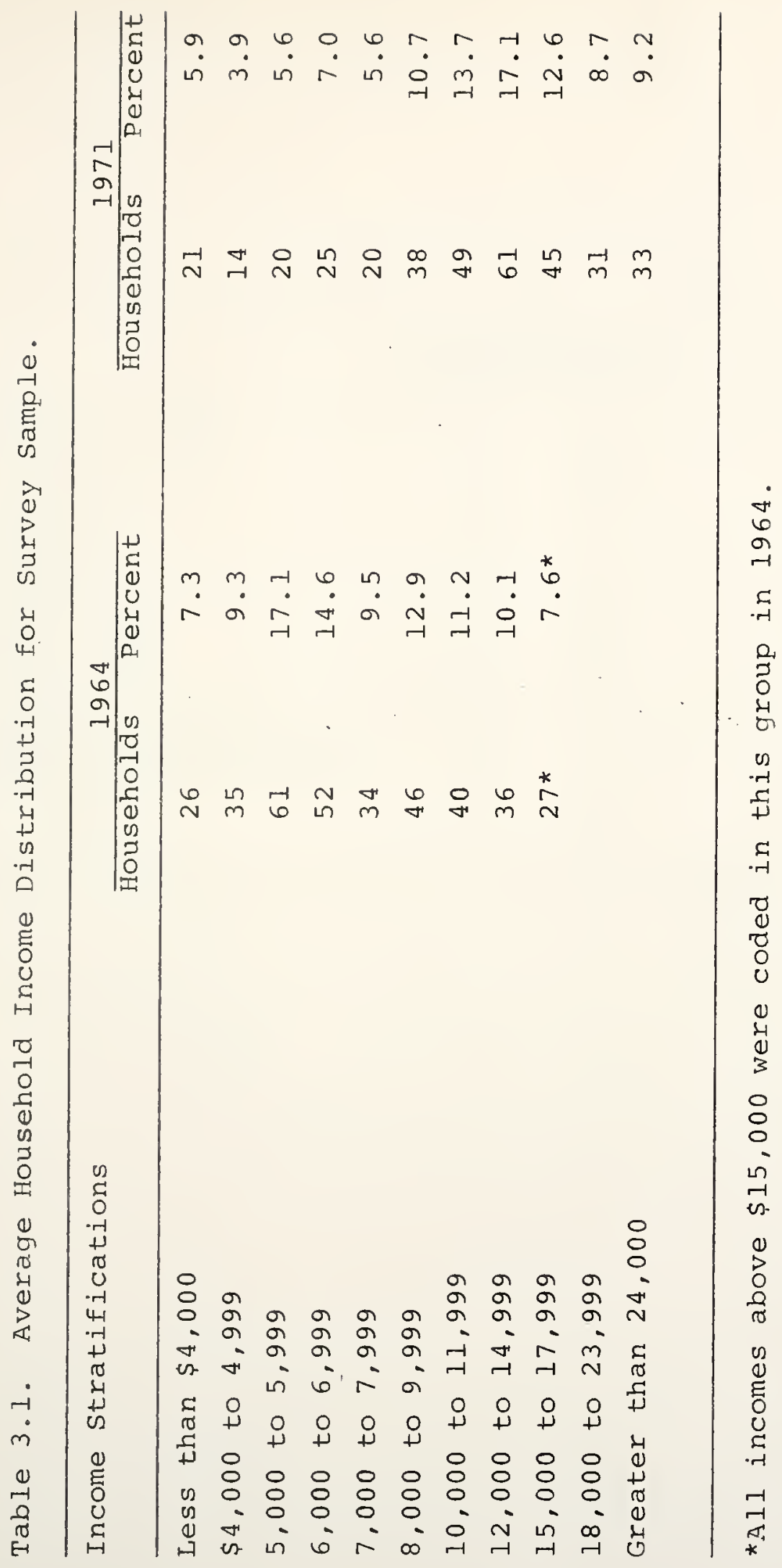


Table 3.2. Occupation of Head of Household.

\begin{tabular}{|c|c|c|c|c|}
\hline & \multicolumn{2}{|c|}{1964} & \multicolumn{2}{|c|}{1971} \\
\hline & Number & Percent & Number & Percent \\
\hline Professional & 46 & 12.9 & 43 & 12.0 \\
\hline Managers & 61 & 17.1 & 32 & 9.0 \\
\hline Clerical & 34 & 9.5 & 23 & 6.5 \\
\hline Salesman & 27 & 7.6 & 40 & 11.2 \\
\hline Craftsman & 99 & 27.8 & 75 & 21.0 \\
\hline Operatives & 30 & 8.4 & 31 & 8.7 \\
\hline Service Personnel & 28 & 7.7 & 16 & 4.5 \\
\hline Retired or Unemployed & 32 & 9.0 & 68 & 19.1 \\
\hline Total & 357 & 100.0 & 357 & 100.0 \\
\hline
\end{tabular}




\section{CHAPTER 4. INDIVIDUAL PERCEPTIONS OF TRAVEL CHOICE FACTORS}

Factors which are important to travel choice extend beyond the realm of socioeconomic and demographic variables which are measured in a typical transportation study survey. Travel decisions are a part of human behavior which are directed toward attaining specific goals. The method and degree of satisfaction realized in attaining these goals are dependent upon the individual, his personality and his past experience. Several paths may be available for meeting the goal or objective. The path an individual selects will be the path which offers the greatest satisfaction or the path which appears to offer the least resistance to achieving the goal.

Due to the difficulty in obtaining measures of perceived human values and evaluating the relationship of these measures to travel behavior, transportation planners have not extensively studied the attitudes of individuals which are related to travel. Since the objective of this research is to concentrate on evaluating important characteristics of the decision unit, an effort was first made to extend the evaluation beyond measurement of socioeconomic characteristics in order to explore individual attitudes and values and their relation to travel behavior. This portion of the research was not intended to develop new concepts or variables which are in the psychological field of the trip maker, but rather, the basic intent was to examine further the factors which other research has found to be important to the individual. This portion of the study concentrated on learning more about factors which are important in mode and route choice and in the selection of a trip destination. 
The mode and route choice variables were studied for two trip purposes, the work trip and the shopping trip. Examination of decision variables important to selection of a trip destination site was restricted to consideration of the shopping trip.

\section{An Evaluation of Factors Important in Mode Choice}

A rating scale method referred to as the method of successive categories was used to evaluate individuals' responses to factors which may be important in selection of a mode of travel. The factors selected in this study for evaluation were those factors found most significant by other researchers $(26,31)$. A total of twelve factors were selected for analysis. The complete statements and the method of presentation are shown in questions 10 and 47 of the questionnaire (Appendix A) for the work trip and shop trip, respectively. The same factors were used for both trip purposes although the order of presentation was varied. Generalized statements of each of the descriptors are included in Table 4.1.

At each household the principal respondent and all other adult members who were present at the time of the survey were asked to rate the descriptors for the shopping trip mode selection. For the work trip purpose, all adult members who worked outside the home, two or more days per week were asked to respond. The number of completed responses for the work trip and the shopping trip was 233 and 400, respectively.

The descriptors were rated on a seven point psychological scale. A descriptor which was perceived to be of greatest importance was rated as seven (7) on the scale and a descriptor which was not at all important was rated as one (1). If the descriptor did not induce an extreme response some scale position between one and seven was selected. Since this scale is considered to be only an ordinal ranking it would be desirable to convert the psychometric scale to an interval scale. With the converted scale, more powerful 


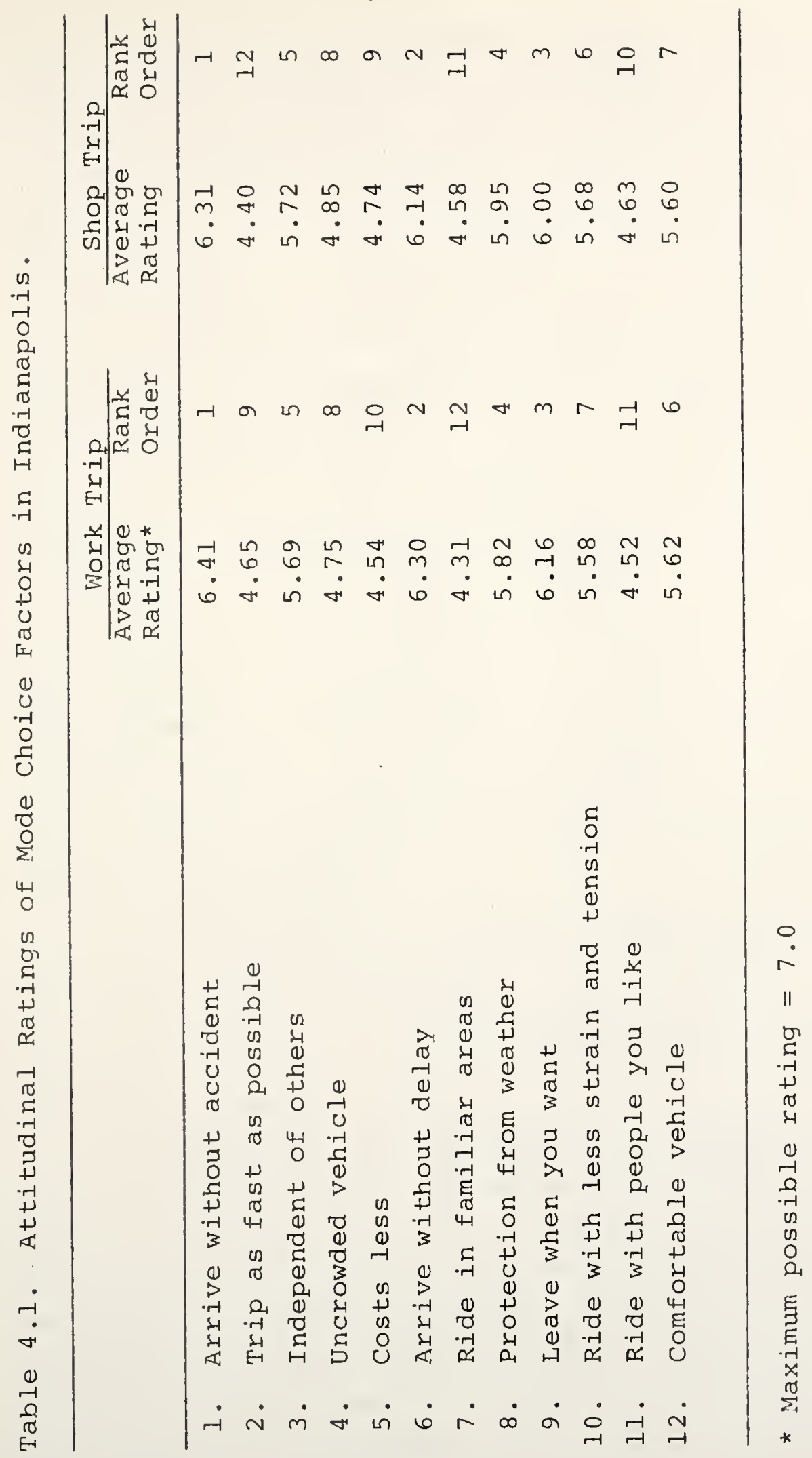


analytical techniques could be used to study the relationships among the individual's actual mode choice behavior, his socioeconomic status, and his expression of importance of the mode choice variables. The Law of Categorical Judgment, which is the basis for the scaling technique, does allow such a conversion to be made if the assumptions of the scaling method are adequately met (II). Unfortunately, the pattern of responses for this survey did not allow such a conversion. The response patterns, rather than being unimodal, and tending toward a normal distribution, were found to be bimodal, or even multimodal, for selected descriptors. Consequently, evaluation of the perceived importance of the descriptors was Iimited to an analysis of average ratings.

Table 4.1 shows the mean rating for each of the factors as well as the rank order of the factors for each trip purpose. Although the rank order of importance changed somewhat across trip purposes, the absolute differences in the ratings were small. This is in agreement with the conclusions reached by paine in the Maryland study (31). Ratings of mode choice characteristics appear to be nearly independent of trip purpose.

It is of interest to compare further the ranking of the importance of the descriptors in this research with the results obtained in the Maryland study. Table 4.2 lists the five factors found to be most important for the work and non work trip reported by paine.

The responses from Indianapolis residents indicated that the most important characteristics were (1) to feel confident vehicle would get to destination without an accident; (2) to feel confident vehicle would not be stopped for repairs; and (3) to be able to go whenever you want to. These characteristics taken together represent a feeling of reliability in the service. That is, the feeling that one would receive the service at the time he wants or expects and, once the service is provided, the destination would be 
Table 4.2. Attitudinal Ratings for Mode Choice Factors Maryland Study.

\begin{tabular}{lcc}
\hline Factor & $\begin{array}{c}\text { Work Trip } \\
\text { Rating }\end{array}$ & $\begin{array}{c}\text { Non-work Trip } \\
\text { Rating }\end{array}$ \\
\hline Reliability & 1 & 1 \\
Travel Time & 2 & 5 \\
Convenience & $*$ & 3 \\
Weather & 3 & 4 \\
Cost & 4 & 2 \\
\hline
\end{tabular}

*Included as a component of travel time for work trip 
attained. This agrees with the Maryland study conclusions.

The next most important consideration for the Indianapolis respondents was protection from the weather. The Maryland study found weather consideration to occupy the second position for the non-work trip and third for the work trip.

The ranking of the third basic factor also agree for the non-work trip in the two studies. That is the factor of convenience. Factor analysis of the Maryland data, however, stated that for the work trip, convenience was a component of travel time. Travel time was rated as the second most important factor in selection of a mode for the work trip. On the other hand, both travel time and costs, which were perceived to be relatively important to the choice of mode in the Maryland study, and which are prominently used in modal split models, were perceived to be of little importance to the Indianapolis respondents. Although the Indianapolis ratings must be studied with the knowledge that the respondents do not represent a cross section of the total population and are not potentially the most likely transit users, the ratings bear significant implications for the transportation planner. The importance ratings would suggest that operational changes of the public transportation system, designed solely to improve travel time or reduce costs of the transit modes, may not be effective in inducing these individuals to use the improved service. Additional consideration would also have to be given to such items as increased comfort and protection from the elements of the weather.

Critique of the Successive Category Rating Technique

Use of the successive category scaling technique provided information which allowed measurement of perceived importance of selected mode choice descriptors. The average ratings can provide the planner with information which will help reflect the impact which changes in the transportation 
facilities may have on the actual use of those facilities. The full power of the scaling technique, however, was lost due to responses falling largely in the extreme categories. The response patterns were, therefore, given greater attention to help understand more about the reasons for the lack of discrimination between categories for the different mode choice descriptors.

Several reasons may be cited to explain the selection of the extreme category as was the case in this study. One of these would obviously be that the descriptors selected did, in fact, excite a strong feeling of importance. A second possibility was that some of the respondents became weary of the "testing" process, lost interest, and subsequentIy failed to make serious effort to discriminate between levels of importance for the various descriptors. Finally, the respondents may not have understood the rating method and were therefore unsure of their role in completing the questionnaire. It was this latter hypothesis which was given further attention.

Even though careful instructions were given to explain the respondents role, it was felt that in the interview situation, the respondent had difficulty "learning" that role. This appeared to be particularly true for the less educated groups. To quantify the degree to which a person's education affected the response pattern, the data were stratified by education level and the average number of categories receiving responses was tabulated for each education level. If the respondent exhibited no discriminatory power in judging the importance of the descriptors, the average number of response categories checked would be one (1). On the other hand, the respondent whose discriminal process was sensitive to varying levels of importance of the descriptors might respond in a maximum of seven scale positions.

Three of the education stratifications have been selected to demonstrate the effect of education on the response 
patterns and the degree to which the scaling procedure is improved as the respondent learns his role. The three groups and the average number of categories receiving responses for the work trip purpose were:

1. eighth grade education or less ( 3.0 categories)

2. high school graduate (3.5 categories)

3. college graduate or more ( 4.3 categories)

Figure 4.1 is a plot of the cumulative frequency of the response patterns. The curves show a wide spread in the distribution pattern for the different education levels. For example, approximately 20 percent of the college graduate group responded in three categories or less; approximately 60 percent of the eighth grade or less education group responded in three categories or less.

The degree to which continued exposure to the scaling technique helps improve the understanding of the respondents role can be obtained by comparing Figure 4.2 , which is a plot of the response pattern for the shopping trip, with Figure 4.1. Many of the individuals responding to the mode choice descriptors for the shop purpose had previously been exposed to the scaling technique for the work purpose selection. The learning process has diminished the degree of spread between the response patterns of the educational groups, but there is still the tendency for the lower education level to have less discriminatory power in perceiving differences in the importance of the descriptors.

Evaluation of Mode Choice Factors by Subgroups

In order to determine if different groups within the sample possessed different feelings about the variables, an analysis was conducted for several subgroups. The groupings selected were sex, education, age, licensed or non-licensed driver and miles driven. Education was categorized into two groups, i.e., less than high school graduate and high school graduate or more. Age was categorized into groups less than 


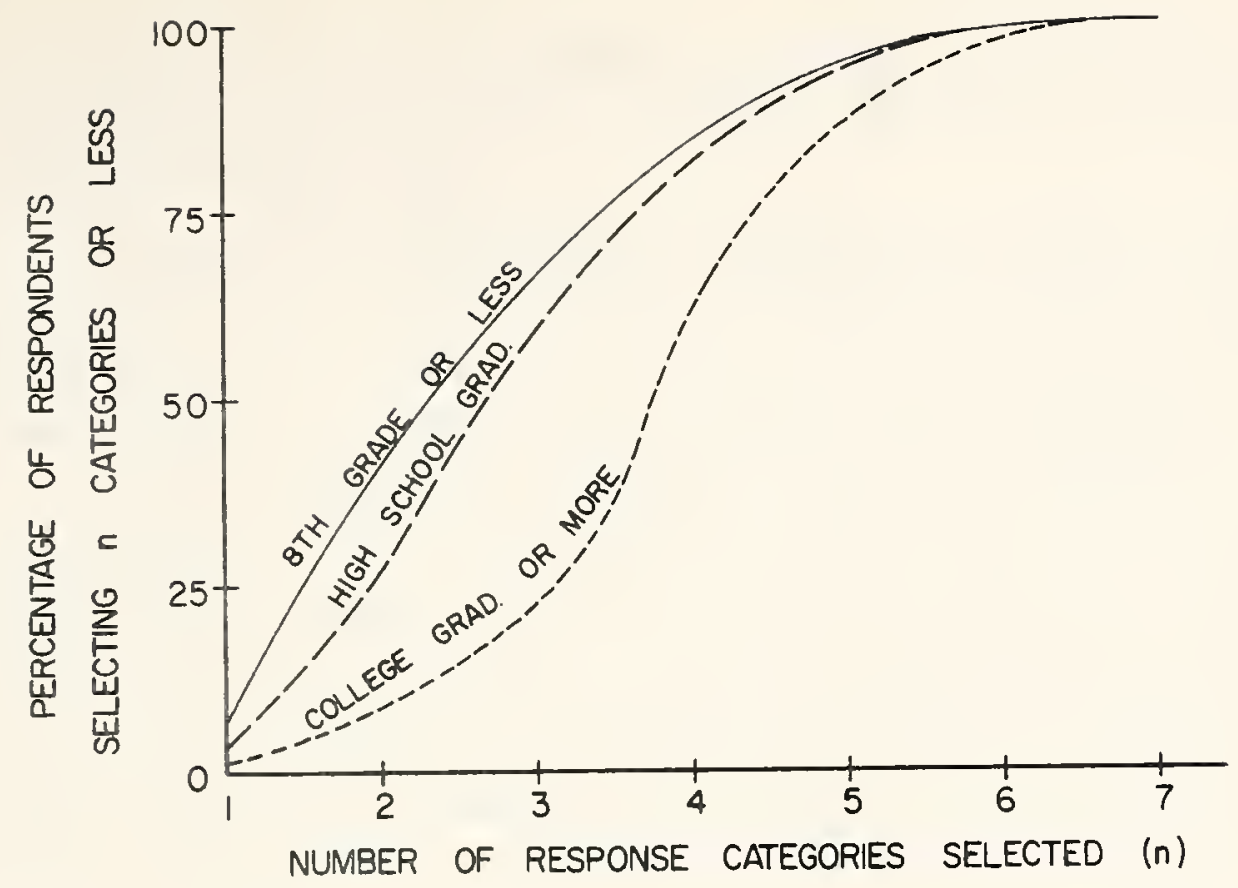

FIGURE 4.1 DISTRIBUTION OF RESPONSE RATES OF SUCCESSIVE CATEGORIES SCALING TECHNIQUE FOR WORK TRIPS

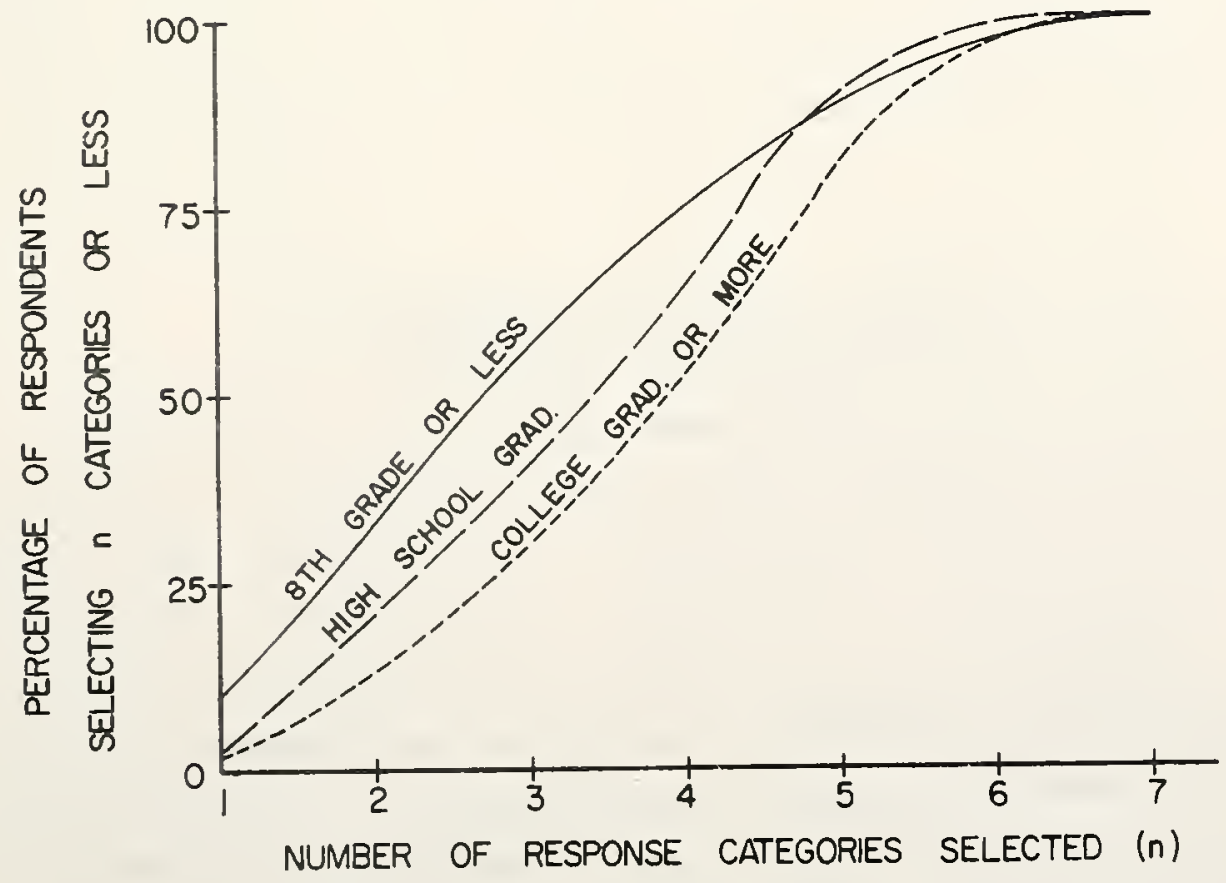

FIGURE 4.2 DISTRIBUTION OF RESPONSE RATES OF SUCCESSIVE CATEGORIES SCALING TECHNIQUE FOR SHOPPING TRIPS 
60 years of age and 60 years or older. Miles drive was categorized into groups which traveled less than 12,000 miles and over 12,000 miles.

To test for significant differences in the responses, the Kolmogorov-Smirnov test was used since this test is independent of the underlying distribution of the responses (34). Table 4.3 shows the results of the analysis.

For the work trip purpose, the null hypothesis of no difference in response rate could be rejected at the 0.01 significance level only for the cost factor for licensed and non-licensed travelers. The non-licensed worker judged costs to be more important in selecting a mode of transportation. This reflects the greater awareness of the out-of-pocket cost to the worker who must rely on others to provide his transportation.

For the shopping trip, female travelers and those respondents whose families travel less than 12,000 miles per year place more importance on riding in areas familiar to them. In addition the under 12,000 mileage group expressed a greater concern for having a comfortable vehicle to ride in.

\section{An Analysis of Driver Preferences for} Route Choice Descriptors

The method of paired comparisons developed by Thurstone was used to determine the relative importance of factors which may be important in individual choice. In the method of paired comparison the responent is presented with pairs of stimuli or descriptors which are to be judged. For each pair the respondent is asked to indicate which descriptor is preferred. An experimental procedure based on the "Law of Comparative Judgment" can be used to obtain relative scale values for the set of stimuli or descriptors which are presented to the respondent. The theory of the experimental models is omitted here but may be found in Torgeson or 


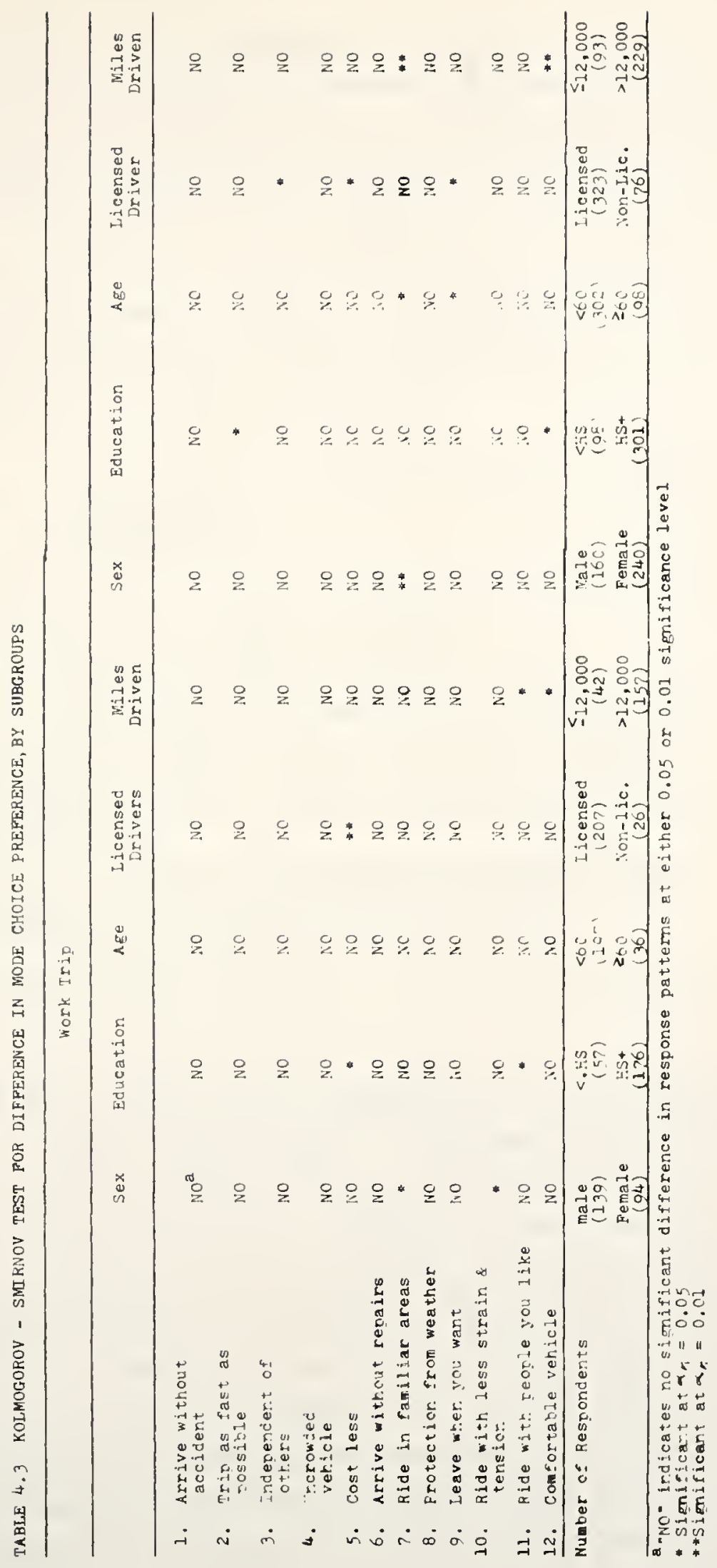


Guilford $(11,38)$. The analysis in this research was facilitated by use of a computer program originally developed by MacGillivray (22). The route choice descriptors presented to the respondents embodied the primary factors which wachs found to be significant in explaining route choice variation in Evanston, Illinois (40). Questions $1 \mathrm{lc}$ and 48 of the questionnaire (Appendix A) show a complete set of the paired descriptors for the work trip and shopping trip. The basic descriptors are listed in Table 4.4 .

Table 4.4. Route Choice Descriptors used in Paired Comparison Analysis.

1. Route with a shorter distance

2. Route with a shorter driving time

3. Route with less congestion and strain to driving

4. Route with fewer stop signs and signals

5. Route with more stores, service stations and restaurants

6. Route through more pleasant neighborhoods

7. Route which you feel may be safer

Seven descriptors were presented to the respondents in the study. Since each stimuli is paired against every other stimuli, a total of $n(n-1) / 2$, or 21 comparisons were necessary. To avoid bias due to respondent fatigue or possible tendency to always select the first or second item of a pair, the descriptor pairs were randomly ordered for different respondents. A total of four random orderings was used.

A relative scale of importance of the descriptors is extracted by creating a proportion matrix $P_{j k}^{\prime}$ which lists the percentage of the time each descriptor $J$ is preferred over descriptor $K$. Tables 4.5 and 4.6 are the respective 
Table 4.5. Observed Proportion Matrix for Evaluating Route Choice Preferences for Work Trip.

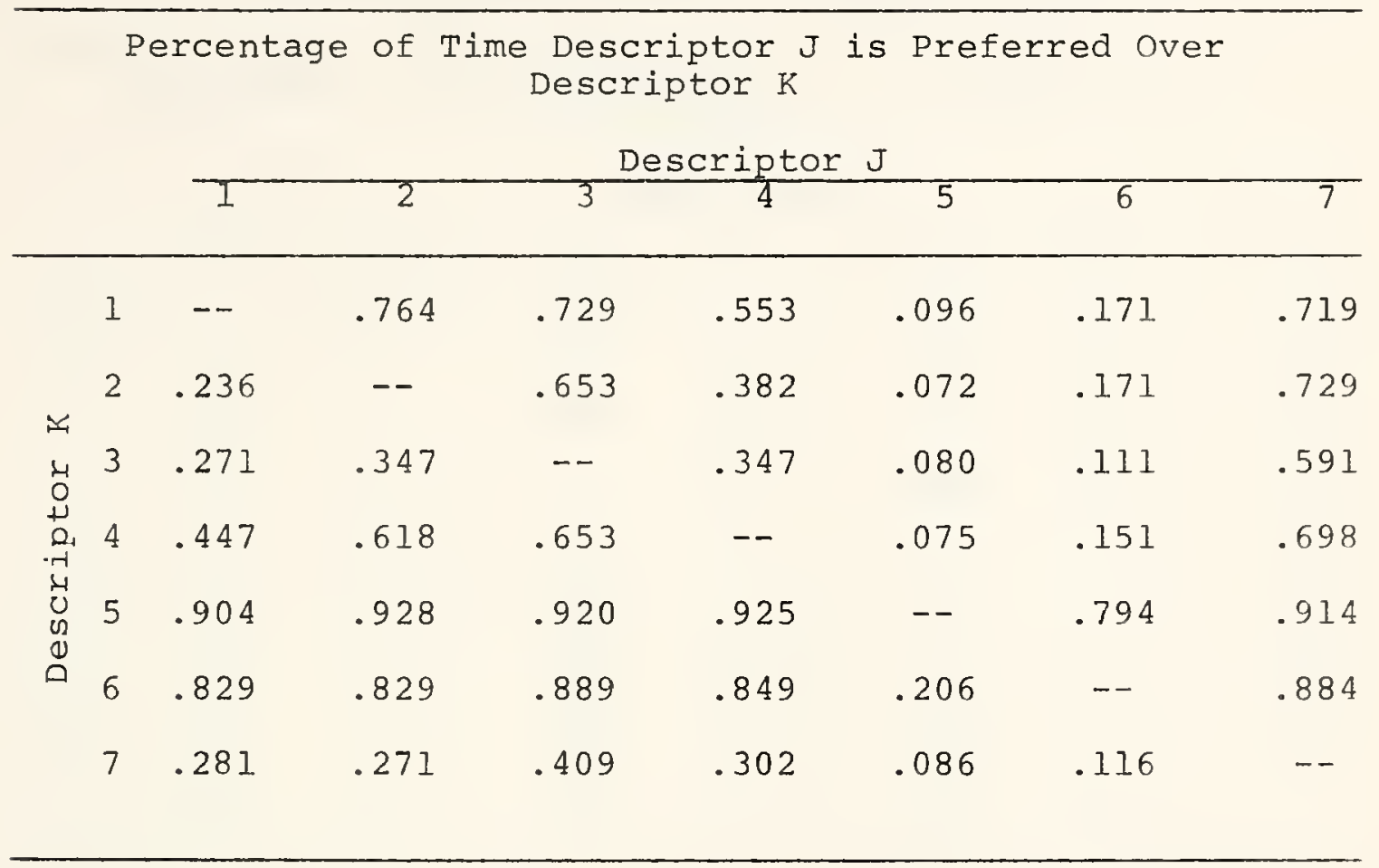

\section{Generalized Descriptors}

1 - Distance

2 - Driving Time

3 - Congestion and Strain

4 - Fewer Stops and Signals

5 - More Commercial Development

6 - Pleasant Neighborhoods

7 - Safety 
Table 4.6. Observed Proportion Matrix for Evaluating Route Choice Preferences for Shopping Trip.

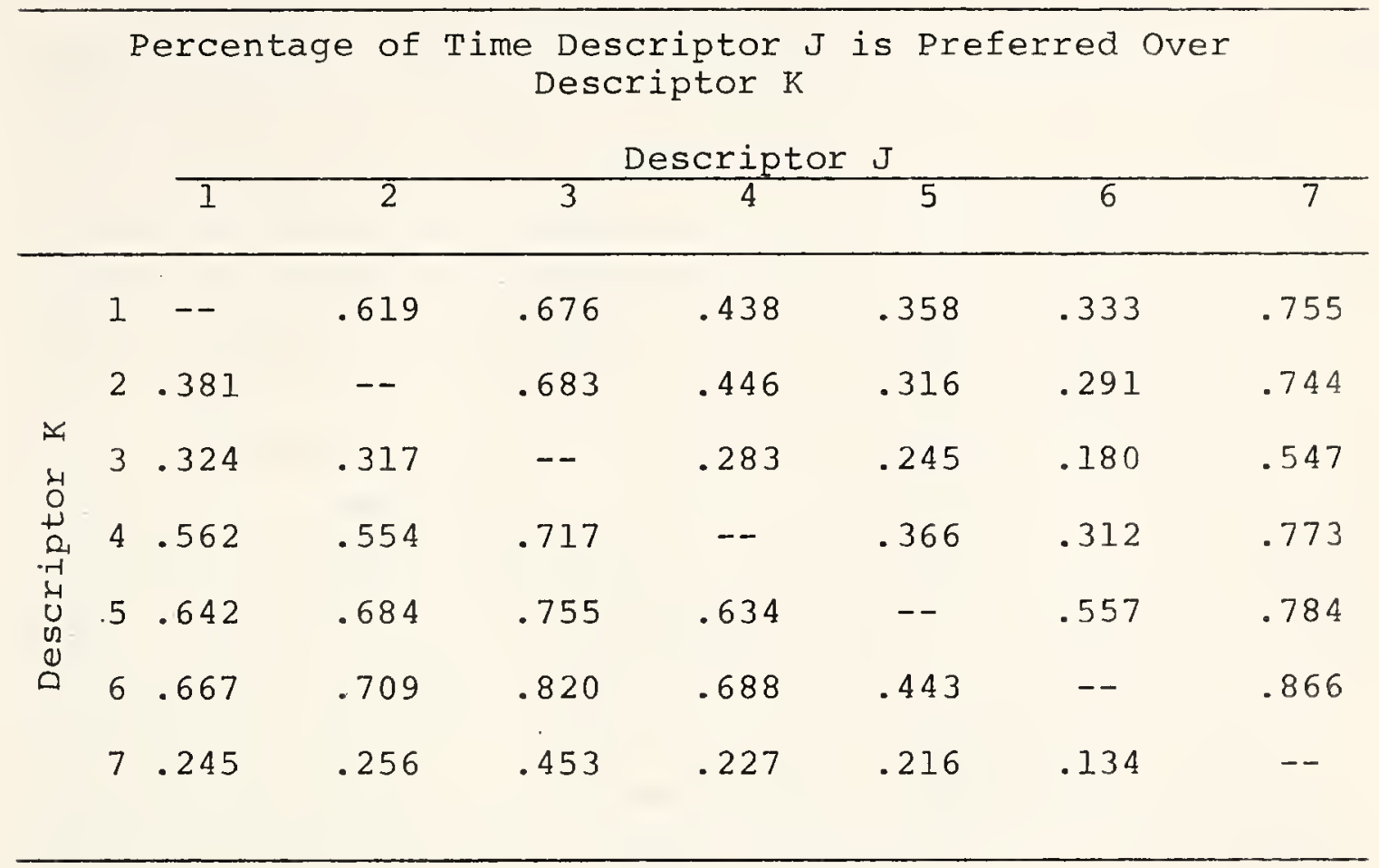

Generalized Descriptors

1 - Distance

2 - Driving Time

3 - Congestion and Strain

4 - Fewer Stops and Signals

5 - More Commercial Development

6 - Pleasant Neighborhoods

7 - Safety 
P jk matrices for the work trip and shop trip. Extraction of a scale from the observed proportion matrix essentially involves a least squares solution if every descriptor is paired against every other descriptor in the group. If some pairs should be missing, the standard model is no longer a true least squares solution, but the model provides an approximate method for obtaining a scale. Gulliksen has presented an alternate method for obtaining the scale if a more exact solution is required (12). This was of interest in this study since, during the course of data collection, it was discovered that in two of the four random orderings, one of the pair combinations had been inadvertently omitted. To evaluate possible distortions in the scale due to the incomplete data set, both the standard model and Gulliksen's model were used initially to establish a scale. These analysis showed that, although the scale values differed slightly, the rank position of each descriptor remained the same and the spread on the scale between descriptors was equivalent. Consequently, the regular scaling model was used in all further analyses.

The scale values obtained from all respondents for each of the trip purposes are given in Figure 4.3. Although the magnitude of the scale values differ for the two sets, it should be noted that the scales are only relative measures. The grouping of the descriptors along the scale and the relative spread are the important considerations rather than the numerical value. Examination of the two scales shows that there is a high degree of consistency in ranking of the descriptors for the two trip purposes. The relative importance of the descriptors is substantially independent of the trip purpose considered. This agrees with the conclusions reached by wachs.

Scale values for the descriptors were found to be grouped at three levels along the scale. The respondents indicated the strongest preference for safety, with reduced 


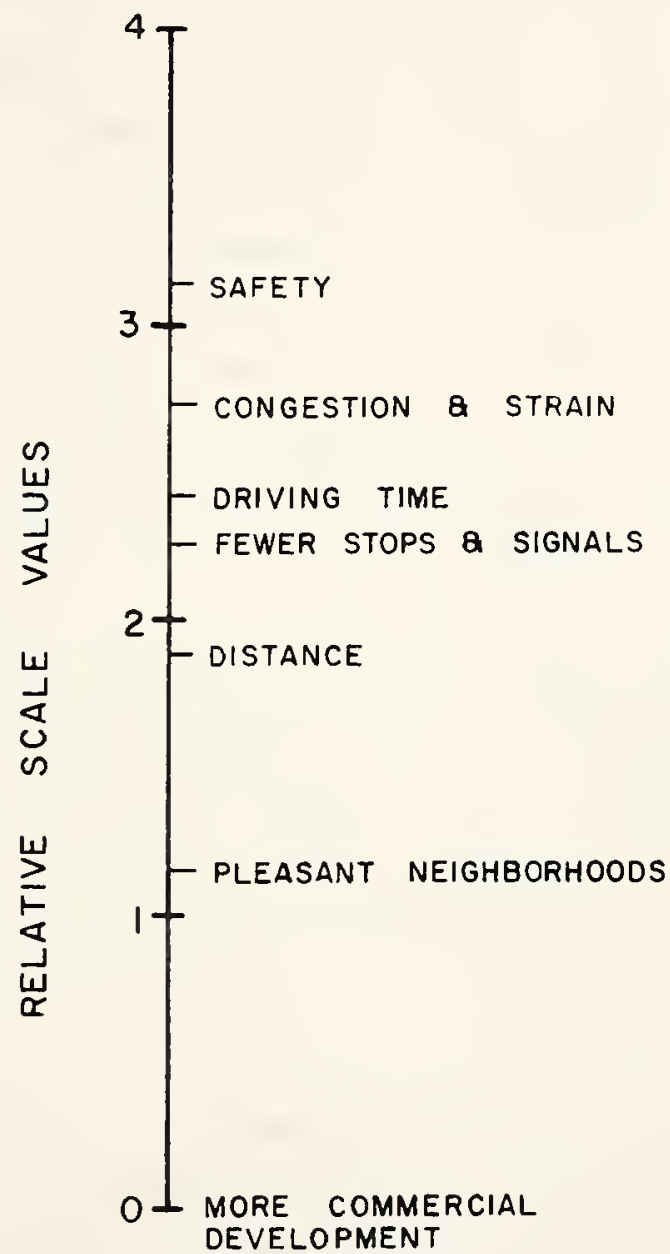

WORK TRIP

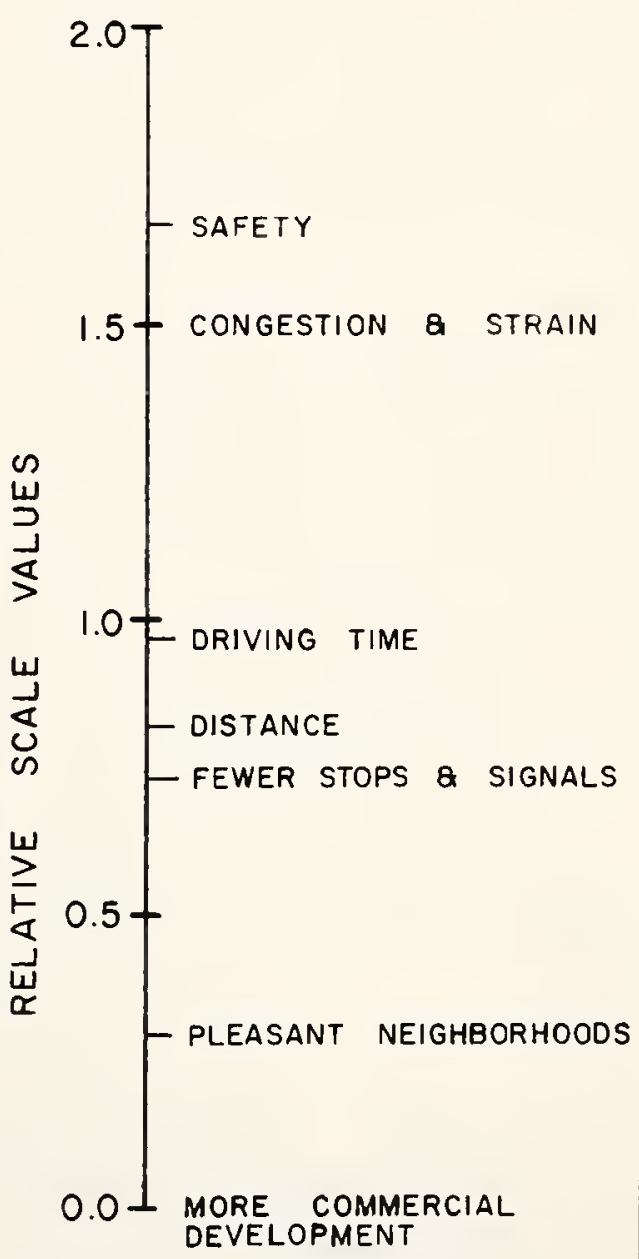

SHOPPING TRIP 
congestion and strain to driving being a close second in importance.

The second group along the scale included minimization of driving time, minimization of the number of signals and stop signs along the route, and minimization of distance. Driving time was considered more important for each of the trip purposes, however, for the shopping trip, distance considerations were more important than the preference for routes with fewer stop signs and signals.

Finally, the lower group on the scale included preferences for routes through pleasant neighborhoods and routes with commercial development. These descriptors may be considered relatively unimportant in the route choice decision compared to the other factors. Even for the shopping trip in which respondents might be interested in shopping at different stores along the route, the implied commercial development descriptor was judged to be least significant. A greater percentage of the respondents, however, did perceive pleasant neighborhoods and commercial development to be more important than was the case for the work trip (Tables 4.5 and 4.6$)$.

Model Evaluation and Critique

To check the consistency of the paired comparison scaling model, the procedure used to obtain the scale was reversed in order to estimate an expected proportion matrix, p'jk. If the scale estimates are unbiased, the reproduced matrix should be equivalent to the original $P_{j k}^{\prime}$ matrix and a plot of corresponding cell entries should form a linear relationship. Further, if the model provided a perfect fit, all points would fall on a line passing through the origin with a slope of 1.00. Figures 4.4 and 4.5 show the plots for each trip purpose. Least squares estimates of the slopes were found to be 1.02 and 1.00 for the work trip and shop trip, respectively. The intercept was 0.00 for each model. 


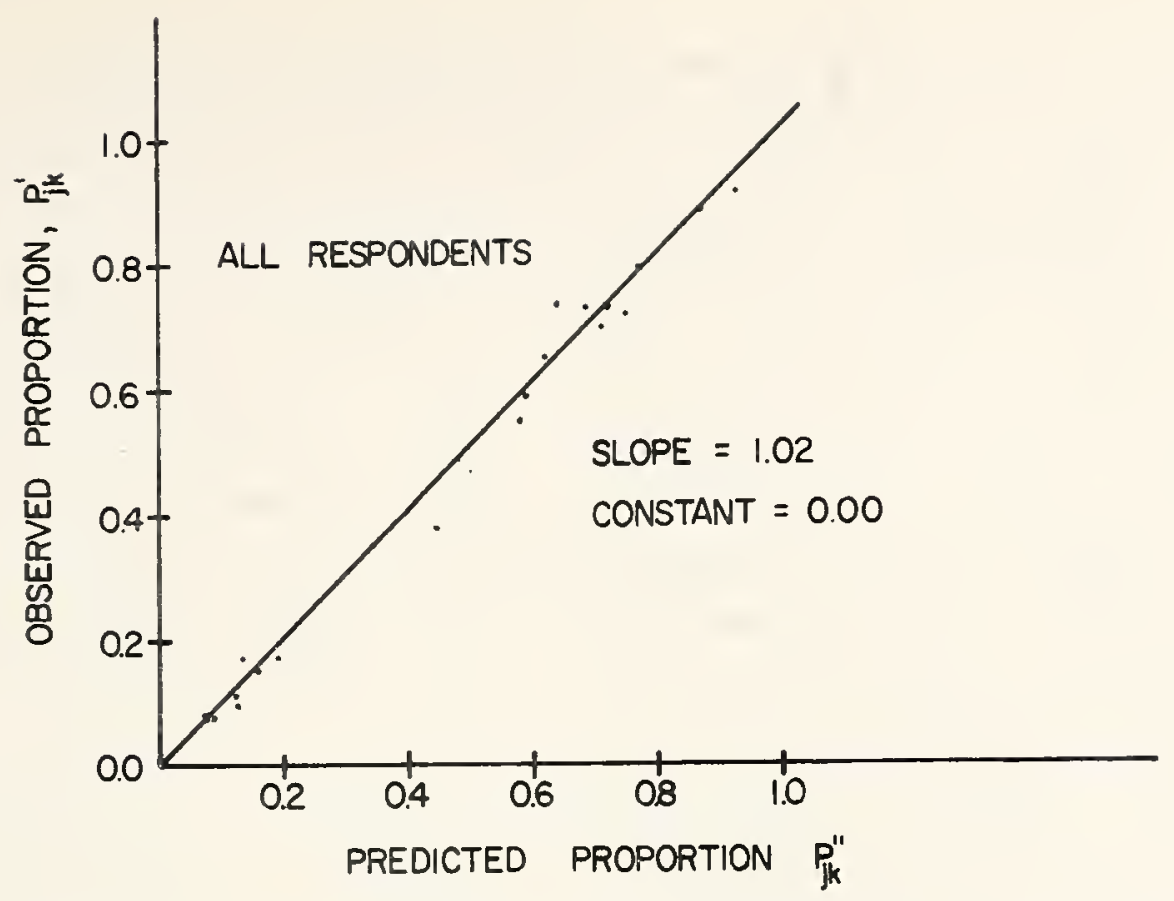

FIGURE 4.4 CALCULATED VERSUS OBSERVED PROPORTIONS FOR ROUTE CHOICE DESCRIPTORS, WORK TRIP

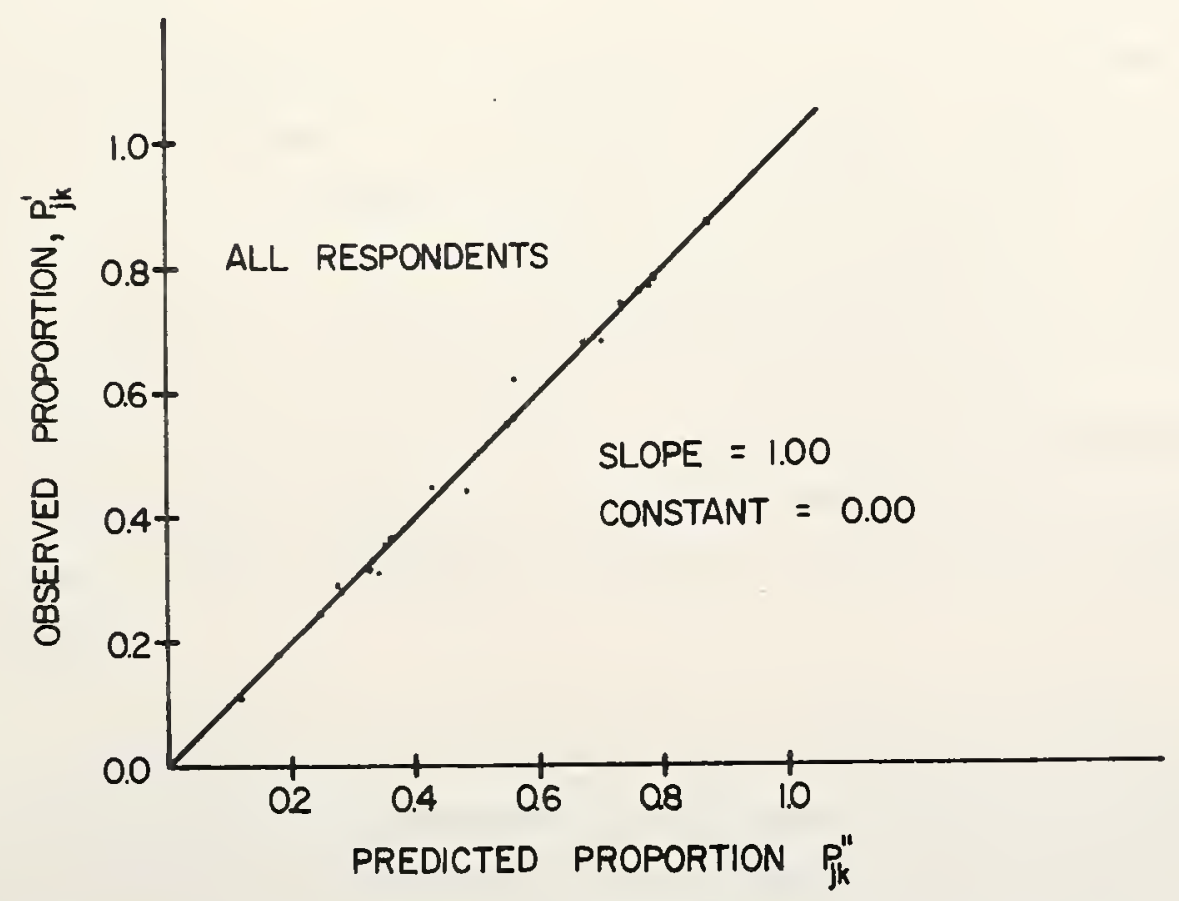

FIGURE 4.5 CALCULATED VERSUS OBSERVED PROPORTIONS FOR ROUTE CHOICE DESCRIPTORS, SHOPPING TRIP 
Unlike the method of successive categories, the paired comparison model was extremely effective in fitting a scale to the observed data. The paired comparison model is operationally simpler for the respondent to understand. One is required to decide only which descriptor is more important in relation to the attribute being measured; he is not forced to select a degree of importance for each descriptor. All respondents were able to more easily adapt to their role in the pair comparison methodology but this seemed to be particularly important to the less educated groups.

The difficulty with the paired comparison method is that the number of comparisons which are necessary increases very rapidly as the number of descriptors increases. Whereas, the analyst may be interested in learning more about the components of a particular factor, the pair comparison method becomes over bearing for the respondent if he is to be charged with several additional components to rate. For example, in this study, in order for the planner to make effective use of the knowledge that safety is a prime consideration in route choice one would have to know more about the elements which the individual considers in safety. Are urban frecways perceived to be safer than arterial streets?; is provision of an emergency lane on expressways perceived to be more important than signalization of a route?; etc.

While the scaling model may effectively measure the relative importance of the set of descriptors, the magnitude of the task is increased greatly as the set of factors increases.

Analysis of Route Choice Descriptors by Subgroups

In order to determine if groups within the total sample had different preferences, the sample was divided into the same groups as in the mode choice analysis except that no stratification was possible for licensed and non-licensed respondents. Figure 4.6 shows the scales obtained from all 


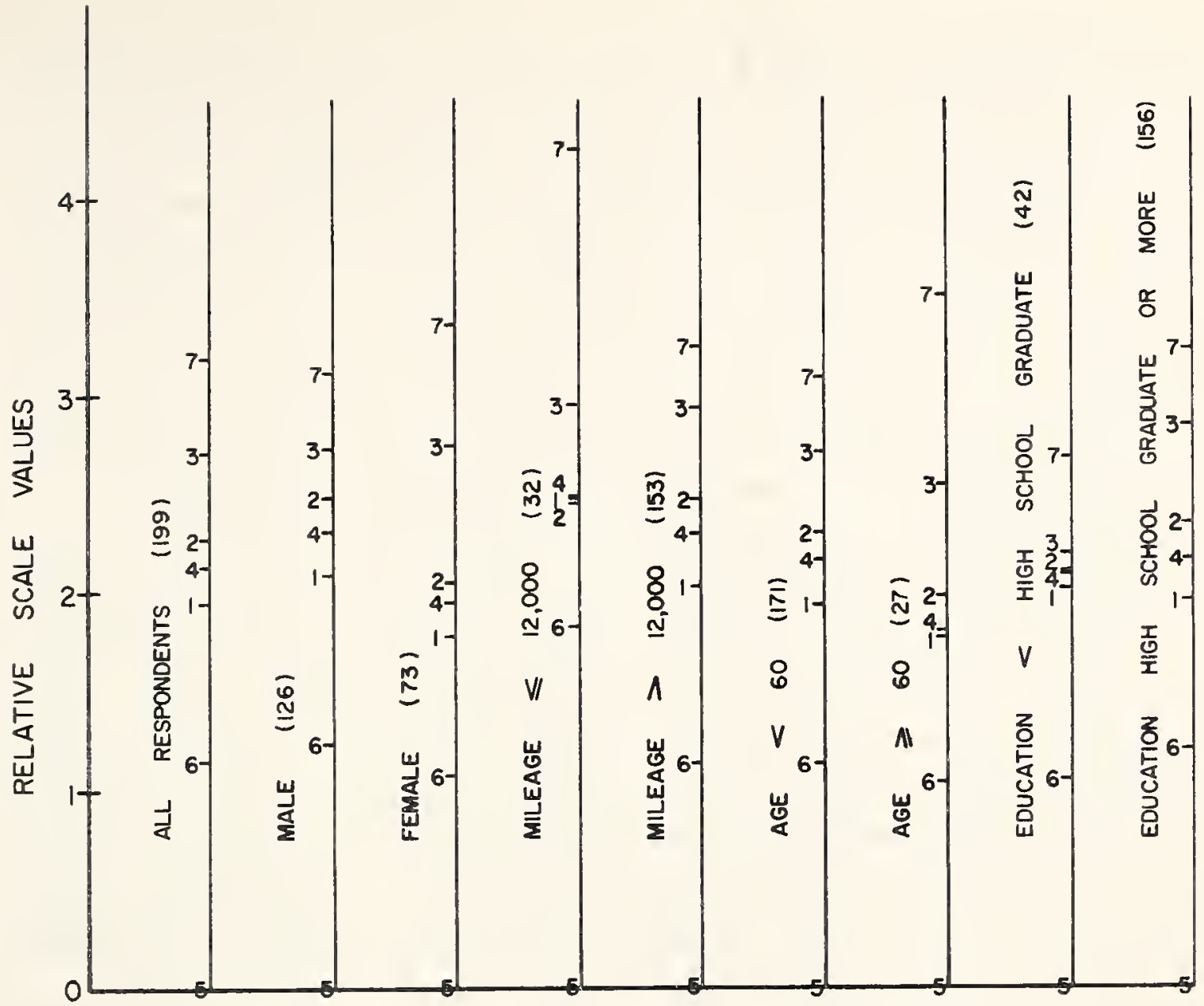

GENERALIZED DESCRIPTORS
(1) DISTANCE
(5) MORE COMMERCIAL DEVELOPMENT
(2) DRIVING TIME
(6) PLEASANT NEIGHBORHOODS
(3) CONGESTION \& STRAIN
(7) SAFETY
(4) FEWER STOPS \& SIGNALS

FIGURE 4.6 RELATIVE SCALES FOR ROUTE CHOICE DESCRIPTORS FOR WORK TRIP, BY SUBGROUPS 
subgroups for the work trip. The ranking of the descriptors was consistent across all subclasses, although variations in relative importance did exist. A greater concern for safety was exhibited by the respondents whose families traveled less than 12,000 miles each year. This group is not a part of what one might call the "traveling set" and is likely to be more apprehensive when traveling. Thus, the greater concern for a safer route. This greater preference for safety was also exhibited by the age group over 60 .

Analysis of the subgroup responses for the shopping trip also showed consistent scale positions across all subgroups (Figure 4.7). The only difference of consequence appears in the groups for age over 60, miles driven less than 12,000, and education less than high school. Each of these groups placed relatively more importance on driving through pleasant neighborhoods than did their corresponding group. It is interesting to note that these subgroups are not independent. In fact one would expect that many of the members from any one group would also fit in the other two.

\section{Analysis of Factors Related to Choice of Trip Destination}

The final area of study in this portion of the research was an attempt to measure the extent of the trip maker's movement space and the weight or importance of specific characteristics which influence the selection of potential destinations. In particular, the individuals perception of factors important in selecting a shopping trip destination were considered. Responses were solicited through open-ended questions (Questions 49 through 70) and through the structured approach of the successive categories rating scale (Question 71). The purpose of the less structured questions was to obtain information about the characteristics of the most recent shopping trip which the respondent had taken within the week of the survey. Of particular interest was 


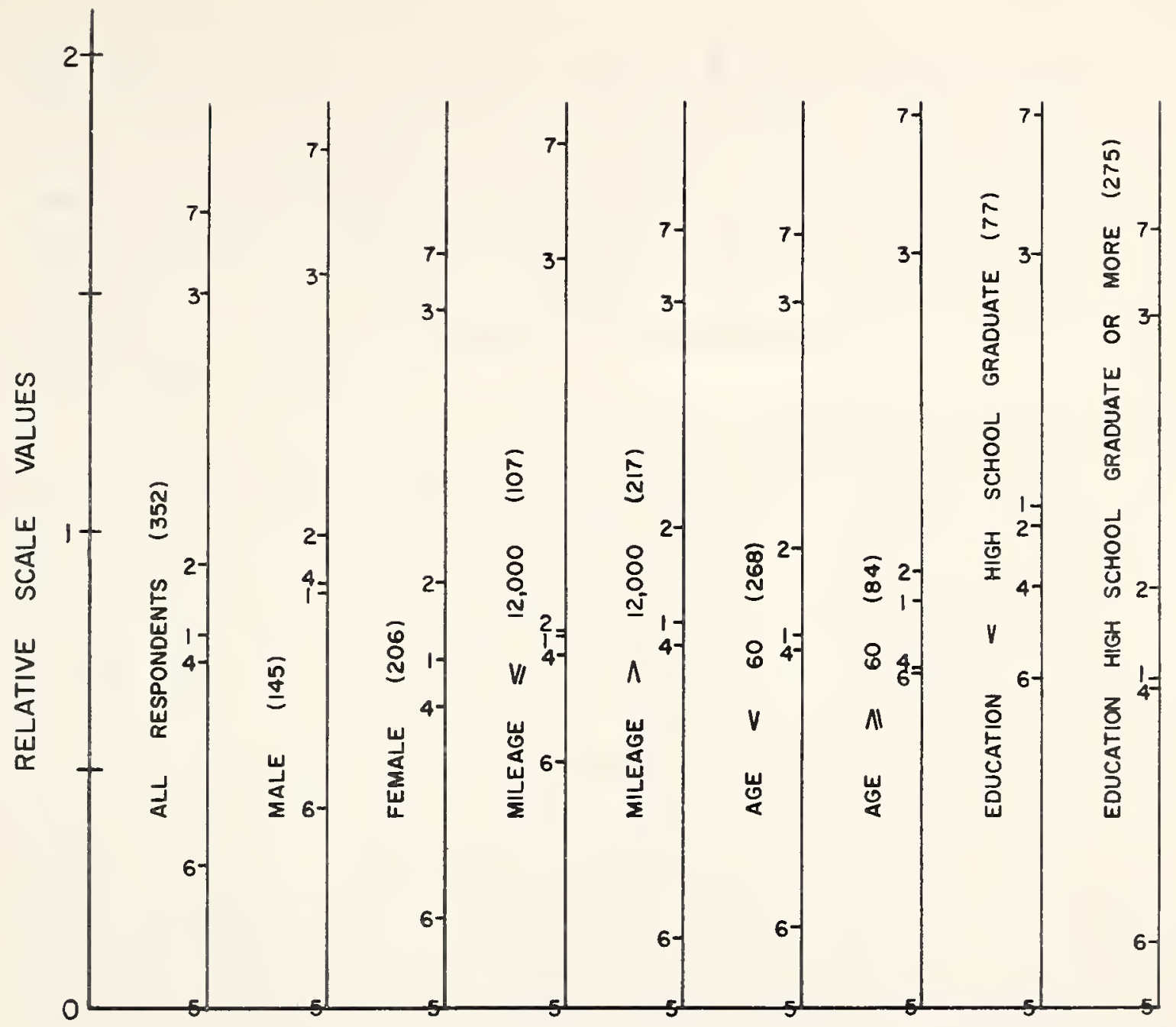

GENERALIZED DESCRIPTORS
(1) DISTANCE
(5) MORE COMMERCIAL DEVELOPMENT
(2) DRIVING TIME
(6) PLEASANT NEIGHBORHOODS
(3) CONGESTION \& STRAIN
(7) SAFETY
(4) FEWER STOPS \& SIGNALS

FIGURE 4.7 RELATIVE SCALES FOR ROUTE CHOICE DESCRIPTORS FOR SHOPPING TRIP, BY SUBGROUPS 
the mode of travel, the destination of the trip, the distance and time for making the trip, and the time of day. In addition, the respondent was asked the "why" of his choice and whether an alternate destination, mode or time would have been preferred. Summaries of this data are included in Appendix $C$ and are briefly discussed there. The discussion here focuses on the responses to the descriptors used in the rating scale analysis.

Table 4.7 gives a.listing of the generalized descriptors and shows the mean ratings and rank order of importance. The ratings show that individuals tend to select their shopping destination more upon the characteristics of the store itself, than on the characteristics of the transportation system which serves the area. Descriptors related to characteristics of the store which received high ratings were selection of goods, and appearance of the store and surrounding environment, number one and three, respectively. on the other hand, descriptors referring to distance, travel time, and travel cost were ranked in positions 11, 12, and 13, respectively. The cost of parking was rated tenth, but the ability to park near the shopping destination was perceived as the second most important decision variable. The ability to quickly find a parking spot was in the fifth ranked position. These latter factors are often actually a characteristic of the destination selected, e.g., as at shopping centers where parking facilities are a composite part of the development. The respondents' desire to shop where they could easily find a parking spot was apparently satisfied as fully 90 percent of all auto mode travelers reported finding a parking location in a minute or less. Less than ten percent of all reported auto mode shopping trips reported were in the central business district of Indianapolis.

When the respondent was asked why he chose the particular shopping location that he cited for the particular trip 
Table 4.7. Attitudinal Ratings of Factors Important in Selection of a Shopping Trip Destination.

Generalized Descriptor

Average

Rating*

Familiar area

Shop at several stores

Employees to help you

Wide selection

Shortest trip time

Parking cost

Go where others shop

Roads not congested

Walking distance from vehicle

Easy to return home

Ride to several stores

Quickly find place to park

Travel cost

Distance

Pleasant appearance
5.07

5.61

5.01

6.25

4.74

4.81

3.31

5.30

5.72

5.67

4.36

5.61

4.74

4.79

5.71
Rank Order

8

$5 \frac{1}{2}$

9

1

13

10

15

7

2

4

14

$5 \frac{1}{2}$

12

11

3

${ }^{*}$ Maximum rating $=7.0$ 
under consideration (Question 58), the most frequent response was that this store was closest (110 responses-see Table C3). On the surface, this would appear to be a contradiction since distance and time factors were given low ratings in the attitude scales. A logical interpretation, however, exists. It can be said that the basic decision variable is not a factor of time or distance per se, but rather, the decision is shaped more by the opportunity to satisfy the goals of the trip. The individual places a high value on serving the needs of the trip at the closest opportunity, but the time necessary to arrive at the goal destination is not the prime factor. Indeed, this is the basic hypothesis of the Intervening opportunity model for trip distribution. The basic hypothesis of the Intervening opportunity model is that trips will desire to be as short as possible, lengthening only as the traveler fails to find a destination which satisfies the needs of the trip. The trip opportunities from any zone are arranged by time of travel, but travel time as such is not the decision variable in the analysis (24). On the other hand, the Gravity model is calibrated using travel times directly.

The pattern of responses from individuals in this research lend further support to the intervening opportunities concept. The respondents were asked if they would consider shopping at other locations (Question 62), and, if so, how many of the alternatives would be closer to home. Figure 4.8 shows a plot of the percentage of individuals selecting the closest destination, second closest, etc. Clearly, as would be expected, the probability of shopping at a location decreases rapidly as the number of intervening opportunities to satisfy the needs of the trip increase. 


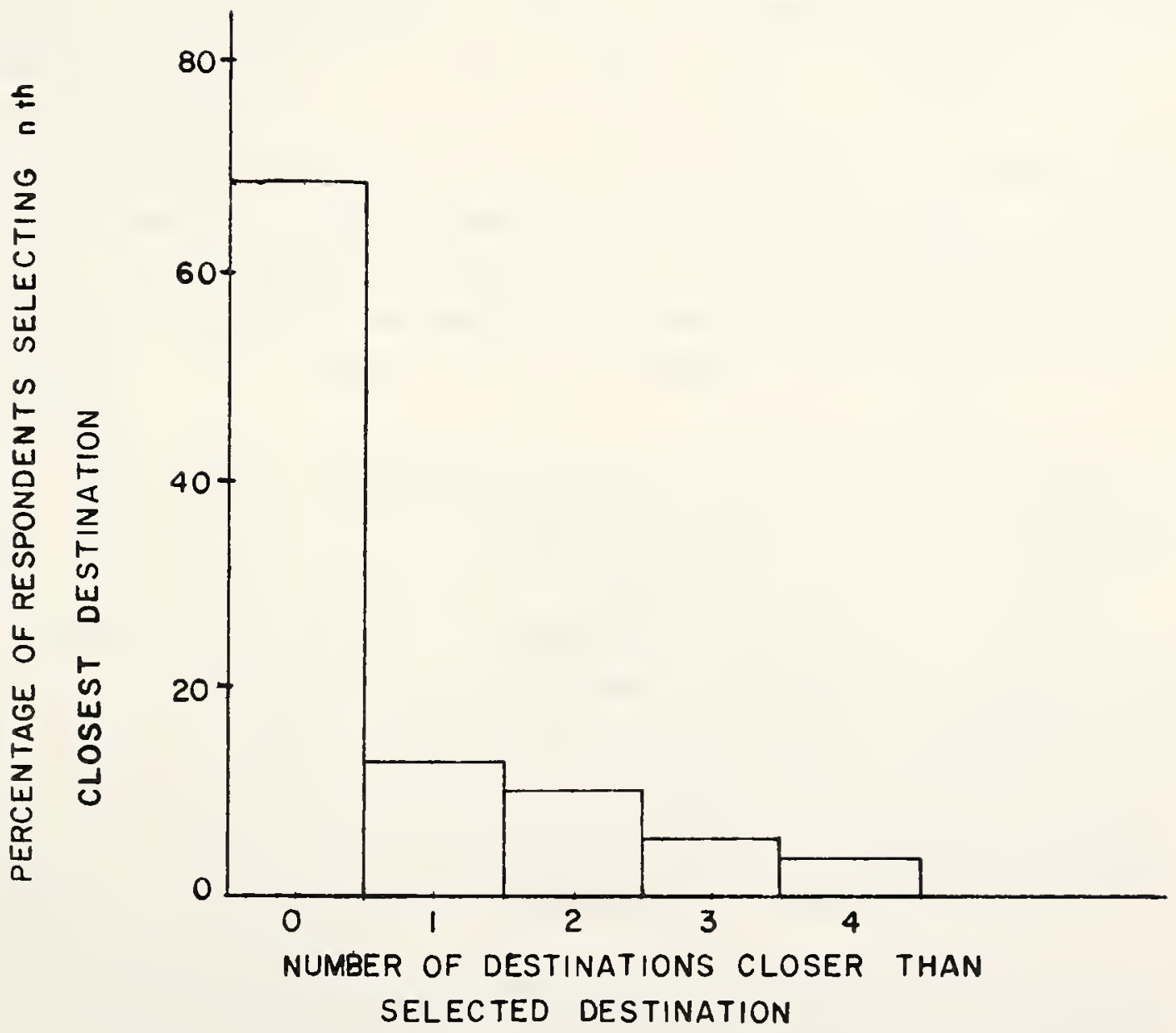

FIGURE 4.8 DISTRIBUTION OF THE TRIP DESTINATION OPPORTUNITIES BYPASSED BEFORE SELECTING A DESTINATION 


\section{Analysis of Preferences for Shopping Trip}

Destination by Subgroups

The shopping trip descriptors were analyzed for three subgroups of the total set. The respondents were grouped into male and female, licensed and non-licensed drivers and length of time taken for trip, i.e., less than 15 minutes and greater than or equal to 15 minutes. The KolmogorovSmirnov test was used to test for differences in the response patterns for each of these groups (34). The results are shown in Table 4.8 .

Females show a greater preference for the shopping area to be familiar, easy to get to, and close to home. Attainment of the desire is reflected by the average reported trip lengths. Whereas the male respondents reported average trip lengths of 4.2 miles, the trip length for females was 3.7 miles.

Non-licensed respondents also perceived familiarity and ease of getting to the intended location as more important than their counterparts. In addition, since this group must depend on other means of transportation such as taxi, or bus, or other members of the family, they exhibited a significantly higher concern for travel cost. Licensed drivers who could drive and have more freedom to go where they desired perceived parking cost and the ability to shop at several stores at the shopping destination as more important than their counterparts.

Finally, those respondents who reported trips longer than 15 minutes showed a significantly greater concern for shopping where they felt they would have a wider selection of goods. These individuals were apparently willing to take a longer trip to satisfy this perceived goal.

\section{Summary}

Results from the attitude scaling concurred with other research in the finding that the perceived importance of mode 
Table 4.8. Kolmogorov-Smirnov Test for Difference in Shopping Trip Destination Preferences, by Subgroups .

\begin{tabular}{|c|c|c|c|}
\hline \multirow[t]{2}{*}{ Generalized Descriptor } & \multicolumn{3}{|c|}{ Subgroups } \\
\hline & $\overline{\operatorname{Sex}}$ & $\begin{array}{l}\text { Licensed } \\
\text { Driver }\end{array}$ & $\begin{array}{l}\text { Trip } \\
\text { Time }\end{array}$ \\
\hline Familiar area & * & $\star \star$ & NO $a$ \\
\hline Shop at several stores & * & * & ** \\
\hline Employees to help you & NO & NO & * \\
\hline Wide selection & NO & NO & NO \\
\hline Shortest trip time & NO & NO & $\mathrm{NO}$ \\
\hline Parking cost & NO & * & NO \\
\hline Go where others shop & NO & NO & NO \\
\hline Roads not congested & NO & NO & NO \\
\hline Walking distance from vehicle & NO & NO & NO \\
\hline Easy to return home & * & ** & NO \\
\hline Ride to several stores & NO & NO & NO \\
\hline Quickly find place to park & NO & * & NO \\
\hline Travel cost & NO & * & NO \\
\hline Distance & * & NO & NO \\
\hline Pleasant appearance & NO & NO & $\mathrm{NO}$ \\
\hline
\end{tabular}

Trip Length

$\begin{array}{ccc}\text { Male } & \text { Licensed } & \leq 15 \text { Minutes } \\ (146) & (290) & (180) \\ & \text { Non- } & \text { Trip Length } \\ \text { Female } & \text { Licensed } & \geq 15 \text { Minutes } \\ (203) & (53) & (166)\end{array}$

a "NO" indicates no significant difference in response pattern at either the 0.05 or 0.01 significance level.

* Significant at $\alpha=0.05$

** Significant at $\alpha=0.01$ 
and route choice descriptors is relatively independent of trip purpose. Reliability, comfort and independence of others were general factors cited as important in choice of mode. Travel time and cost which are typical variables used in modal split analysis. were rated low by the respondents of this study.

In selecting a route, safety was perceived as the most significant factor. Next in importance were concerns for selecting routes with less congestion and strain to driving, and selection of routes which minimize travel time. These latter characteristics are typically the considerations used in trip assignment modeling.

Finally, the choice of a trip destination for shopping was dependent more upon the characteristics of the shopping location itself, than on the transportation system serving the area. Travel time, distance, and cost were all perceived to be of small importance. The conceptual basis of the Intervening opportunities distribution model was supported by the results of the survey. 
CHAPTER 5. HOUSEHOLD TRAVEL CHARACTERISTICS AND TRIP GENERATION EQUATIONS

In this chapter the analysis concentrates on variables important in home based trip generation models. Several aspects concerning household level travel analysis are evaluated. These include: the form of the relationships between the socioeconomic variables and trip production rates; the variance of trip production rates; the ability to estimate the trips reported by all single family dwelling units from which the survey sample was drawn; and the ability of household models, based on the entire 1964 data set, to estimate the total zonal home based trip productions used in IRTADS. The trip generation models are developed using linear regression analysis. The models considered are home based trip production models. The variables used in the household equations are selected to be comparable to those used in the 1964 IRTADS models. Chapter 6 considers other variables which may also be relevant at the household level of analysis.

\section{Household Travel Characteristics}

The 357 households selected from the 1964 survey list and re-interviewed in 1971 possessed characteristics which were generally equivalent to the population from which they were drawn. Table 5.1 shows the average household characteristics of the "population" and the sample used in this study. The households in this study exhibit trip production rates which appear to be somewhat greater than the sample from which they were drawn, but these differences are consistent with the larger labor force, auto ownership rate and income levels of these households. The form of the relationships 


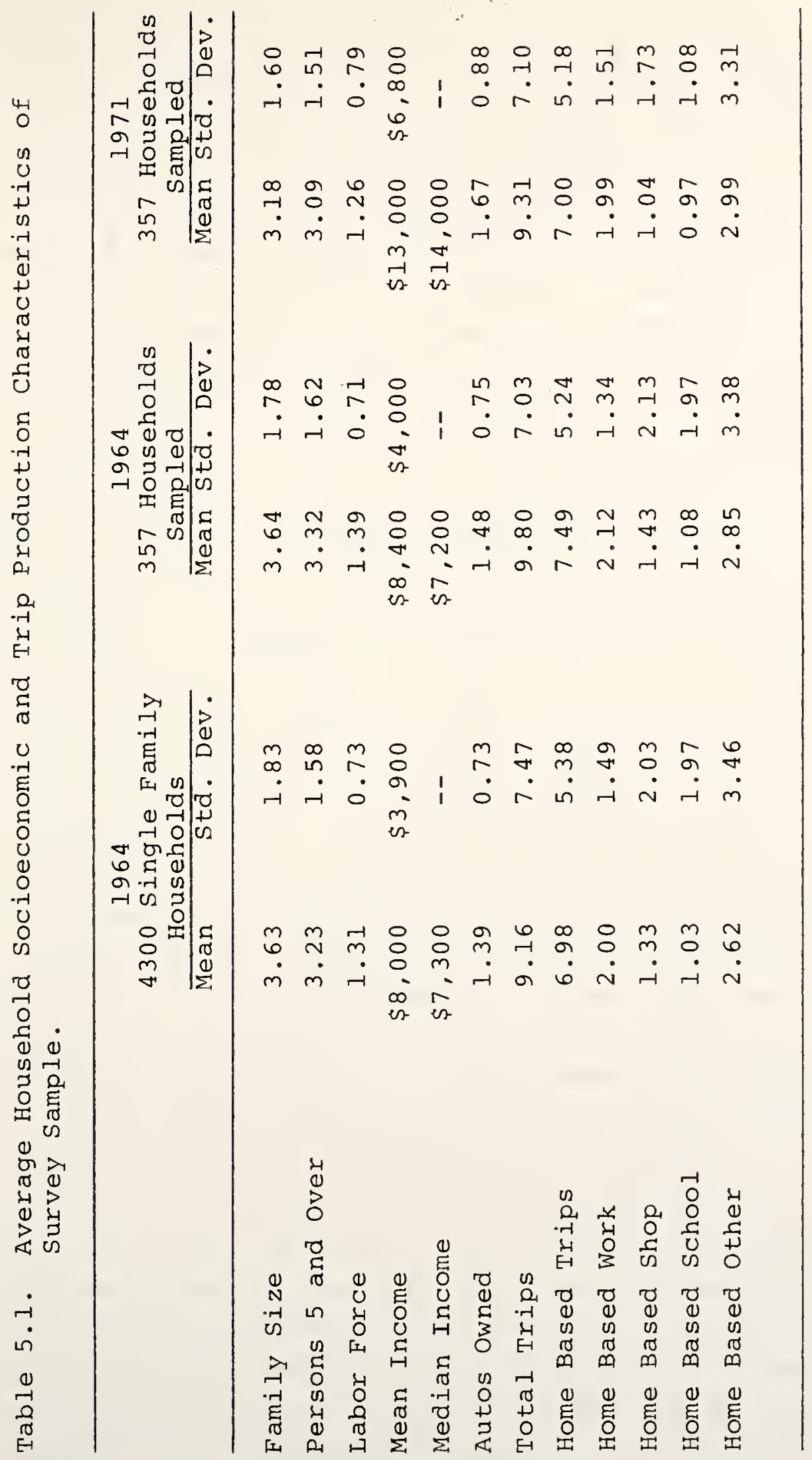


between family size, auto ownership, and income; and the home based trips produced by the households are given the greatest attention since these are the variables found to be most often associated with trip production. Figures 5.1, 5.2 and 5.3 provide a graphical summary of these relationships for the households selected for this research. The cross classification tables appear in Appendix B. The points on the Figures represent average trip production rates for each level of the variable on the horizontal axis.

Figure 5.1 indicates the relationship between family size and home based trip production. Two aspects of these curves should be given special consideration. First of all, family size has a linear relationship with trip production for family sizes of four or less but as family size increases the rate of trip production increases at a decreasing rate. This overall nonlinear trend agrees with the findings reported by $O i$ and shuldiner (30). Since trip generation models generally assume linear relationships, large departures from linearity could have important effects on these prediction models. The analyst must recognize where the assumptions of the model are not met, and the consequences of using the variable or model formulation in spite of these irregularities. Statistical tests are available to test for lack of fit of a linear model. These tests, and the implications of adopting alternate variable inputs are discussed later in conjunction with linear regression models.

The other significant observation to be made from Figure 5.1 is the relatively good agreement of the curves for the two data sets. Although, as illustrated in Table 5.1, the family composition has changed over the years, as obviously has the age structure, the average trip production for families of similar size for the two periods are relatively stable. This again has important implications in developing models of travel behavior. The stability of the form of the relationship indicates a possible causal 


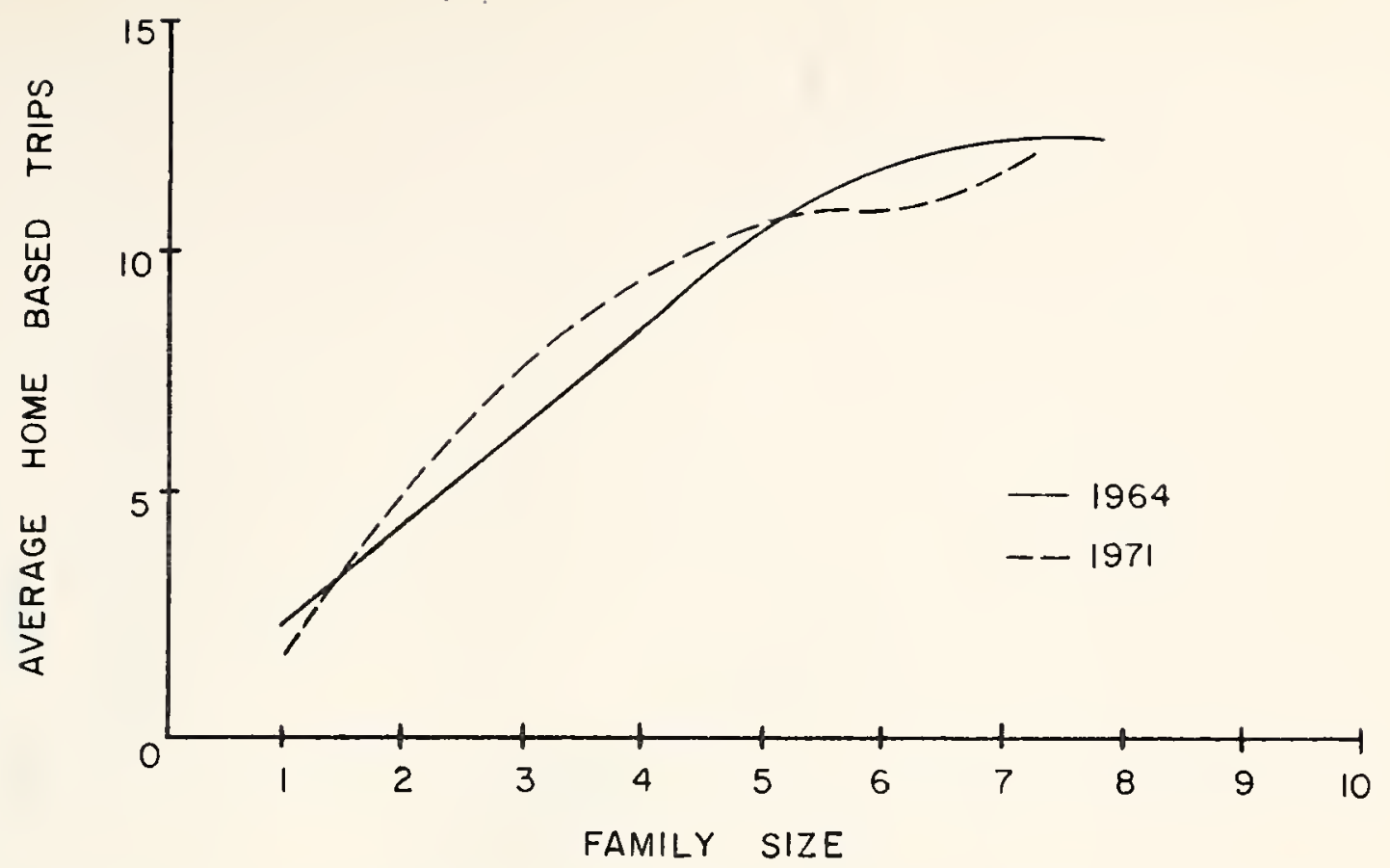

FIGURE 5.1 HOUSEHOLD TRAVEL RATES FOR VARYING LEVELS OF FAMILY SIZE

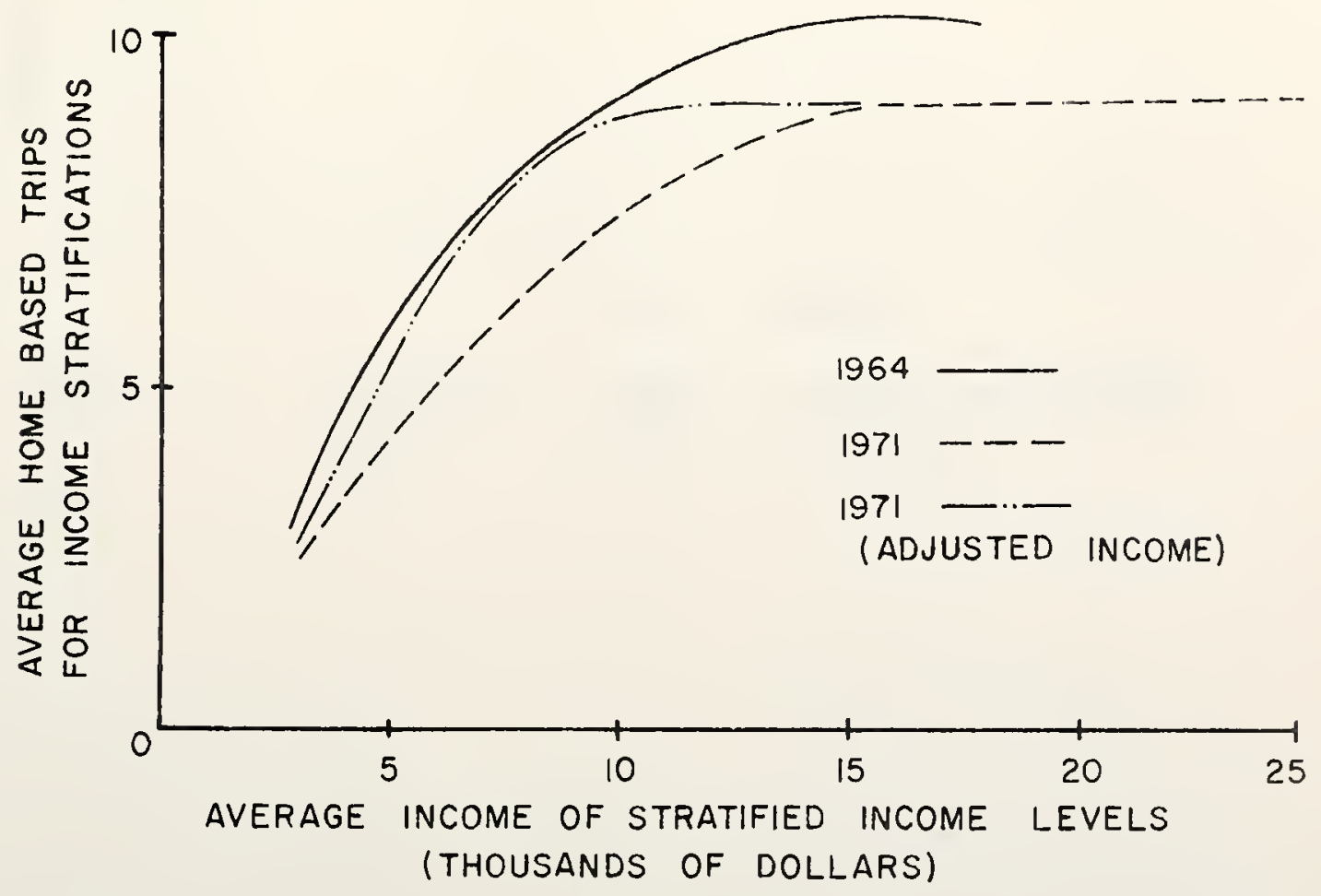

FIGURE 5.2 HOUSEHOLD TRAVEL RATES FOR VARYING LEVELS OF INCOME 


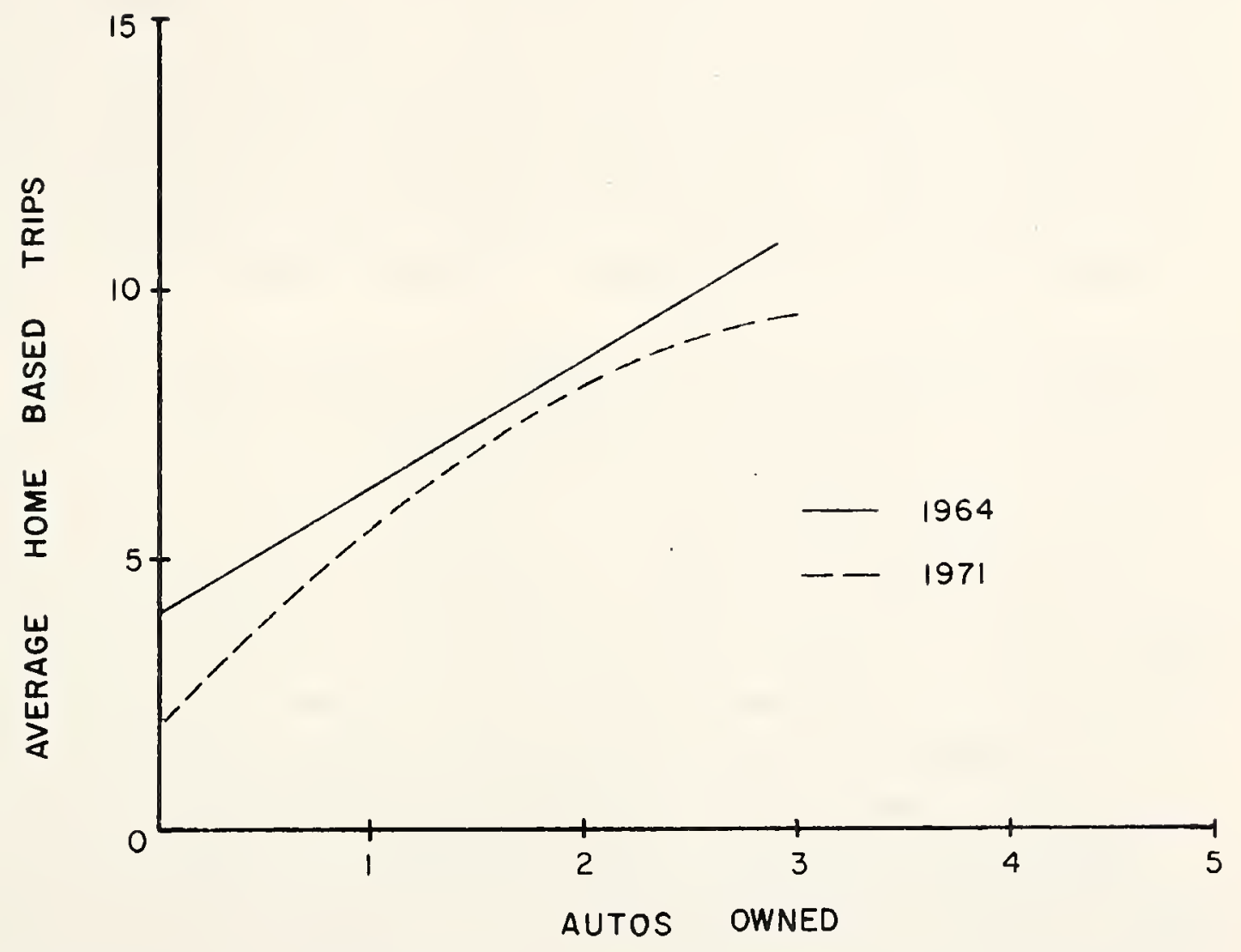

FIGURE 5.3 HOUSEHOLD TRAVEL RATES FOR VARYING LEVELS OF AUTO OWNERSHIP 
relationship between family size and trip production. If the relationship between the dependent and independent variables remains stable over time, this relationship should be useful in forecasting models. This relationship has far more meaning than other relationships which may have higher linear associations, but do not possess the quality of causal validity and stability. The family size variable has the distinction of having both relative stability and, relatively strong correlation with trip production. The linear correlation between family size and home based travel is 0.52; this is considered high for analysis at the disaggregate level.

The relationship of income and trip production shown in Figure 5.2 also exhibits nonlinear tendencies. In fact, the 1971 data set which allowed a finer breakdown of the high income categories, indicates that the average trip production rate actually stabilizes at incomes above $\$ 15,000$. Due to changing values of the dollar and changes in buying power, the effect of changes in the income variable are more difficult to assess than fixed variables such as family size. To account for differences in buying power of a dollar over the seven years, a deflation factor based on 1970 income census data was applied (39). Although the reported incomes in Indianapolis increased at an annual rate of 6.7 percent, the census reported that the annual rate of increase in constant dollars during the past decade was only 3 percent. Therefore the incomes reported in 1971 were multiplied by the factor 0.80 to approximate the 1964 dollar. The adjusted income line in Figure 5.2 shows considerable agreement with the 1964 curve within the range for which comparable data were available.

Finally, Figure 5.3 shows the corresponding curves for auto ownership. The curve exhibits strong linear trends with greater fluctuation from linearity exhibited in the 1971 data. However, the slope and intercept of the Iines, 
and thus the effect of auto ownership on trip production, appears to have shifted over the years. The effect of changes over time in the response variable may be statistically evaluated. This will be accomplished in conjunction with linear regression estimation models, but the practical significance of such a shift is reiterated here. Unless a shift in the values of model parameters is detected by observation at intervals less than the planning period for which forecasts are made, the final estimate could yield considerable error. As pointed out earlier, one of the major deficiencies of the aggregate models is that large quantities of data are gathered at a single point in time; since funds to obtain similar data sets are not available for the continuing phase, the planner must be content to assume the correctness of the estimates over the planning period, or adjust the original estimates by forcing the original projections in the direction of the observed changes. This forcing process leaves the analyst with the task of continually searching for the next discrepancy to appear. Without understanding the "why" of the change, one cannot really hope to find an objective explanation which will provide an adequate estimate of all changes which should be expected. Such objective analysis can only be obtained by analyzing the subtle changes which occur at the decison level.

The limitations of aggregate models were illustrated in Chapter 2. These models do not provide true estimates of travel behavior because they attempt to explain only the variation which exists between the mean trip rates of the zones. Due to the skewed distribution of the household variables, these mean zonal rates are not representative of all individual household which compose that mean. As a result, the true relationships are not measured. Further, the regression modeling technique assumes that the variance of the data within the zones are equal. Again, other 
research has shown this assumption is unwarranted $(10,25)$. This is further substantiated in the zonal data for Indianapolis. Bartlett's test for homogeneity of variance shows a significant heterogeneity of variance beyond the 0.001 level of significance.

This research suggests that the analysis of travel behavior should be conducted at the household level. This approach does not wash out the variations in travel behavior, but rather, it attempts to understand the significance of the variations and to explain these variations in the model. While the disaggregate analysis avoids the loss of information due to aggregation, the homogeneity of variance assumption must still be considered. Therefore, before discussing linear regression models for estimating household travel, the homogeneity assumptions of the disaggregate data will be reviewed and the significance of the household variables tested.

Reviewing the distribution of variance of household trip production at all levels of the independent variables shows that the household level analysis does not provide a neat solution to all of the problems associated with heteroscedasticity of variance in model development. Table 5.2 provides a typical example of the degree of variation in the data at the household analysis level. The table exhibits the variance, $s_{i}{ }^{2}$, of home based trips for seven levels of family size $(i=1,7)$. Variation in auto ownership and income categories exhibit similar characteristics but are not given here.

The variance over all levels of family size exhibits a considerable range, however, it is noted that the magnitude of the variance is proportional to the mean of the dependent variable. Comparison of the coefficient of variation at each level indicated that the deviation, expressed as a fraction of the mean trip rate, is quite stable. 
Table 5.2. Distribution of Variance in Household Travel for Varying Family Size Levels.

\begin{tabular}{ccccc}
\hline $\begin{array}{c}\text { Family } \\
\text { Size } \\
\text { Levels }\end{array}$ & $\begin{array}{c}\text { Number of } \\
\text { Observa- } \\
\text { tions }\end{array}$ & $\begin{array}{c}\text { Mean } \\
\overline{\mathrm{X}}_{i}\end{array}$ & $\begin{array}{c}\text { Variance } \\
\mathrm{s}_{i}^{2}\end{array}$ & $\begin{array}{c}\text { Coefficiert of } \\
\text { Variation } \\
\mathrm{s}_{i} / \overline{\mathrm{X}}_{i}\end{array}$ \\
\hline 1 & 21 & 2.24 & 1.99 & .63 \\
2 & 89 & 4.40 & 5.68 & .54 \\
3 & 80 & 6.63 & 13.43 & .55 \\
4 & 70 & 8.77 & 27.72 & .48 \\
5 & 47 & 9.68 & 21.70 & .59 \\
6 & 26 & 12.62 & 56.17 & .49 \\
$7+$ & 24 & 12.42 & 36.51 & .60 \\
\hline
\end{tabular}


Bartlett's test for homogeneity of variance shows that the variances are significantly different $(\alpha=0.001)$, just as was true for the aggregated data (6). The relation between the variance and the mean suggested that the dependent variable is not normally distributed, but may be more appropriately described by a Poisson distribution. This is substantiated by the frequency distribution of Figure 5.4. A square root transformation is therefore suggested to normalize the distribution. This transformation considerably reduced the degree of heteroscedasticity, but the variances were still non-homogeneous over the classes.

Box has considered the problem of homogeneity of variance and has found that an analysis of variance to test for difference in means was capable of withstanding quite a degree of heteroscedasticity (3). In addition, it was concluded that if the weighted variance is less than the unweighted variance of the $k$ levels, one would tend to overstate the significance of the variables and, vice versa. The weighted variance is expressed as:

$$
\sum_{i=1}^{k}\left(n_{i}-1\right) s_{i}^{2} /(N-k)
$$

where

$$
\begin{aligned}
& n_{i}=\text { number of observations in level } i ; \\
& k=\text { number of levels; and } \\
& \mathrm{N}=\text { total number of observations }
\end{aligned}
$$

The unweighted variance is expressed as:

$$
\sum_{i=1}^{k} s_{i}^{2 / k}
$$




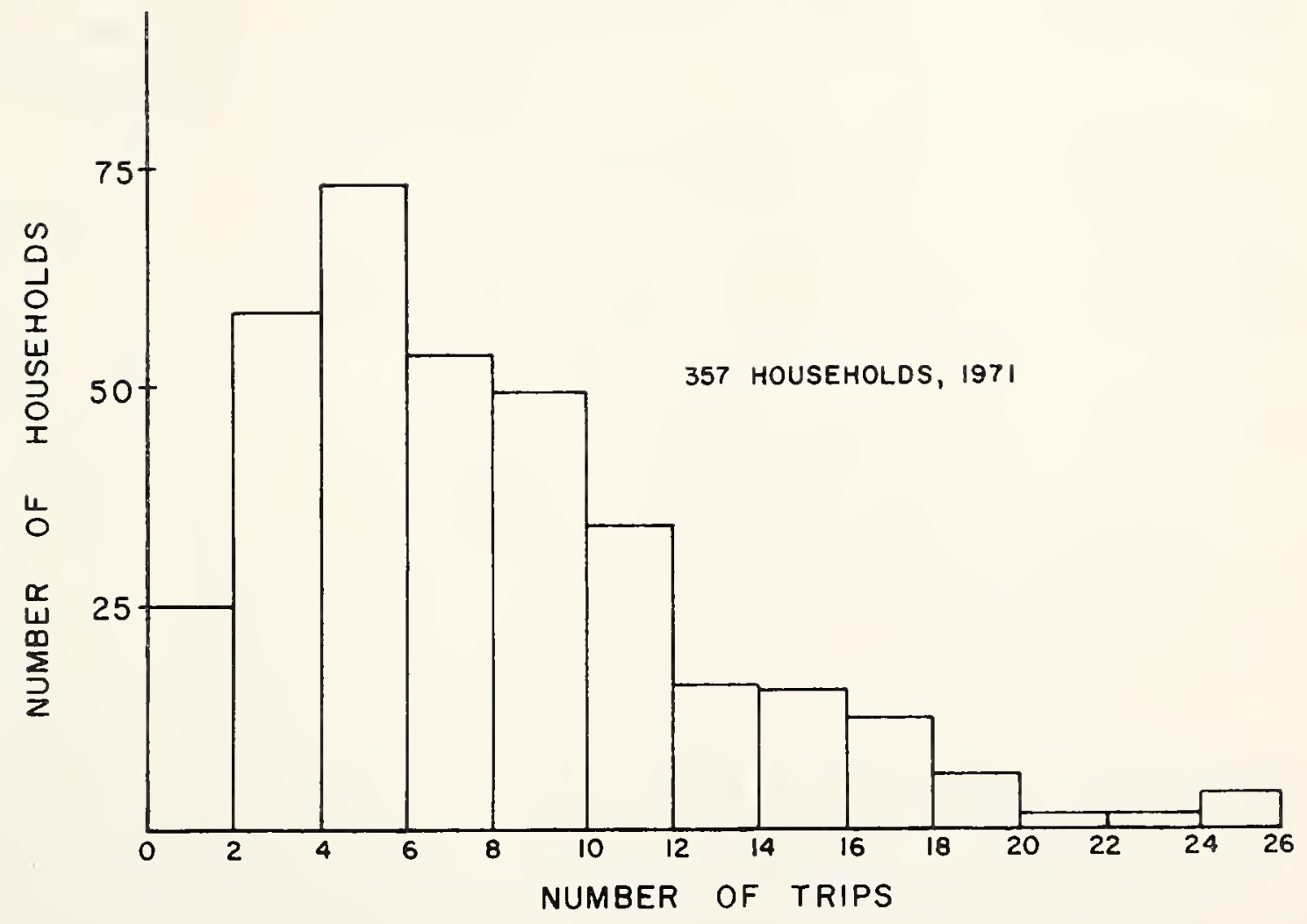

FIGURE 5.4 HOME BASED TRIP FREQUENCY DISTRIBUTION 
Thus, if the computed $F$ ratio is insignificant at the nominal level of significance, the variable would certainly be insignificant. On the other hand, if the $F$ ratio is significant at the nominal level, the confidence in the statement of significance at that nominal level, $\alpha_{n}$, cannot be as strong since one tends to overstate the significance of the variable. The data evidenced here gives a weighted variance less than the unweighted variance so one might tend to overstate significance.

Bearing the above relationships in mind, two-way analysis of variance with unequal cell sizes was conducted to test for significance of the relationships between family size, auto ownership, and income; and the dependent variable, home based trips. The analysis of variance is based upon a fixed effect model; $i . e .$, the levels of the factors are not random samples from an infinite population of all possible levels, but are the levels of interest in this investigation. The results of the ANOVA for the 357 households are shown in Table 5.3. To obtain the most information possible from the available data, the groups were stratified to levels which would allow an adequate sample size in each level. For the 1964 data set shown here, income was stratified into three levels: less than $\$ 5,000, \$ 5,000$ to $\$ 7,999$, and greater than $\$ 8,000$. Family size was stratified into seven levels for the comparison with auto ownership, but only four stratifications were considered for the model in which the second factor was income. Family sizes of four or more were grouped together in this model. The auto ownership groups were zero car, one car, and multi-car stratifications.

All main effects were found to be significant $\left(\alpha_{n}=\right.$ 0.01). Interaction was significant only for the family sizeincome combination. The significance of all main effects indicated that these variables would be important determinants in a linear regression model of trip generation. 


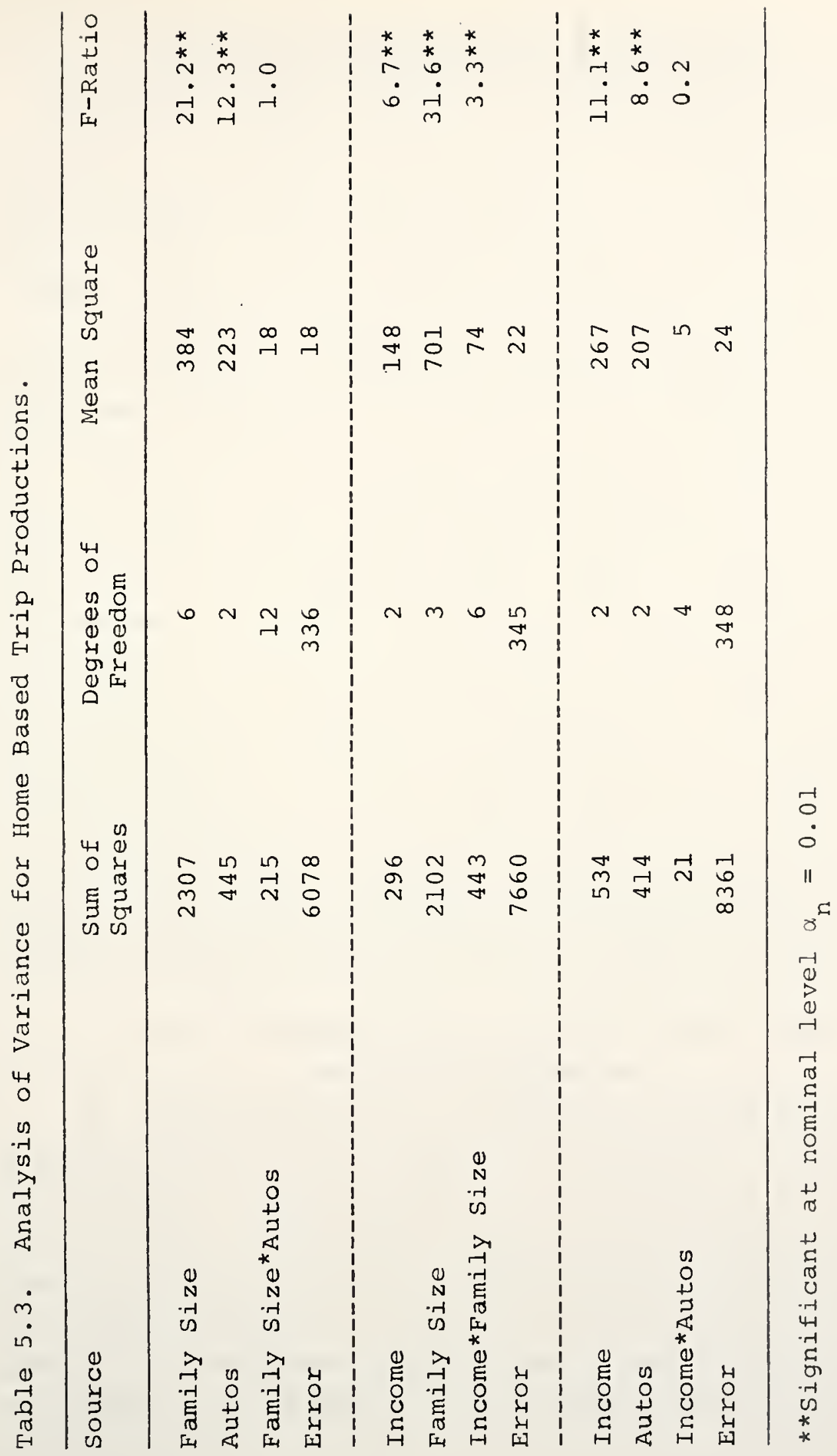


Household Trip Prediction Equations for

Estimating Trips from Single Family Dwelling Units

The 4300 households from which the survey sample was drawn were located in 313 zones of the study area. Since the present transportation modeling system requires zonal inputs for distribution and assignment, it is necessary to estimate trip generation inputs at this zonal level.

In the usual planning process a model is calibrated using current data and then forecasts are made for all the independent variables. The model is then applied to forecast future travel. In this research the model based on 1964 data from the 357 households was first used to estimate the home based trips which should be reported in 1971 if the model is a good predictive model. Then the regular planning process was essentially reversed in that a model developed from the 1971 survey was taken back in time and compared with a household model based on data collected in 1964. Each of these models was evaluated for its ability to estimate total reported trips of the 4300 single family units from which the sample was drawn. If the form of the relationships are correct, and the household relationships are stable as hypothesized, travel estimates from the 1971 model should compare favorably with the estimates from the 1964 model.

Test of Assumptions of Household Model Trip

Generation Equations

As indicated earlier, the dependent variable, household trip production, is not normally distributed. Further, the variances are not homogeneous at each level of the independent variable. Although this does not preclude the use of linear regression analysis to estimate the parameters of the model, one may not be able to make probablistic statements about the accuracy of estimated trip productions with the degree of confidence that is usually associated with the 
statistical tests. Recognizing these limitations, Iinear regression analysis was used to evaluate the ability of disaggregate household models to estimate aggregate travel.

Table 5.4 presents the results of the linear models for estimating home based trip production. As was expected, the parameters of the model have shifted somewhat over time. The degree of change is in agreement with observations made from Figures 5.I and 5.3. That is, the parameter for family size is very similar over the period while auto ownership has greater variability.

Two way analysis of variance models (ANOVA) were evaluated to test the influence of the variables over time. The time factor may be labeled simply as a years effect, but years is considered only as a surrogate for the effect of changes in other possible pertinent variables such as income, and stage in the family life cycle. When the effect of years and family size were examined, only family size explained a significant portion of the variation in home based travel. On the other hand, the effect of time was a significant factor when all levels of auto ownership were considered. Over the seven years of this study the effect of auto ownership level has changed. From Figure 5.3 one could speculate that the change occurred primarily in the zero car and the three car households. Indeed, when only one and two car households were considered, there was not a significant variation due to time changes.

The coefficient of determination, $R^{2}$, and the standard error of the estimate provide other measures for comparing the two models. The coefficient of determination is a measure of the percent of the variation which is explained by the model and the standard error of the estimate is a measure of the spread, or the expected limits, of the predicted variable. Both models give very similar statistics for these measures but, for the analyst who is accustomed to observing $\mathrm{R}^{2}$ values around 0.90 for zonal data, they are unimpressive. 


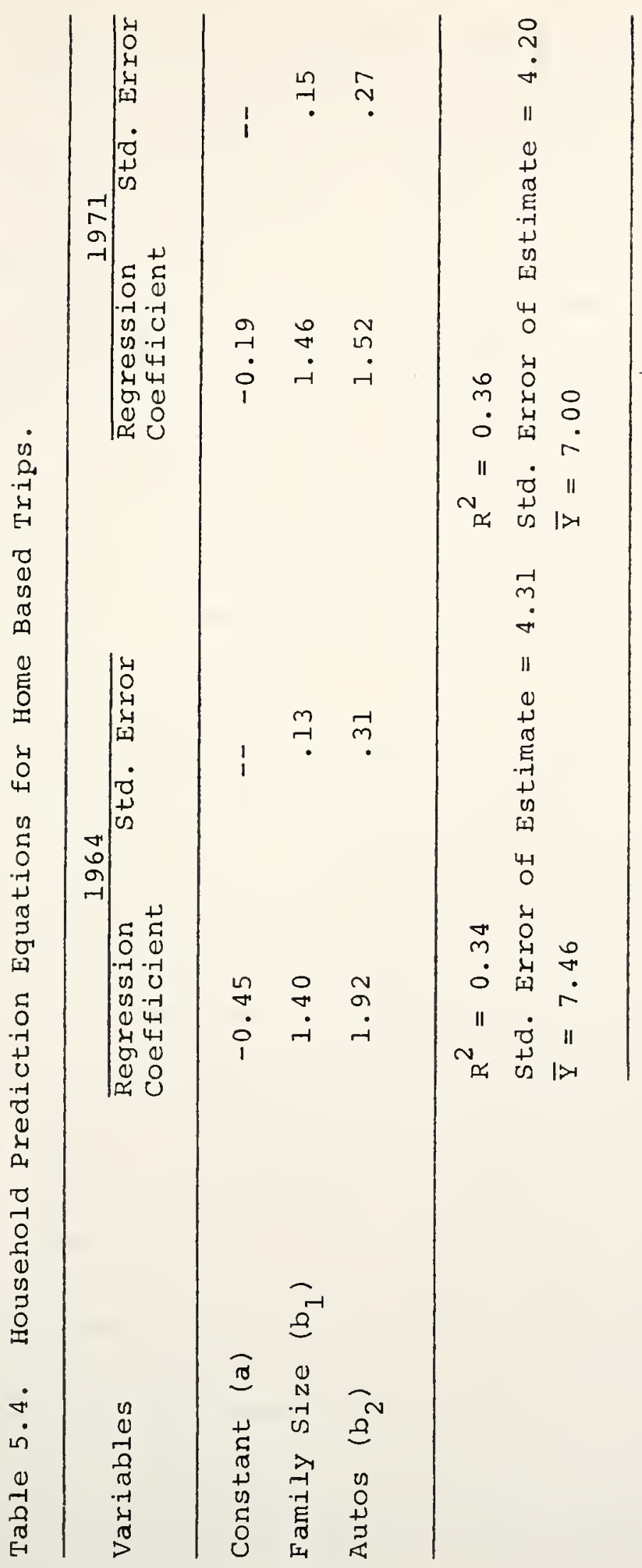


These values were not, however, unexpected as the models are attempting to explain all of the variation in trip production -- not just the variation between zones. Within any household the number of trips reported may be two to three times the average rate of trip productions of all households of similar characteristics. The household model formulated here can not hope to be able to predict these large variations for each household. The measure of the usefulness of the household model for forecasting trip production must be based on its ability to predict average travel for some higher level of aggregation. If the model is successful in accomplishing this task, then model development at the household level would be of value to the researcher as a means of evaluating causal relationships at a behavioral level and to the practitioner for developing area travel forecasts.

Before aggregated estimates of travel were made, the assumption of linearity of the response surface was also tested. Since repeat measurements of the dependent variable have been made at each level of the independent variables, the linearity assumption can be tested by obtaining a "pure error" variance which is used to test for lack of fit of the model (8). The test is of course restricted to the same comments referred to earlier, i.e., this assumes that the variances are homogeneous. The complete analysis of variance table for the 1971 regression model is given in Table 5.5. The $F$ ratio for regression is significant $\left(F_{2}, 352,0.95=\right.$ 3.0). The test for lack of fit, however, also indicates that the response surface may not be linear $\left(\mathrm{F}_{32,322,0.99}=1.8\right)$. Further tests of lack of fit were made for the two variables taken individually. Taken alone, the lack of fit variance for auto ownership was found to be insignificant. There was a significant lack of fit for the family size variable; the calculated $F$ was 4.2 and $F_{6,349,0.99}=2.9$. After adding a second order term for family size, the lack of fit 
Table 5.5. Lack of Fit Test of 1971 Household Linear Regression Model.

\begin{tabular}{lcccr}
\hline Source & $\begin{array}{c}\text { Sum of } \\
\text { Squares }\end{array}$ & $\begin{array}{c}\text { Degrees of } \\
\text { Freedom }\end{array}$ & $\begin{array}{c}\text { Mean } \\
\text { Square }\end{array}$ & F-Ratio \\
\hline Regression & 3412 & 2 & 1706 & $98.2 * *$ \\
Residual & 6149 & 354 & 17.4 & 39.7 \\
Lack of Fit & 1268 & 32 & 15.2 & $2.6 *$ \\
Pure Error & 4881 & 322 & & 39 \\
\hline
\end{tabular}

**ignificant at 0.01 Level 
variance was no longer significant.

The above results indicate that the model should include a second order term for family size to provide a better understanding of the response surface. However, as will be shown, inclusion of a second order term in the model has important implications at the operational stage when expanding the household equation to obtain estimates of total trips produced in the study area.

Estimating 1971 Home Based Trip Productions The 1964 household trip generation model given in Table 5.4 was used to estimate home based trip production for the same families in 1971. The total estimated home based travel from these households was 2542 trips compared to the observed production of 2498 trips. The 1964 model was successful in estimating the trips reported with an error of less than two percent.

Sufficient data were available in the one and two car households, and all family size levels to statistically evaluate discrepancies in the estimated and surveyed trips using a chi-square contingency analysis (6). The null hypothesis of no difference in the trip rates could not be rejected at the 0.01 significance level. Visual inspection of zero and three car families also did not show any major discrepancies. The household equation was remarkably successful in estimating trip production for these households. Of course, the independent variables in the prediction of 1971 trips were known exactly at each household. This is a luxury which is not available in the operational study, but it does exhibit the faithfulness of the model for estimation even though all theoretical considerations of linear regression are not met. 
Expansion of Disaggregate Single Family Dwelling Unit

\section{Equations to Obtain Zonal Trips}

The statistical weaknesses of the household trip generation model have been outlined. Although the statistical evaluations show that, as in zonal analysis, the assumptions used in development of the model are not always met; the household equations must still be tested for the ultimate goal of estimating total travel. Estimates of total travel in each zone could be obtained by summing the predicted trips from the individual households as follows:

$$
\begin{aligned}
& Y_{1 j}=a+b_{1} x_{11 j}+b_{2} x_{12 j}+b_{k} x_{1 k j} \cdots+b_{m} x_{1 m j} \\
& Y_{2 j}=a+b_{1} x_{21 j}+b_{2} x_{22 j}+b_{k} x_{2 k j} \cdots+b_{m} x_{2 m j} \\
& Y_{n j}=a+b_{1} x_{n 1 j}+b_{2} x_{n 2 j}+b_{k} x_{n k j} \cdots+b_{m} x_{n m j}
\end{aligned}
$$

where

$$
\begin{array}{ll}
\mathrm{Y}_{\mathrm{ij}}= & \text { trips produced in household } \mathrm{i} \text { of zone } j ; \\
\mathrm{X}_{\mathrm{ijk}}= & \text { the value of the independent variable } \mathrm{k} \text { for } \\
& \text { household } \mathrm{i} \text { in zone } \mathrm{j} ; \\
\mathrm{b}_{\mathrm{k}}= & \text { parameter for variable } \mathrm{k} ; \\
\mathrm{a} & =\text { constant of the regression model; } \\
\mathrm{n} & =\text { number of households in zone } \mathrm{j} \text {; and } \\
\mathrm{m} & =\text { number of independent variables in the model. }
\end{array}
$$

If all of the independent variables are linear, the total trips in a zone can more easily be determined by summing all household characteristics to a zonal total and then applying the appropriate model parameter. The resulting expression would be:

$$
\begin{aligned}
Y_{j}= & n a+b_{1}\left(\sum x_{1 j}\right)+b_{2}\left(\sum x_{2 j}\right)+b_{k}\left(\sum x_{k j}\right) \ldots \\
& +b_{m}\left(\sum x_{m j}\right)
\end{aligned}
$$


That is to say that, obtaining zonal estimates is a matter of summing trips produced at each household in the zone. It is not necessary that one be able to forecast values of the independent variables for each household; but rather, just as in the zonal regression model, it is only necessary to obtain zonal estimates of the independent variables. This is true because mathematically $\sum^{n} b_{k} x_{k j}$ is equivalent to $b_{k} \sum x_{k j}$. Of course, if the variables used are not linear, this one to one comparison no longer exists. For example:

$$
\sum_{i=1}^{n} b_{i}\left(x_{i j}\right)^{2} \neq b_{i}\left(\sum_{i=1}^{n} x_{i j}\right)^{2}
$$

Table 5.6 shows the results of expanding the household equations to obtain estimates of the home based trips reported by the 4300 households from which the survey sample was selected. Several interesting elements are noted in the results. First, when the household equations are expanded to obtain zonal estimates, the percent of the variation explained is increased while the standard error, expressed as a percent of the mean value, is reduced. The adjusted values are similar to values which are found in zonal regression analysis. Although the household equations could only explain about 30 percent of the variation in household home based travel, the equations explain 96 percent of the variation which occurs in larger units of aggregation.

Secondly, the mean of the residuals is small compared to the mean of the dependent variable. Even though the household equation indicated lack of fit in the model and the residuals exhibited a linear trend with the dependent variable, these deficiencies are averaged out when the model is used to obtain areal estimates. Sample plots of the distribution of residuals and the relation between observed and predicted zonal trips are shown in Figures 5.5 and 5.6 of 
the next section.

The final, and most important point to be drawn from Table 5.6 is the comparability of estimates obtained from the two data sets. The 1971 model estimated the zonal trip productions reported in 1964 with the same statistical efficiency as was possible with the 1964 household data set. This supports the basic hypothesis of this research, i.e., analysis at the household level should provide relationships which are more meaningful and these relationships should remain stable over time. Over a period of time the relationships may shift. In the past, the possibility of such shifts may have been recognized, but the aggregate analysis level made it impossible for the planner to obtain sufficient data to detect the changes in the aggregate models. Unlike the aggregate models in which several households are averaged together before any analysis is undertaken, analysis at the household level, allows each piece of data to be used to reflect changes which are occurring in that household. Subtle changes which may be due to changes in auto ownership levels, increased participation of females in the labor force, increased recreational time, etc., can be observed more efficiently at this disaggregate analysis level.

\section{Expansion of Disaggregate Equations from}

All Dwelling Units to Obtain Zonal Trips

It is recognized that the 357 single family units selected in this research provide a limited inference space in that they represent only a portion of the total population. The models developed for this sample can be expanded to give acceptable estimates of travel for the households from which they were selected, but would the same be true if one were to use a sample of all household and family characteristics? Further, these models have been expanded to obtain estimates of reported trips of the households from which the sample was drawn; can these models be expanded to determine the 
Table 5.6. Summary Statistics of Single Family Household Equations Expanded to Obtain Zonal Travel Estimates.

\begin{tabular}{lcc}
\hline & 1964 & 1971 \\
\hline Adjusted $R^{2}$ & 0.96 & 0.96 \\
Adjusted Standard Error of Estimate & 18.4 & 19.0 \\
Mean of Zonal Trips & \\
Mean of Residuals & 95.8 & 95.8 \\
Slope: Yactual $/$ predicted & -4.1 & -4.1 \\
\end{tabular}

a Dependent Variable is 1964 Zonal Home Based Trips

Number of zones $=313$

Household Models Based on 357 Observations

factored trip volumes which represent the trips of the total population in the study area? Would these model parameters remain stable over time in the same way as the survey sample? The first two questions can be evaluated in this research by developing models of home based travel using the household data from the entire IRTADS home interview data set.

Household trip generation models were developed using the same variables as were used in the zonal estimates performed for IRTADS (14). Models were developed for total home based trips, as well as for the trip purpose stratifications of work, shop, school and all other purposes. The variables used by IRTADS and the associated statistics are given in Table 5.7. The household equations for all household types have the same weaknesses as the single family equations. However, like the single family models, adjustment of the equations to predict zonal travel provides acceptable estimates of zonal trips. Table 5.8 contains the adjusted statistics for expansion of the household equations. 


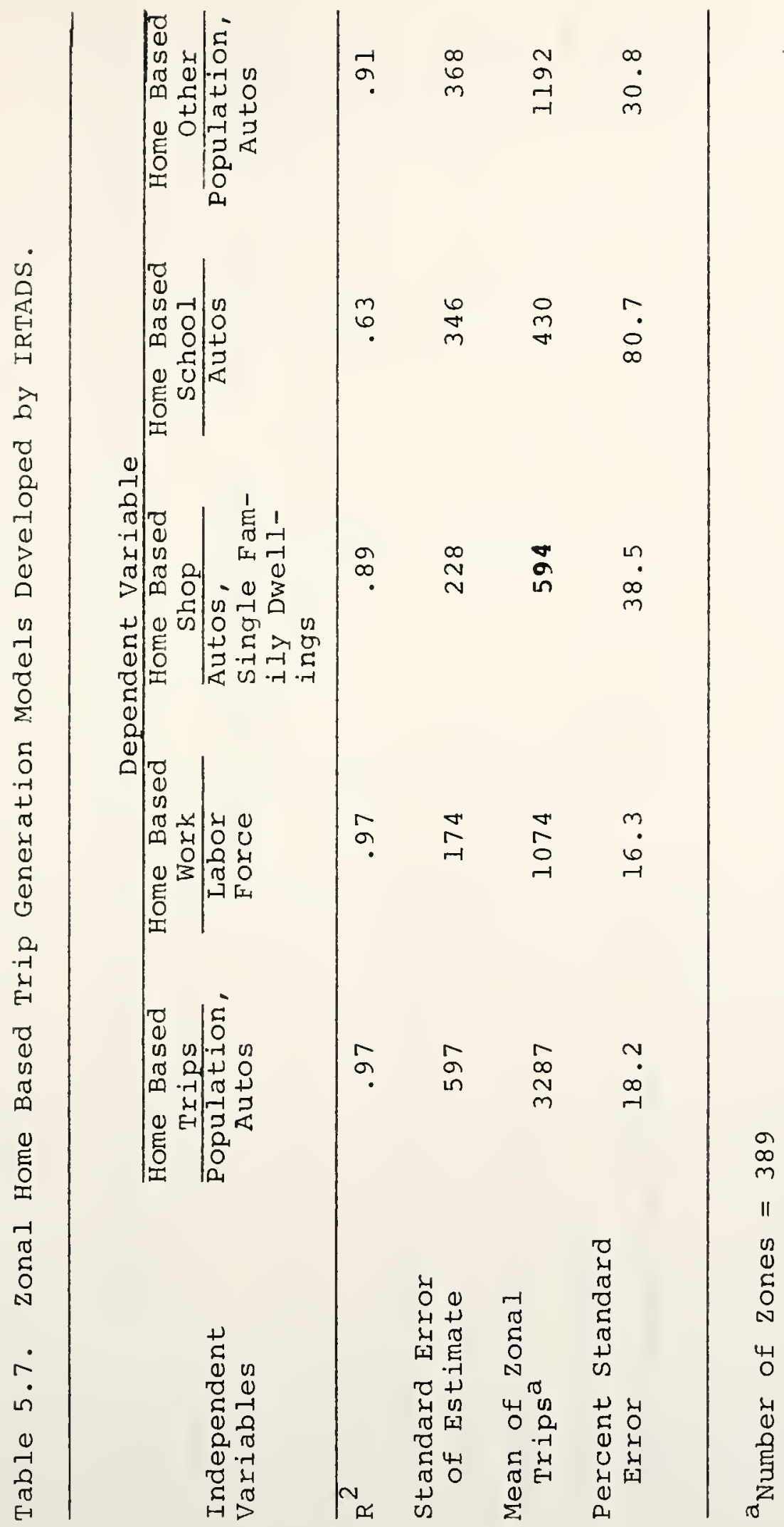




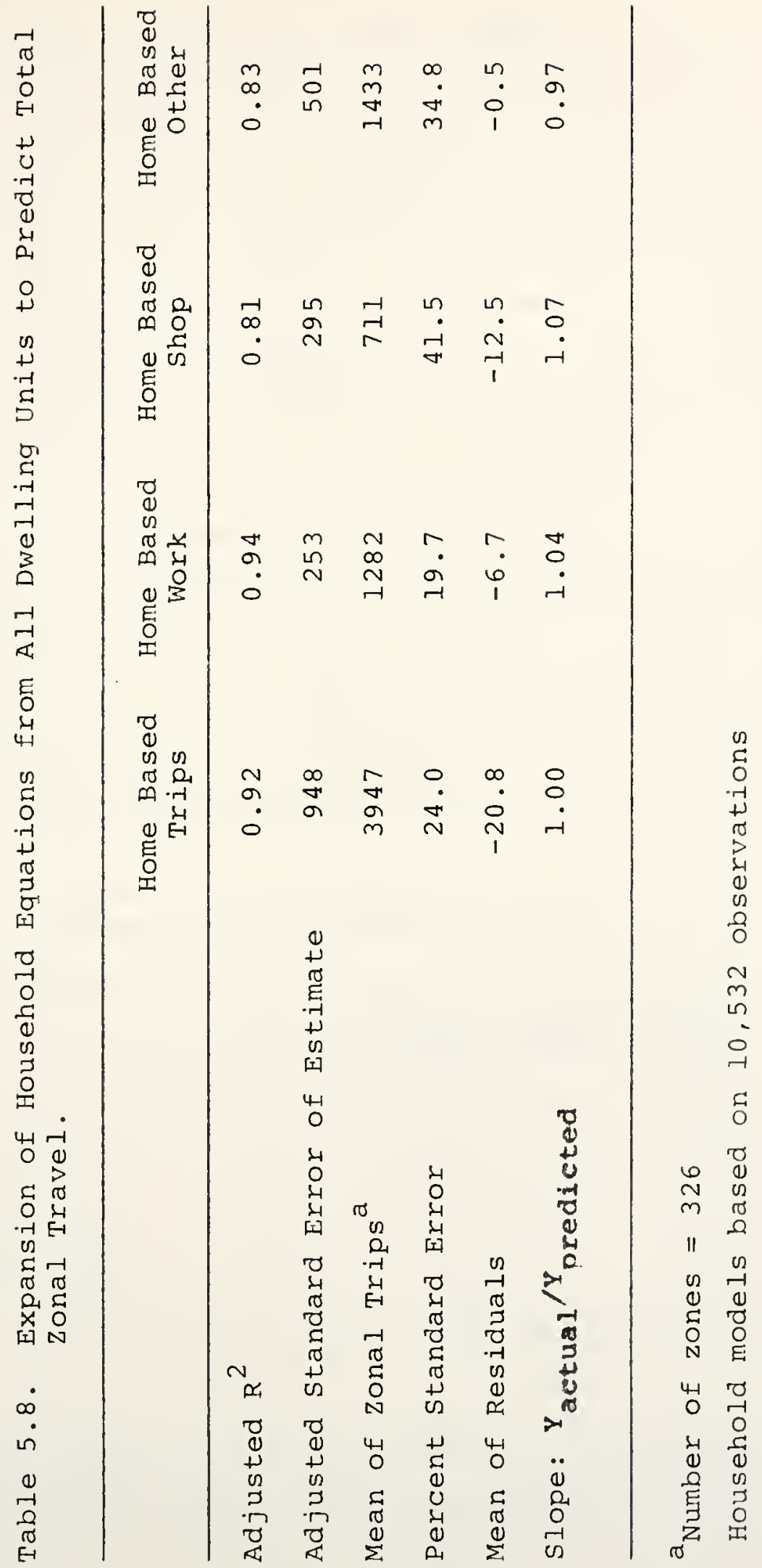


Three comments are necessary when comparing the results of Tables 5.7 and 5.8. First, all equations in Table 5.7 are based on data from 389 zones, while the household equations are expanded to represent travel from only 326 zones. The reduction is due to elimination by the researcher of all zones in which there were no dwelling units or labor force. Secondly, it was not possible to develop an adequate home based shop model using the same variables selected by IRTADS. To include single family units in household analysis, dummy variables would be required (37). Estimates of the number of different structure types in each zone were not readily available, but some assumptions were made to include these in the model. Predictions from this model were not acceptable, however, and are not included here. Instead, the home based shopping model used auto ownership and family size variables. Finally, the home based school model using auto ownership was found to be inadequate and is not reported. The household model parameters are listed in Table 5.9.

Table 5.9. Linear Regression Parameters for Household Models Based on Entire 1964 Data Set.

\begin{tabular}{lcccc}
\hline Dependent Variable & \multicolumn{3}{c}{ Independent Variables } \\
\cline { 2 - 5 } & Constant & Family Size & Autos & $\begin{array}{c}\text { Labor } \\
\text { Force }\end{array}$ \\
\hline Home Based Trips & -.232 & 1.015 & 2.148 & -- \\
Home Based Work & .173 & -- & -- & 1.352 \\
Home Based Shop & .035 & .144 & .437 & -- \\
Home Based Other & -.123 & .351 & .856 & -- \\
\hline
\end{tabular}

Visual inspection of the ability of the household equations to estimate zonal travel is afforded by inspection of Figure 5.5. This is a plot of predicted zonal home based 
trips against total zonal trip estimates derived by IRTADS. If the model predicted perfectly, all points should fit a 45 degree line passing through the origin. The actual regression line exhibited a slope coefficient of 1.00 and a constant term of -45 . This constant term is only one percent of the mean zonal trips; the model was therefore accepted as a good fit of the data.

The residuals were examined by plotting the travel volumes against the residuals. This plot exhibited a random scatter of points. Further, Figure 5.6 shows a histogram of the residual distribution. Ideally, this plot should exhibit a normal distribution with a mean value of zero. In this study it was found that, although the household data did not meet all the assumptions for linear regression at the household level, residuals from the expanded equation did meet the criteria of independence and normality.

Comparison of the prediction ability of the household models with zonal totals models indicates that the household models produce estimates with greater variation. It must be noted, however, that parameters of the IRTADS zonal equations are estimated to produce the minimum error in the zonal productions. By definition, the sum of residuals must be zero. These zonal parameters are applicable only to the level of analysis for which they are developed. On the other hand, the parameters for the household models are estimated to produce minimum error at the household level. The mean of the residuals at the household level must by definition be zero, but generally there can be no assurance that the residuals will be zero when the model is used to estimate larger area travel. The degree to which the mean. residual error approaches zero provides another measure of the applicability of the expanded equation. In this study the maximum average residual exror, expressed as a percent of the mean, is 1.8 percent for home based shopping trips. 


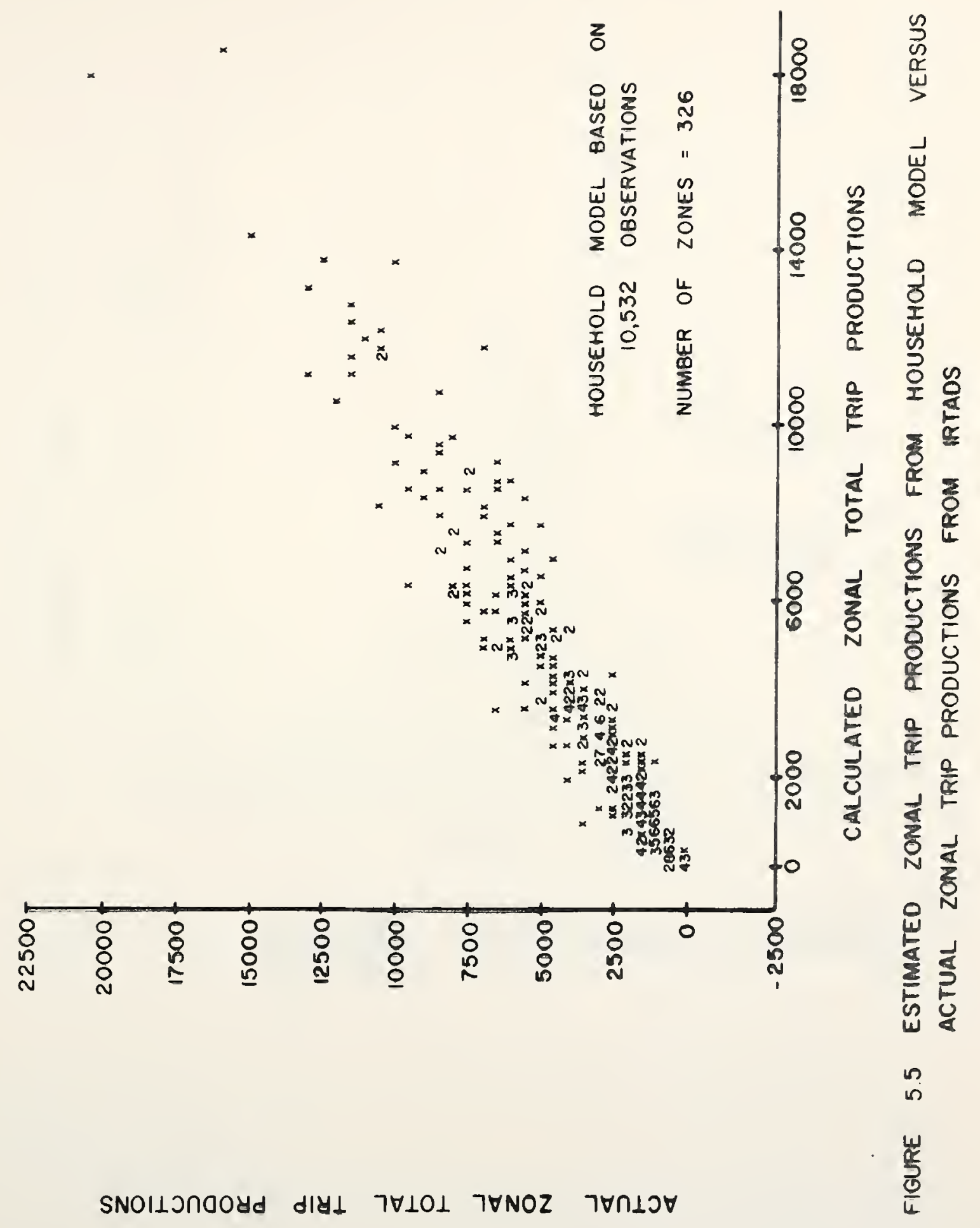




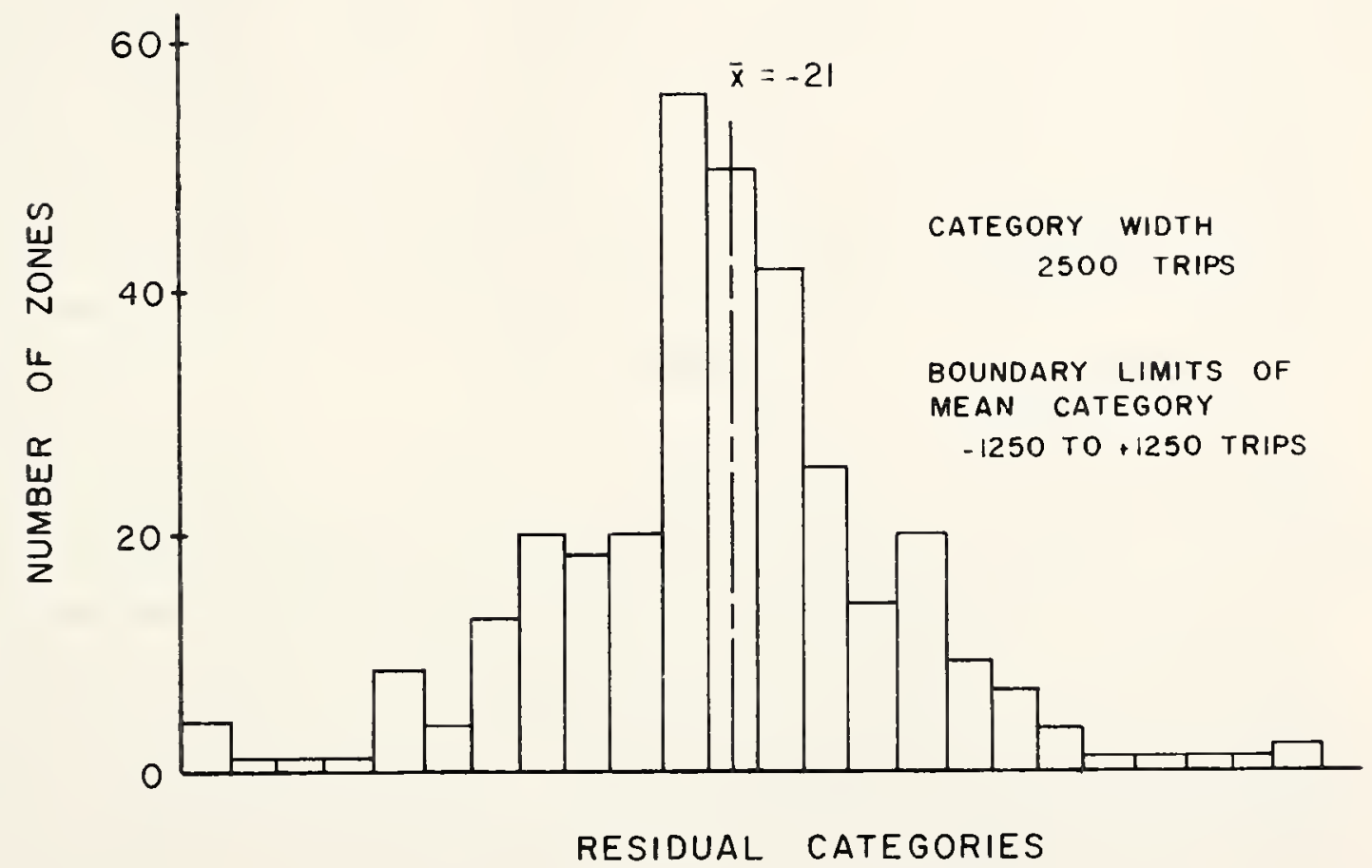

FIGURE 56 FREQUENCY DISTRIBUTION OF ZONAL RESIDUALS DETERMINED FROM EXPANDED HOUSEHOLD EQUATIONS 


\section{Potential for Data Reduction in Continuing Study}

It has been stated that analysis at the household level would allow the transportation analyst to evolve models using the available data more efficiently. Since each piece of data is being used in the forecast model, the data base could presumably be smaller with a resultant savings in inventory cost. In this chapter, it has been shown that the household model can be expanded to produce total area travel estimates with nearly the same efficiency as the zonal models which are formulated with the expressed purpose of providing the best description model possible. However, since both models investigated to this point have used the same basic data set which includes over 10,000 home interviews, there has been no indication that the household modeling approach would save data collection expenditures. To estimate the savings possible it would be necessary to conduct a full scale analysis of sampling variability and expected errors. From this analysis the ideal sample size necessary to obtain estimates within desired confidence limits could be determined. In this research a single sub-sample was drawn to determine the order of magnitude of sample size reduction which might be possible. This sub-sample was equivalent to a one percent sampling rate, whereas the IRTADS sample was designed as a five percent sample. Table 5.10 repeats the adjusted household equations given in Table 5.9 for the five percent sample and provides the comparable statistics for the one percent sample $(2240$ cases). The ability of the two household equations to predict total travel is very similar. The standard error of the estimate is actually somewhat smaller for the smaller sample size but, on the other hand, the mean residual is larger.

Certainly additional research is required to determine the limits on sample size necessary for estimating travel. Also, consideration must be given to the data requirements 
Table 5.10. Comparison of Predictive Ability of Household Models Based on a Five Percent Sample and a one Percent Sample.

\begin{tabular}{|c|c|c|}
\hline & $\frac{\text { Sample Size }}{10532}$ & $\frac{(\text { Households) }}{2240}$ \\
\hline Adjusted $\mathrm{R}^{2}$ & 0.92 & 0.92 \\
\hline $\begin{array}{l}\text { Adjusted Standard Error } \\
\text { of the Estimate }\end{array}$ & 948 & 922 \\
\hline Mean of Zonal Trips & 3947 & 3947 \\
\hline Mean Residual & -20 & +56 \\
\hline Slope: $Y_{\text {actual }} / Y_{\text {predicted }}$ & 1.01 & 1.02 \\
\hline
\end{tabular}

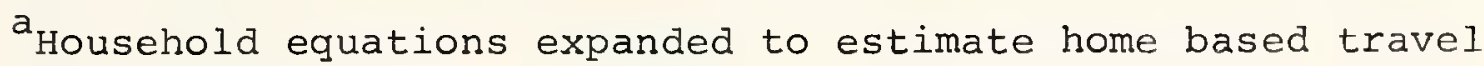
in 326 zones.

of other aspects of travel forecasting, i.e., trip attraction, distribution, modal split and assignment. In the continuing study, the analyst must determine the degree to which the existing calibrated models can simulate changing travel patterns. Will the sample size which provides adequate information about changes in trip generation rates also provide sufficient data to evaluate changing attitudes and patterns of spatial distribution and mode choice? Behavioral model research for the other planning models may also indicate similar efficiency. Careful planning of the survey design may provide information adequate for development of aII disaggregate models. If knowledge of the complexities of travel behavior can be attained at this disaggregate level, the analysis could be conducted at this level and then aggregation may proceed to whatever level is necessary. The important item to emphasize is that the disaggregate model approach is sensitive to changes which occur at the behavioral level and therefore provides a means to measure changes. 
This is an essential consideration as the transportation analyst considers the changing conditions which occur during the continuing planning process. After evaluation of these changes at the behavioral level, aggregation may proceed to whatever analysis unit is necessary.

Comparison of Model Parameters in Different Urban Areas

Evaluation of travel data at the household level of analysis provides a common base for comparing travel characteristics in different urban centers. Unlike the artificial aggregate units such as the traffic zone or district, the household is basically the same size and the same internal consistency in different geographical areas. Due to the common nature of the household unit, one might expect household model parameters to be more consistent from area to area.

The model parameters given in Table 5.11 provide a measure of the degree to which household and zonal model parameters are comparable for two study areas, i.e., Indianapolis and the Tri-State area which includes New York City. The Tri-State area equations were developed in the research by Kassoff and Deutschman (19).

The magnitude of the household model parameters for the independent variables are strikingly similar for the two study areas, even though the areas themselves would not be considered as comparable in nature. The largest variation is in the magnitude of the constant term. One might reflect that the constant term of the model is the geographic factor which explains differences in household travel in the two areas. Of course, other differences in average trip rates in the areas would be reflected by differences in the average value of the independent variables.

on the other hand, there are substantial differences in the parameters of the zonal based models. Although this 


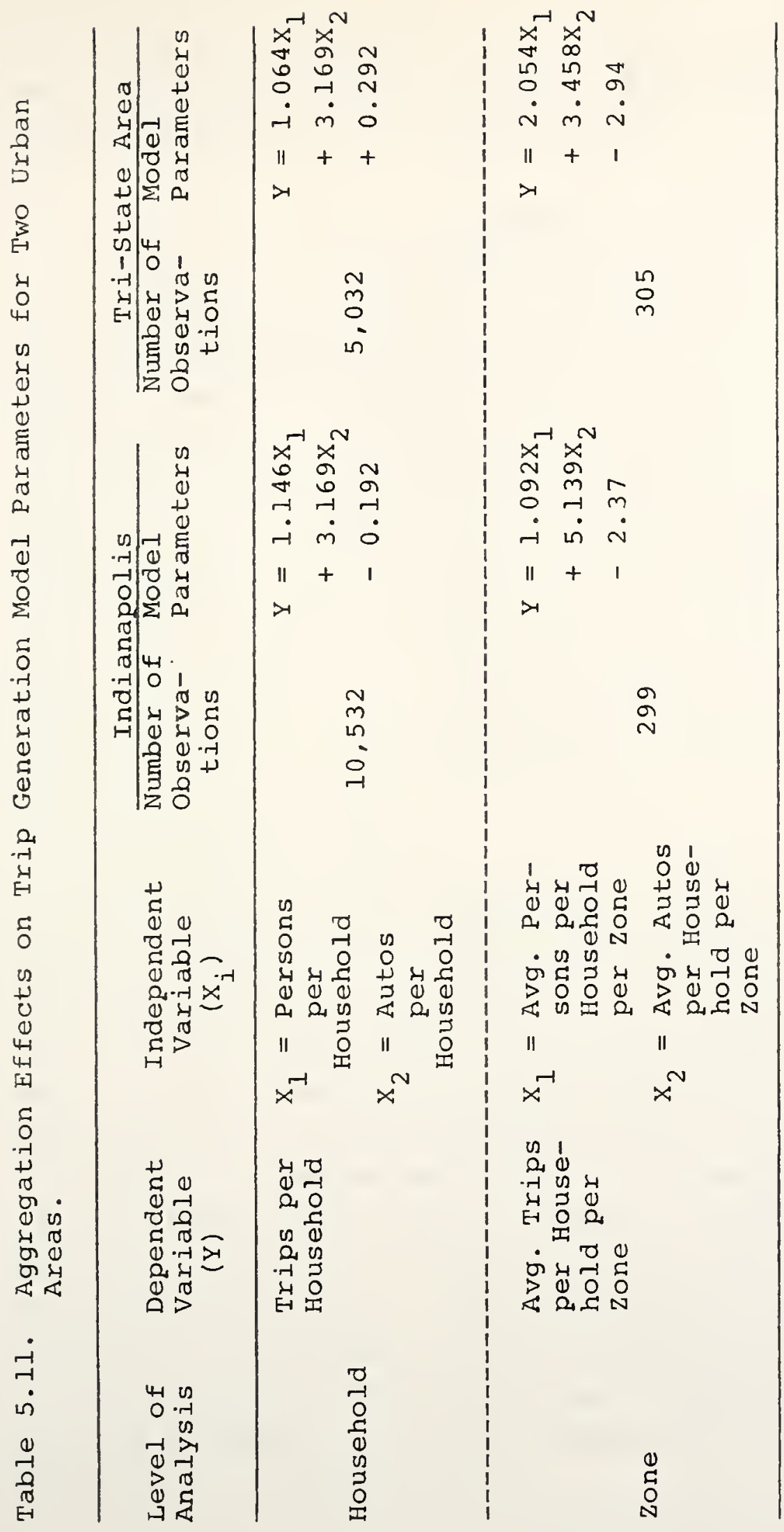


comparison is only for two study areas, the basic premise that household parameters measure a more stable, basic relationship appears to be substantiated.

\section{Summary}

Analysis of travel behavior using the household as the basic decision unit provides a method of evaluating the changing relationships which occur over time. Household equations based on data obtained from a small scale home interview study conducted in 1971 provided estimating relationships which were similar to trip production models based on the characteristics of the same households in 1964. The hypothesis that the behavioral level analysis would provide parameter estimates which are more stable over time was substantiated for the sample used in the study. The behavioral models for the two time periods were judged to be equally effective in estimating zonal travel which was reported by the single family households from which the 1971 survey sample was drawn.

Behavioral models were also developed using all household data from the 1964 IRTADS study. These models were expanded to estimate total home based travel for the entire study area and were judged to be nearly comparable with the aggregated model for estimating present travel. However, since they are sensitive to measuring changes in the travel characteristics of the behavioral unit, the household model is preferred. Indications are that the household data set may be reduced by at least 80 percent for estimating model parameters at the disaggregate analysis level. In addition, since the household is a basic unit in all urban areas, analysis at the household level may help the planner understand true travel variation between areas, rather than apparent differences which are a reflection of the areal unit selected. 
CHAPTER 6. EVALUATION OF ADDITIONAL VARIABLES IN TRIP GENERATION MODELS

In Chapter 5 the analysis of the household data was confined to development of trip generation models which could be used to estimate zonal travel. The explanatory variables incorporated in the models were constrained to those variables which were used by IRTADS so the estimation capability of the household model formulations could be compared with the models based on the zonal aggregate relationships. Zonal population and auto ownership were the major factors used in the zonal models; the equivalent variables for the disaggregate models were family size and auto ownership. Other research efforts, however, have found additional socioeconomic variables which contribute to the explanation of varying trip generation rates $(30,36,41,42)$. Included among this list are variables such as income, occupational status and stage in the family life cycle. It has also been suggested that, in addition to socioeconomic characteristics, measures of the service level provided by the transportation system itself, should be included in the estimation models $(7,28)$. For example, Nakkash defined an accessibility variable which is a measure of separation between activity centers such as residential areas, and shopping or employment centers. The accessibility measure accounts for the relative travel friction between zones by incorporating in the variable a function of the travel times on the transportation network. The rationale is that areas which are relatively more accessible to activity centers would have different trip generation rates than less accessible areas.

Indeed, travel behavior is more complex than the simple two variable model which has been used for estimating travel. 
The difficulty in forecasting variables such as income or occupational status of the population, however, has kept the analyst from attempting to obtain a better understanding of these relationships. In Chapter 6 and Chapter 7 the interrelationships among the afore-mentioned variables will be examined. Even though some of the variables may be considered to be difficult to forecast and therefore difficult to use in travel forecast models, it is just as inappropriate to ignore these effects without attempting to understand the nature of their contribution to the explanation of travel behavior. This chapter examines the interrelationships between sub-sets of the variables which have been found to be significant in trip production models as a background for development of an integrated theory of the causal structure of these variables.

\section{Individual Perceptions of Factors Influencing Changes}

\section{In Trip Production}

Because of the nature of the data which is collected for transportation studies, the models which are developed are based on observation of actual behavior as exhibited by the data. If a relationship is consistent with the planner's intuitive judgment about the causative effects between the independent and dependent variables, the variable is used in the model. Although the models used in this research are also based on standard, measured survey data, an additional approach was used to evaluate the causal relationship as perceived by the individual trip maker. The respondents were asked to indicate whether selected changes in their socioeconomic characteristics and changes in the community structure and transportation system had increased, decreased, or had not changed the amount they traveled (Question 72). The summary of responses indicating the effect of these changes on travel by private auto mode appear in Table 6.1. In 


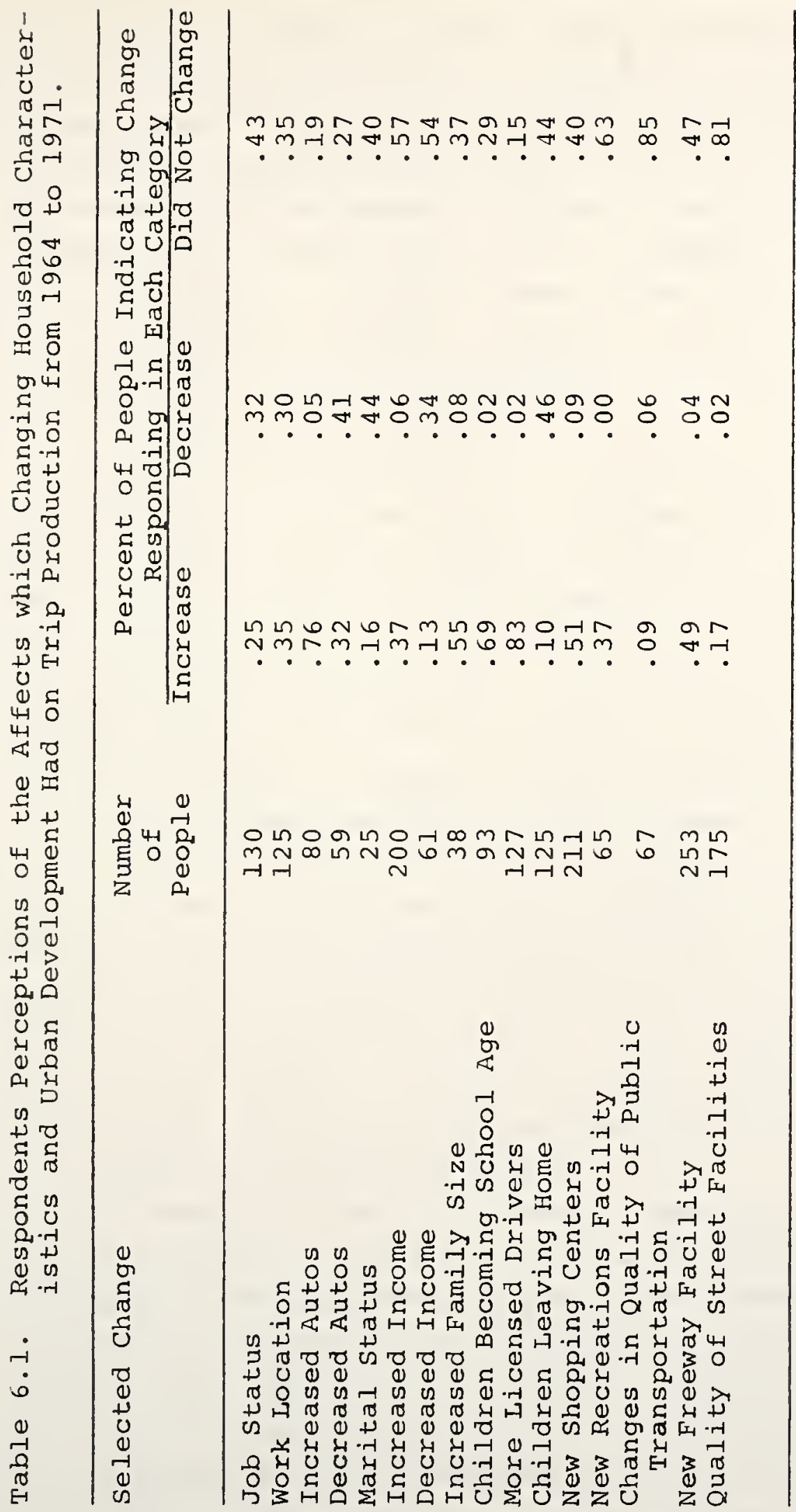


evaluating the results several factors should be noted. First, for the income and auto ownership variables, the respondents were only asked if a change had occurred and, if so, how that change affected their travel. The researcher determined from the travel study data whether the change was an increase or a decrease. In a few instances no actual change was noted in the data even though the respondent felt that a change had occurred. Secondly, the primary changes in marital status were changes going from the married status to a "single" classification.

The summary indicates that the predominant factors which the respondents felt had caused a change in the amount the family travels were auto ownership, family size and stage in the family life cycle. Over 75 percent of the households which noted an increase in autos felt that this increase had increased the family's travel. Fifty-five percent of the respondents who experienced an increase in family size felt that their travel increased. Children becoming school age or licensed drivers was perceived as a reason for increasing travel by 69 and 89 percent of the families experiencing these changes. A decrease in auto ownership and family size, however, was not so strongly recognized as a determinant for changing travel. Households experiencing a decrease in auto ownership responded about equally in all three categories. The factor, "children leaving home," was perceived as not affecting the family's travel as often as it was perceived as a reason for decreasing travel.

A change in income level was not generally recognized as a major cause for changing the amount of travel. Regardless of whether income increased or decreased, over 50 percent of the families did not feel the change had affected their travel. Where changes in travel were indicated, the direction of change was generally as would be expected.

No marked trend was reported for the effect of changing job status or work locations. The percentage distribution in 
the three categories was nearly equal.

Finally, changes in the transportation system were evaluated. The respondents indicated that neither changes in the quality of public transportation, nor changes in the quality of existing street facilities had affected the amount which the family travels by auto. The construction of new freeway facilities, however, was perceived to be a cause for increased travel by nearly 50 percent of the respondents; the remainder felt their travel was unaffected. The indication was that improvement of existing street facilities may not induce the traveler to make additional trips, but addition of controlled-access routes may be a determinant in generating trips which otherwise might not have been taken. Likewise, improved accessibility to shopping centers was perceived as an inducement to travel by half of the respondents experiencing such a change.

\section{Estimation Model for Auto Ownership}

Since automobile ownership levels have been used extensively in trip generation analysis, there has been considerable effort to develop estimation models to predict future levels of automobile ownership. Some factors which have emerged are family size, income, residential density and occupational status $(2,5,21)$. Deutschman reviewed the methods used by transportation studies and concluded that family size and residential density considerations were not adequate when used alone to predict autos. Income could be used alone if care was taken to check the model in areas where the density of development changes. Lansing, evaluating the household as the analysis unit, indicated that income and residential density should be considered together in explaining variation in auto ownership.

Analysis of auto ownership relationships in this research indicated that auto ownership was most closely associated 
with the family income, the number of people in the labor force and the relative accessibility of the household to other activity centers. To evaluate the ability of a model based on household data to estimate future auto ownership levels, linear regression models based on the 1964 data from the 357 households were developed. The models were used to predict the level of auto ownership these same families would have in 1971. Since only income and labor force variables were measured for the two periods, these were the variables used in the prediction models. The first prediction equation was:

$$
Y(\text { Autos })=0.65+0.12 \text { (Labor Force })+0.079 \text { (Income) }
$$

where income was expressed in thousands of dollars. Before applying the model, the 1971 reported income levels were reduced to represent equivalent 1964 dollars. The model predicted that the total auto ownership in the 357 households would be 620. The reported ownership in 1971 was 597, resulting in an over prediction of less than four percent.

The second model considered only income as the explanatory variable for predicting future auto ownership. The estimation model was:

$$
Y(\text { Autos })=0.76+0.087 \text { (Income })
$$

Using only income, 580 autos were estimated. This was approximately a 3 percent underestimation. The prediction equation overstated by approximately 10 percent the ownership levels of the lowest income group (less than $\$ 4,000$ ) and the highest income groups (over $\$ 18,000$ ) and underpredicted slightly in the middle income range. Figure 6.1 indicates the reason for over prediction in the high income range. Although the relationship is linear through low and medium incomes, the increasing rate of auto ownership levels off above $\$ 15,000$. 


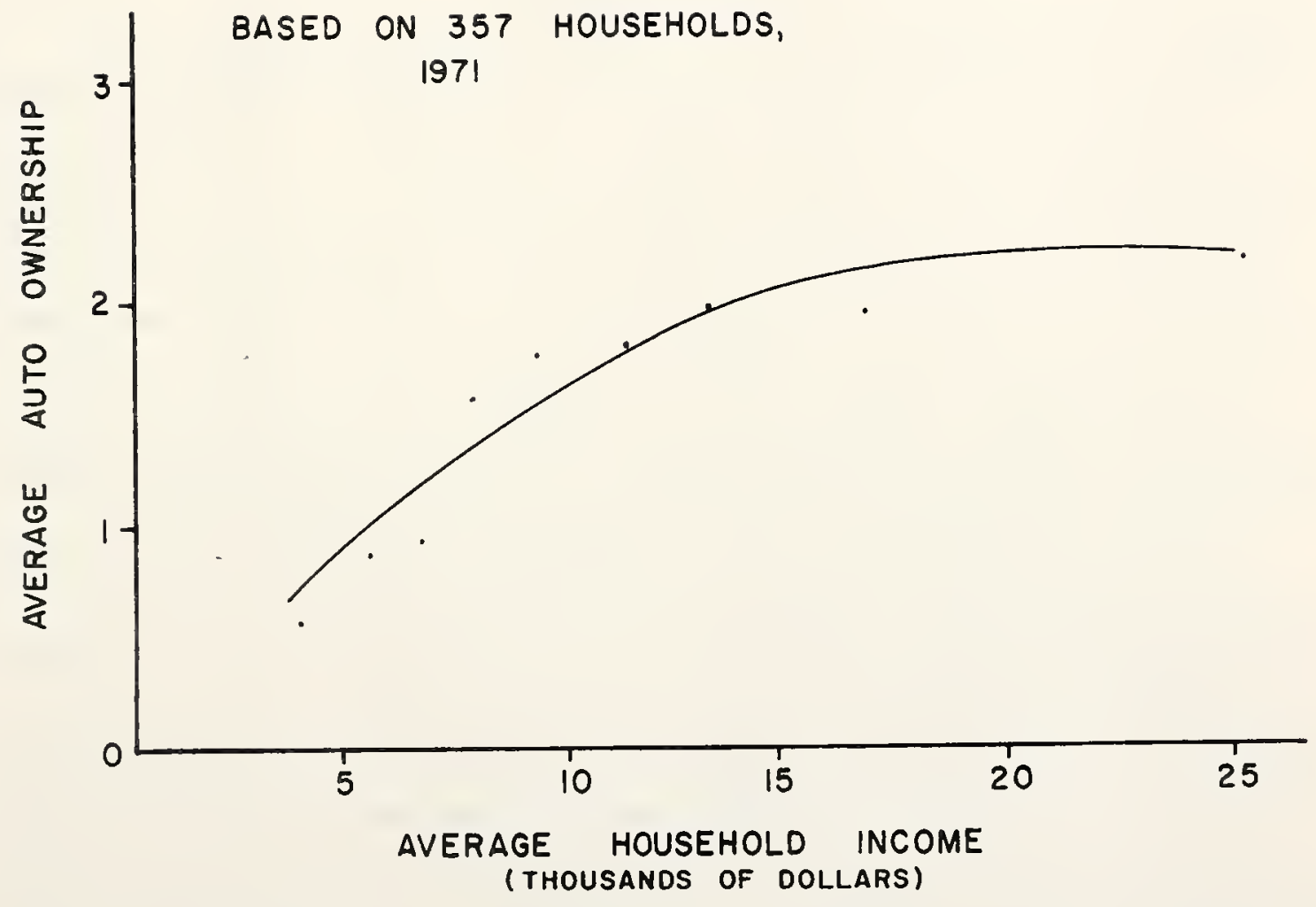

FIGURE 6.I AVERAGE HOUSEHOLD INCOME RELATED TO AUTO OWNERSHIP 
If only the average adjusted income of all households had been used, the estimated auto ownership would have been 590 vehicles. This estimate is essentially the same as that obtained by using the stratified income levels; thus in the forecast of auto ownership, prediction of the overall auto ownership using the linear model would produce a reasonable control total for comparing total auto ownership obtained from the stratified income levels.

\section{Other Factors Considered In Trip Generation Analysis}

\section{Accessibility}

The basic model for defining the accessibility variable developed by Nakkash for the zones in Indianapolis in 1964 was presented in Chapter 2. The variable is a composite measure of travel friction between urban areas and the density of development in and around the area being considered. Relative accessiblity variables were defined for each zone of the study area for several different categories of activity, e.g., relative accessibility to retail floor area, to employment centers, and to educational facilities were among the list of measures developed. For the purpose of this research, a single accessibility measure was selected as a representative descriptor of the general characteristics of the area. The logical measures for use here were noted to have a fairly high degree of linear correlation. For example, the correlation between accessibility to retail floor area and accessibility to employment centers was 0.80 . The relative accessibility to employment was selected and will hereafter be referred to simply as accessibility.

The households in the study were located in areas which covered the entire range of accessibility; the range being from 0.01 to about 0.50 . The mean value was 0.22 with a standard deviation of 0.08. A household in the low end of the scale would tend to be in the outer limits of the study 
area. Households closer to the urban activity centers would tend to have higher accessibilities.

The relationship between home based trip production and accessibility was studied by stratifying accessibility into five levels and examining several cross classification and two way analysis of variance models. Table 6.2 shows the stratifications used and the average trip rates reported by the households in these classes for 1964 and 1971. Since it was impossible to obtain new measures of accessibility in 1971, all households which appeared in one level in 1964 are assumed to be in the same level in 1971. The variables exhibit an obvious negative correlation. As the accessibility of the household to other activity centers increases, the reported trips decreases. On first glance, one might argue that this appears to be an illogical trend. Why wouldn't those households which have greater accessibility tend to generate more trips? The answer is supplied, at least in part, by consideration of two additional elements which have not been mentioned. The first of these is the controlling effect of other variables which simultaneously affect travel, and the second is related to the basic definitions used to describe a trip, i.e., inclusion of only vehicular trips in the Origin-Destination survey.

Two controlling variables which must be considered are income and auto ownership. As the household income level increases it was noted that the family was more likely to move away from the center of activity. Correspondingly, these households have higher auto ownership levels which increases the opportunity for the individual members to make vehicular trips. Figures 6.2 through 6.4 illustrate these effects. In Figure 6.2 the overall negative relationship is shown for all households irrespective of income group. In addition, the average trip production rates for three levels of income have been super-imposed. For households with less than $\$ 5,000$ income, the trip rate is nearly constant for all 


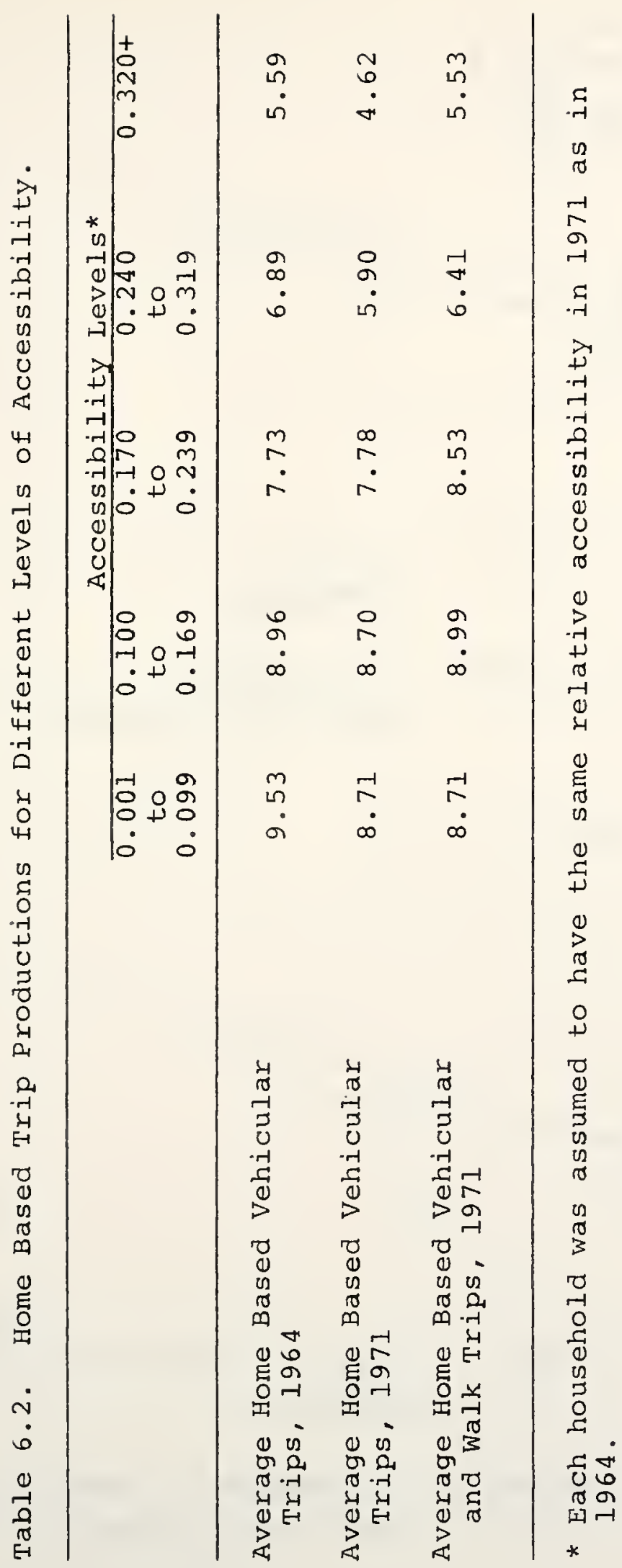




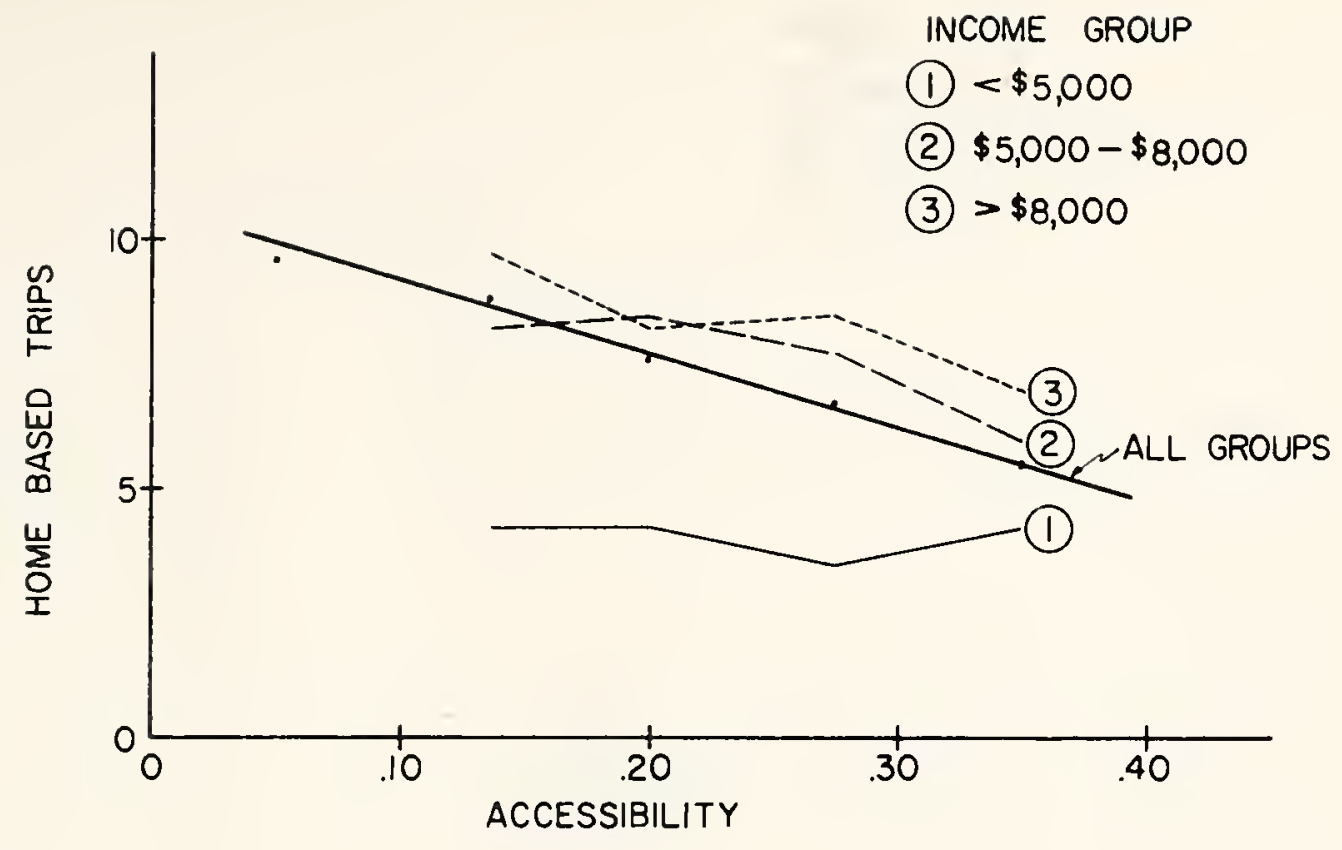

FIGURE 6.2 EFFECT OF ACCESSIBILITY ON HOUSEHOLD TRIP PRODUCTION, CONTROLLING FOR INCOME

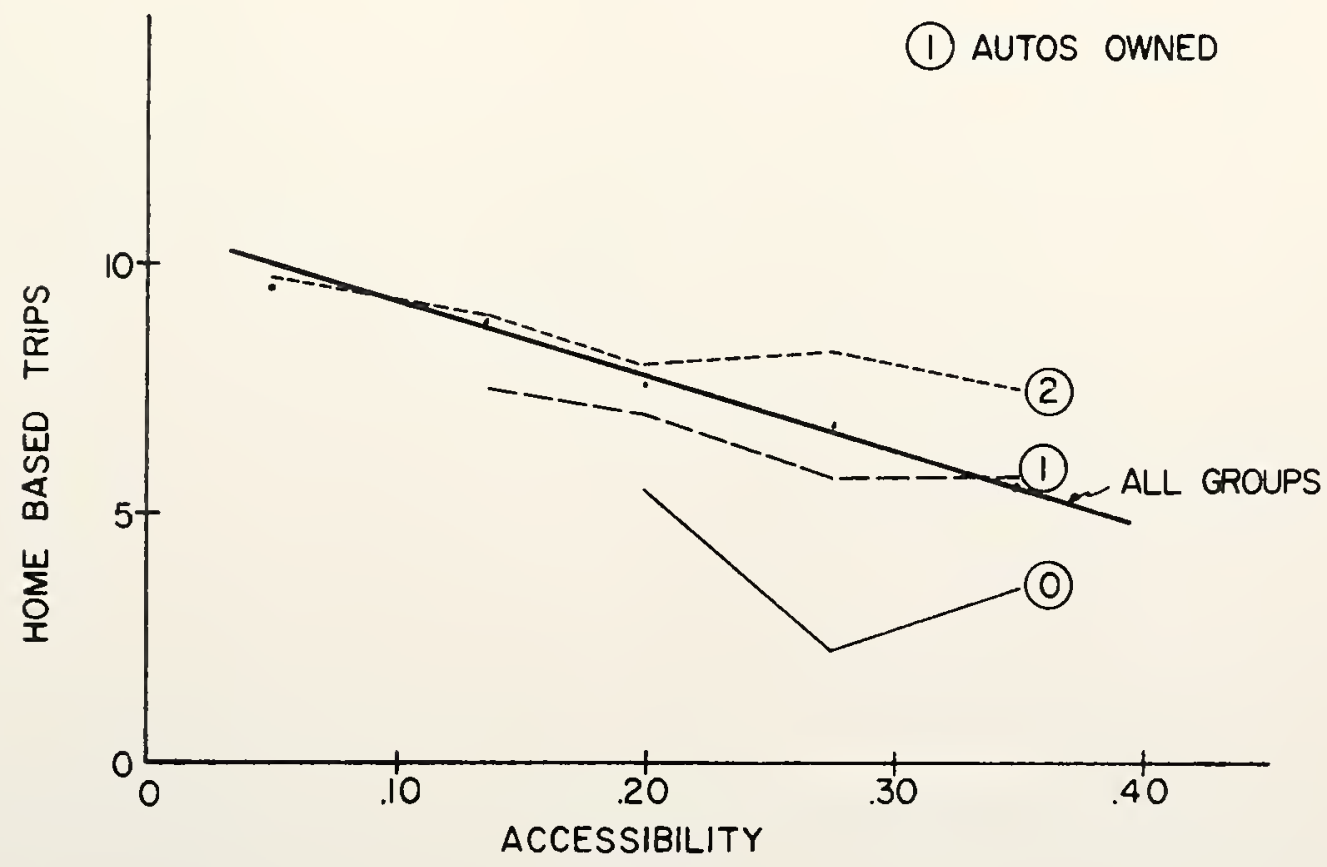

FIGURE 6.3 EFFECT OF ACCESSIBILITY ON HOUSEHOLD TRIP PRODUCTION, CONTROLLING FOR AUTOS 


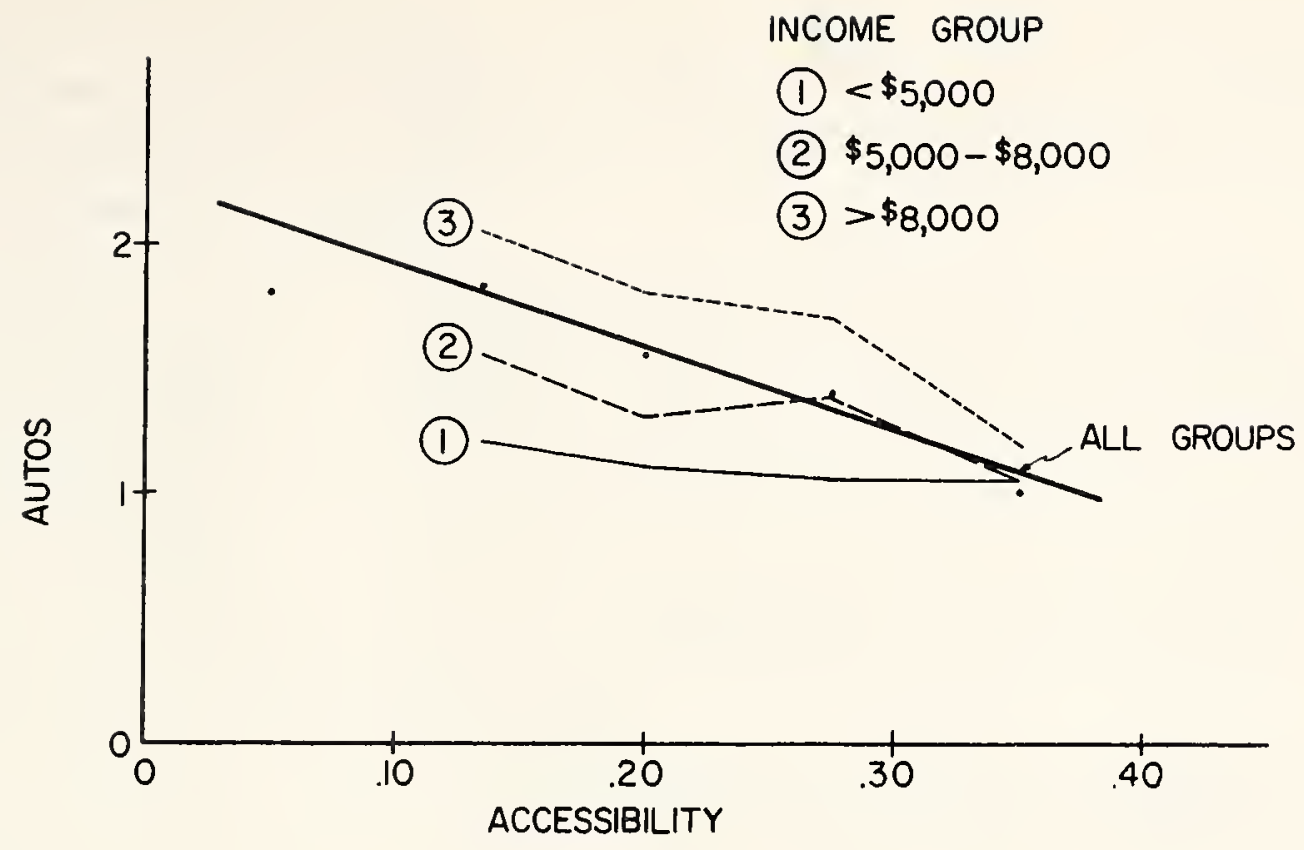

FIGURE 6.4 EFFECT OF ACCESSIBILITY ON AUTO OWNERSHIP, CONTROLLING FOR INCOME 
levels of accessibility. For the higher income groups, the decrease in trip production rates corresponds to an increase in accessibility, although the slope is not so decisive as in the overall plot.

Figure 6.3 shows the effect of controlling for levels of auto ownership. Much of the variation in home based travel between the different levels of accessibility disappears when the level of auto ownership is controlled. For the households in which a car is available the trip production rate decreases, with increasing accessibility levels, but the rate of decrease is considerably less than that indicated by the overall plot.

Figure 6.4 shows the relationship between accessibility and level of auto ownership for all households together and for income stratifications. This relationship illustrates that families living in lower accessibility areas have higher auto ownership rates. Since these households also have higher income rates, one might point to this as the reason for increased ownership. The plot, however, shows that when income is held constant, the auto ownership level still increases as accessibility decreases. This indicated that accessibility levels did affect auto ownership rates even when income was held constant.

Two way analysis of variance (ANOVA) models for unequal sub-classes were run to statistically evalute the effects of accessibility on home based travel and auto ownership. It should be recalled that the variances of the dependent variable may not be equal for all levels of the explanatory variables. Therefore the statistical $F$ ratio is not exact for the selected probability level. If the variable is declared insignificant, it would in fact be insignificant at the chosen level, but on the other hand, a variable found to be significant at a selected level may not be significant at the nominal level. Not all levels of each variable could be used in all models due to insufficient data. Households 
ranging from two through five members and households owning either 1 or 2 cars were considered in the ANOVA. Income was stratified as indicated in Figure 6.3.

Table 6.3 provides the results of the analysis of variance for the models in which the dependent variable was home based trips. When family size and accessibility were the independent variables, each of the main effects and the interaction term provided a significant contribution, however, when either income or auto ownership was considered with accessibility, the latter variable was not a major contributor to explaining differences in home based travel.

For the models in Table 6.4 the dependent variable was auto ownership. When accessibility and family size were used as the explanatory variables, accessibility was the dominant factor in explaining ownership levels. When income and accessibility were taken as the explanatory variables, both were found to be important in explaining the variation in auto ownership.

The conclusion which is drawn from this discussion is that, while accessibility, considered alone, appears to be an important explanatory variable, this contribution is diminished when income and auto ownership are included in the analysis. The effect of accessibility on trip production rates would appear to be an indirect effect due to its influence on auto ownership.

Non-vehicular Trips. A final consideration which helps to explain declining travel with increasing accessibility is that the families living in relatively more accessible areas may find it possible to satisfy their travel needs by other than vehicular transportation. For example, more school trips may be made by walking or bicycling. Similarly, short trips to a local store or to a neighborhood recreation area could be made by these modes. Transportation studies 
Table 6.3. ANOVA Models for Evaluating the Effect of Accessibility on Home Based Travel.

\begin{tabular}{|c|c|c|c|c|}
\hline Source & $\begin{array}{l}\text { Sum of } \\
\text { Squares }\end{array}$ & $\begin{array}{l}\text { Degrees of } \\
\text { Freedom }\end{array}$ & $\begin{array}{l}\text { Mean } \\
\text { Square }\end{array}$ & F-Ratio \\
\hline Autos & 275 & 1 & 275 & $11.2 * \star$ \\
\hline Accessibility & 62 & 4 & 15 & .6 \\
\hline Autos *Accessibility & 58 & 4 & 14 & .6 \\
\hline Error & 7276 & 296 & 25 & \\
\hline Family Size & 1722 & 4 & 431 & $30.1 * *$ \\
\hline $\begin{array}{l}\text { ramly Size } \\
\text { Accessibility }\end{array}$ & $\begin{array}{r}1122 \\
191\end{array}$ & 4 & 48 & $3.3^{\star}$ \\
\hline $\begin{array}{l}\text { Family Size* } \\
\text { Accessibility }\end{array}$ & 586 & 16 & 37 & $2.6 * \star$ \\
\hline Error & 4118 & 288 & 14 & \\
\hline Income & 683 & 2 & 341 & $14.0 * *$ \\
\hline Accessibility & 124 & 4 & 31 & 1.3 \\
\hline $\begin{array}{l}\text { Income* } \\
\text { Accessibility }\end{array}$ & 246 & 8 & 31 & 1.3 \\
\hline Error & 8370 & 342 & 24 & \\
\hline
\end{tabular}

*Significant at nominal level, $\alpha=0.05$ **Significant at nominal level, $\alpha=0.01$ 
Table 6.4. ANOVA Models for Evaluating the Effect of Accessibility on Auto Ownership.

\begin{tabular}{|c|c|c|c|c|}
\hline Source & $\begin{array}{l}\text { Sum of } \\
\text { Squares }\end{array}$ & $\begin{array}{l}\text { Degrees of } \\
\text { Freedom }\end{array}$ & $\begin{array}{c}\text { Mean } \\
\text { Square }\end{array}$ & F-Ratio \\
\hline Family Size & 4.6 & 4 & 1.2 & 2.0 \\
\hline Accessibility & 23.4 & 4 & 5.9 & $10.1 * *$ \\
\hline $\begin{array}{l}\text { Family Size* } \\
\text { Accessibility }\end{array}$ & 7.1 & 16 & .4 & .8 \\
\hline Error & 169.0 & 292 & .6 & \\
\hline Income & 15.8 & 2 & 7.9 & $17.5 * *$ \\
\hline Accessibility & 12.4 & 4 & 3.1 & $6.9 * *$ \\
\hline $\begin{array}{l}\text { Income* } \\
\text { Accessibility }\end{array}$ & 3.2 & 8 & .4 & .9 \\
\hline Error & 154.1 & 342 & .5 & \\
\hline
\end{tabular}

*Significant at nominal level, $\alpha=0.05$ **Significant at nominal level, $\alpha=0.01$ 
do not worry about these non-vehicular trips because this travel is not transferred to the transportation system. However, to develop an understanding of the basic travel needs of the behavioral unit, these trips are important.

In the 1971 survey, home-based walking or cycling trips were determined. Only those trips which were a regular part of the household routines were included. For example, if a child walked to school the trip was counted as a walk trip, but if the child were out playing and merely rode down the street on his bicycle, the "trip" was not counted. Table 6.2 provided the average "vehicular" and "vehicular plus walk" trip rates for 1971. Figure 6.5 illustrates the relationship. Although the walk trip is not an overwhelming factor -- an average of 0.6 walk trips per household -- the trend is in the direction expected. Families in areas of

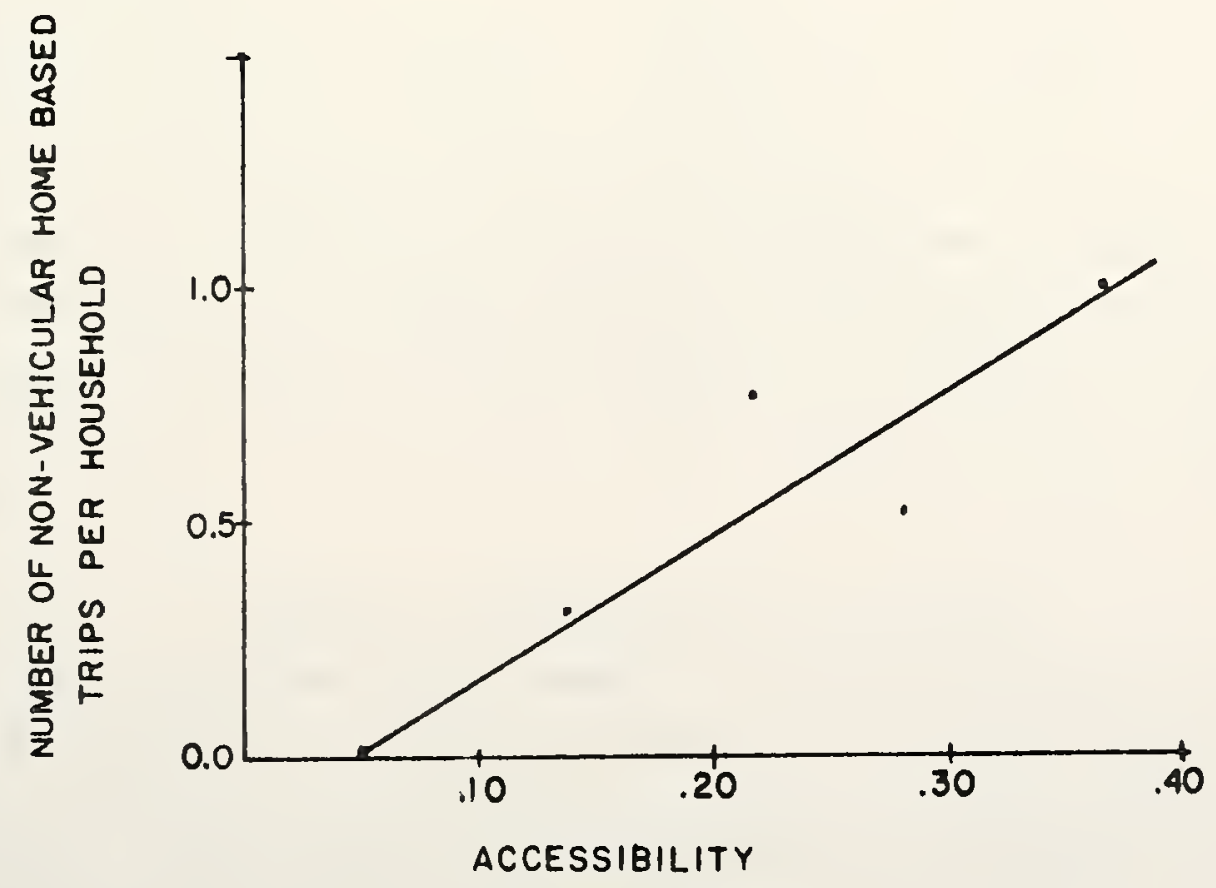

FIGURE 65 EFFECT OF ACCESSIBILITY ON NON-VEHICULAR HOME BASED TRAVEL 
higher accessibility satisfy a greater portion of their travel needs by non-vehicular transportation.

\section{Occupational Status}

The effect of occupational status on trip production and auto ownership was also analyzed by analysis of variance techniques.

Occupation of the head of the household was stratified into four groups for the analysis of variance. The members constituting these groups were as follows:

1. Professional, Manager, and Salesmen

2. Clerical and Craftsmen

3. Service personnel, Operatives and general labors, and

4. Non-gainful employment including housewives, students, the unemployed and the retired.

Considered in a one way analysis of variance model, occupational status would be a significant variable in explaining trip generation and auto ownership. However, when family size and income are each considered with occupation, the latter variables dominate the model and occupation is not significant in explaining trip generation. For explaining auto ownership, income dominates the effect of occupational status to the extent that occupation is not significant.

Stage in the Family Life Cycle

The distribution of family characteristics in the survey sample did not allow elaborate tests of the family life cycle variable since nearly all heads of households were married. The variable was established by breaking the households into the following groups:

1. head of household less than 45 years of age and having school age children; 
2. head of household over 45 years of age and having school age children;

3. head of household less than 45 years of age and having no school age children; and

4. head of household over 45 years of age and having no school age children.

Since this classification scheme was tied rather directIy to the size of the family, the family size variable explained the same variation which might be explained by the family life cycle variables. As a result, the variable was insignificant in explaining travel behavior in this study.

\section{An Evaluation of Changes Over Time}

This research project afforded a unique opportunity not only to evaluate the stability of models based on household data taken at two points in time, but also to evaluate the actual effect of changes in an explanatory variable on the dependent variable for each household unit. When one develops a model based on cross-section data the variables are selected on the basis of observed correlation and intuitive causation. Even though similar correlations may exist in the data at a later date in the planning period, the change in the dependent variable may not have been due to changes in the independent variable. Instead, the change may have been a reflection of some other ultimate cause outside of the prediction model. For example, two data sets might well show that higher income groups have higher auto ownership rates. Observation of individual household income may, however, show that the increase in income was due to additional household members joining the labor force. In turn, the additional working member, may create a greater need for transportation, causing the family to increase the level of auto ownership. Thus, the joint increase in income and auto ownership would tend to "validate" the correctness of the original model. 
The prediction models developed for home based trip production and auto ownership were found to be very reliable in estimating the dependent variable in 1971 from parameter estimates obtained from the 1964 data. To evaluate whether observed changes in the independent variable might be the true cause of changes in the dependent variable, plots of the reported changes in the variables were examined. If an independent variable exhibits a unit change, but the relationship between the independent and dependent variable is only spurious, one would not necessarily observe the corresponding change in the dependent variable. On the other hand, if the relationship is causal, the variables should both exhibit a corresponding change.

Figure 6.6 illustrates the differences in reported trip rates compared to differences in reported family size. The plots were obtained by taking differences in the reported household characteristics and reported trips in 1964 with the corresponding figures from the same household in 1971. Each point on the plot is the average difference in reported trips for each level of family size change. The plot indicates that family size changes are, indeed, a prominent factor in explaining trip production differentials within the households. The overall plot considers trip differentials for varying family size changes, irrespective of changes in other household characteristics. This plot exhibits a strong linear trend. When one considers only those households which increased their level of auto ownership by one, the linear trend is still evident with the trip production rate being higher than the overall average. It is interesting to note that, even when the level of ownership increased by one, a decrease in family size always caused a decrease in trip production. A change in family size is apparently the dominant factor in explaining trip production differentials within the household. 
In Figure 6.7 the effect of auto ownership is illustrated. Changes in trip production rates respond to changes in auto ownership within the household. The dominance of family size, however, is illustrated again. Where the family size decreased by one, the average trip production rate increased only in those households which reported two additional vehicles. No explanation can be cited for the apparent inconsistency of the point on the constant family size curve where the average trip rate was higher, even though autos decreased by one.

Finally, the relationship between income and auto ownership is depicted in Figure 6.8. The overall curve shows that a change in income has a positive association with auto ownership. The trend is linear for small changes in income, but flattens out at the extreme positions. Of greater significance is the behavior of auto ownership when the number of family members in the labor force remained constant over the period. It is noted that for this situation, an increase in constant dollar income may increase the level of auto ownership, but a decrease in reported income does not produce a corresponding decrease in ownership. It would appear that as long as the number of family members who must get to work remains constant, the family will try to maintain the same auto ownership rate even though their ability to pay for the cost of owning and operating that vehicle may have decreased. one might extend this implication to other aspects which relate to planning policies. It would appear that households which attain a level of auto ownership and have become accustomed to the freedom of movement allowed by that level of auto availability, would be unlikely to reduce their ownership because of other changes in the pattern of urban development or level of service provided by other means of transportation. In the long run, an improvement in public transit service may induce travelers to use that service rather than acquiring an additional automobile to operate on the highway 


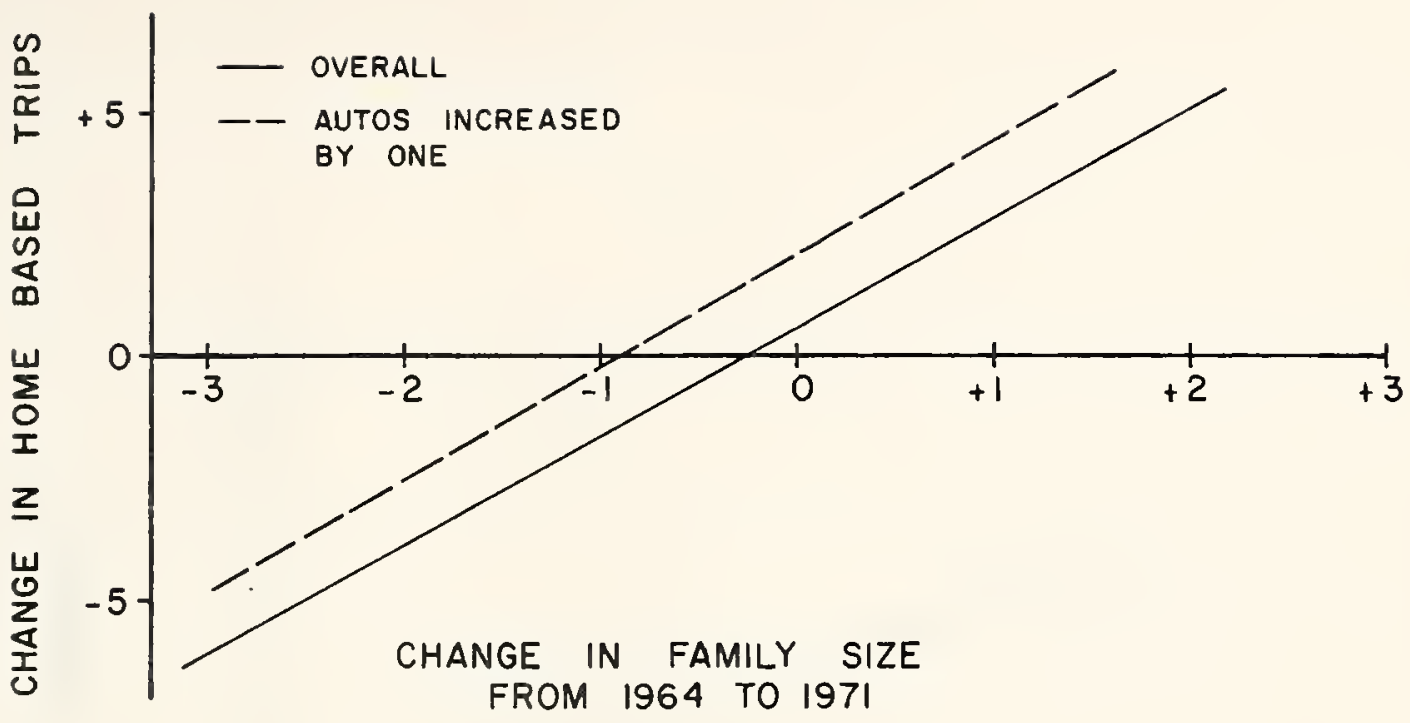

FIGURE 6.6 CHANGES IN TRIP PRODUCTION RATE WITHIN THE HOUSEHOLD WITH CHANGES IN FAMILY SIZE

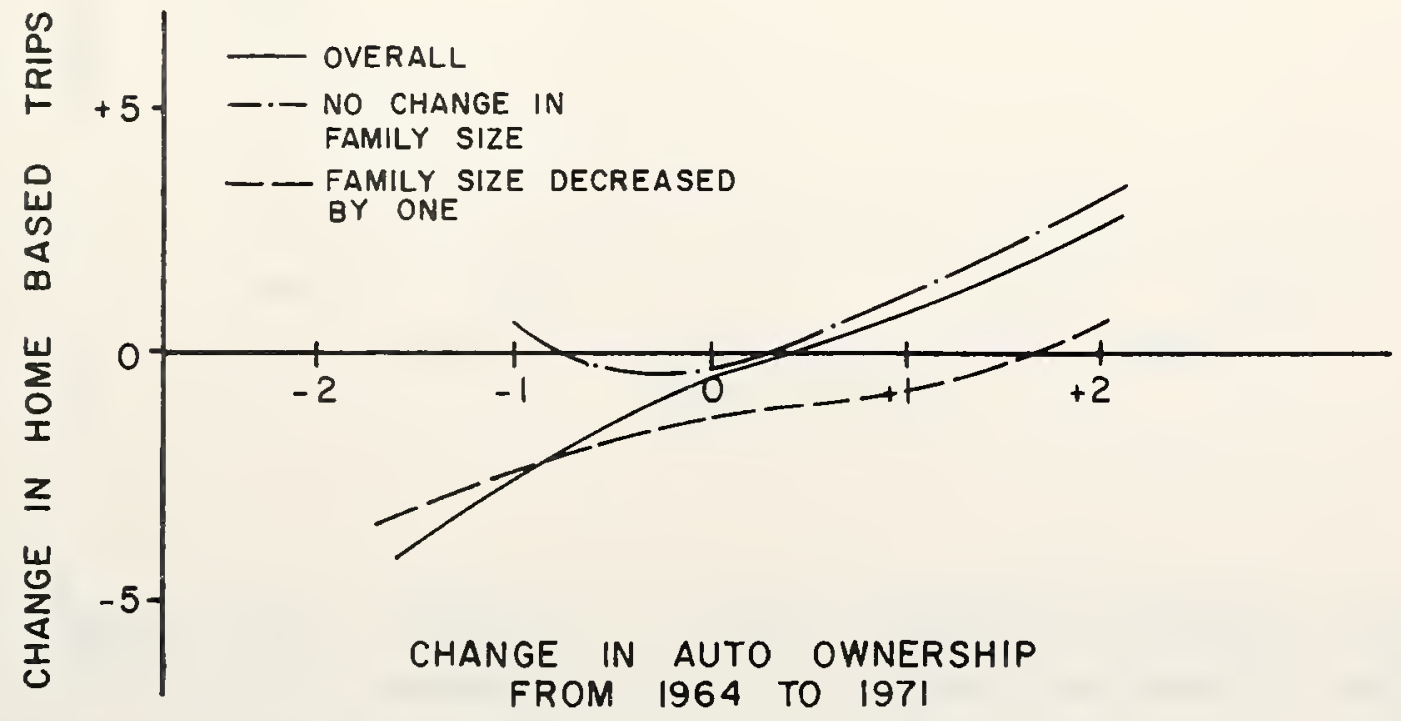

FIGURE 6.7 CHANGES IN TRIP PRODUCTION RATE WITHIN THE HOUSEHOLD WITH CHANGES IN AUTO OWNERSHIP 


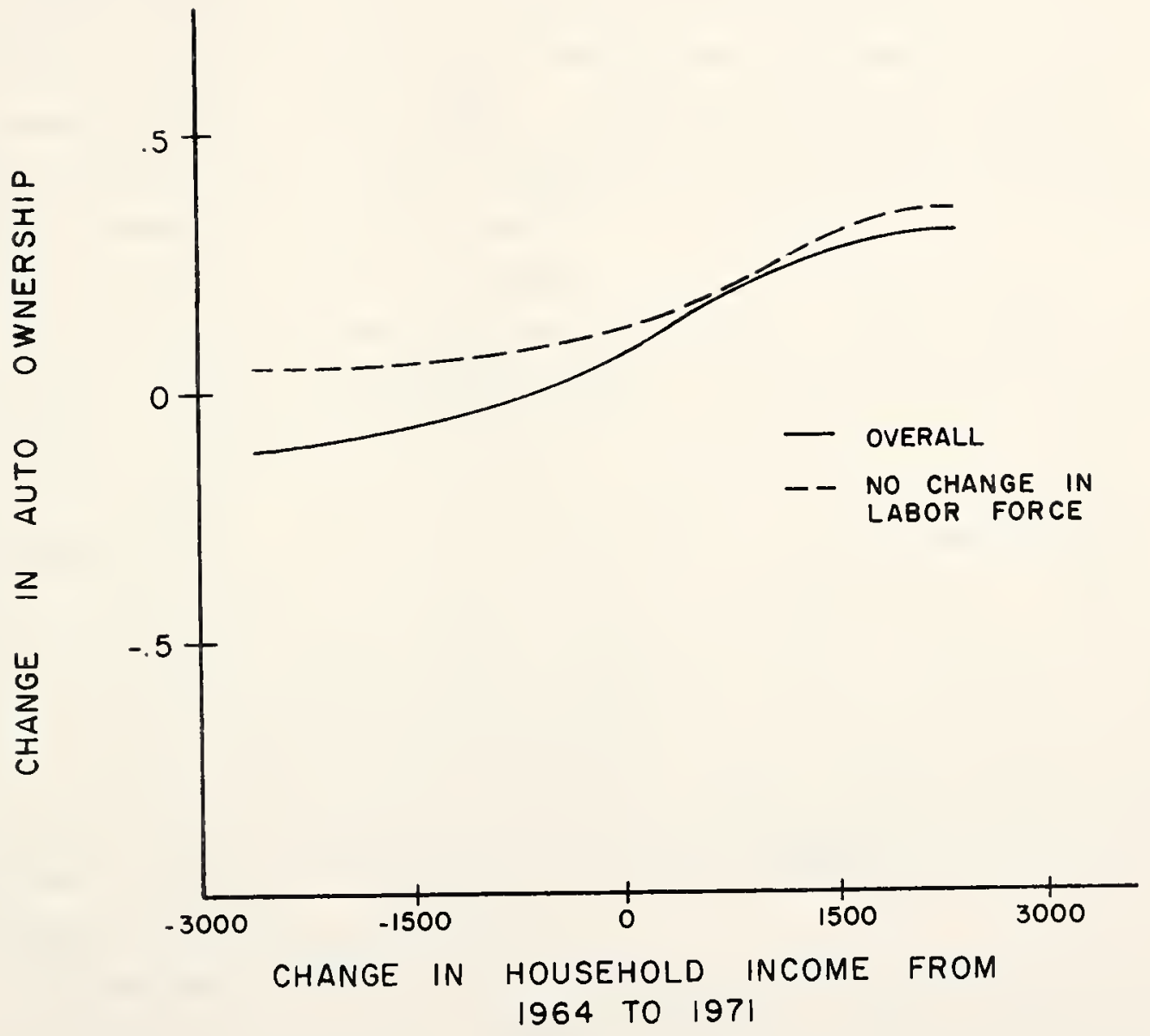

$\begin{array}{lll}\text { FIGURE } & 6.8 & \begin{array}{l}\text { CHANGES IN AUTO OWNERSHIP } \\ \text { HOUSEHOLD WITHIN }\end{array} \text { THE } \\ & & \text { CHANGES IN FAMILY INCOME }\end{array}$ 
facilities. It seems unlikely, however, that families at a level of auto ownership would be willing to reduce that level because of the improved transit service.

\section{Summary}

Respondents in this study perceived that changes in auto ownership, and changes in family size and stages in the family life cycle were the most important changes which affected the amount which they travel. These perceived reactions support the use of these variables in developing trip generation models which are sensitive to changes in household characteristics over the years.

Income change was not perceived as a major factor in directly causing increased travel, but income was the primary factor in the prediction model for auto ownership. Using income and labor force as explanatory variables, the auto ownership level of the 357 households in 1971 was estimated within four percent of the actual auto ownership. Income, taken by itself, was able to produce similar estimates, however, a check on the relationship over time indicated there is an interacting effect between income and the number of people employed in the household. This suggests that both variables would be necessary to fully understand the relationship with auto ownership.

Households which were relatively more accessible to activity centers exhibited lower trip production rates than households in less accessible areas, but this difference was due primarily to difference in income and auto availability of the households in different areas and to the greater portion of the travel needs which are satisfied by the walking mode in the more accessible areas. When accessibility and auto ownership were analyzed together, only auto ownership contributed significantly to explaining variations in travel behavior. Accessibility was, however, important in explaining auto ownership, even when income was used as a joint 
explanatory variable.

Occupational status and stage in the family life cycle did not contribute significantly to explaining variation in home based travel when considered jointly with family size and auto ownership. 
CHAPTER 7. ANALYSIS OF THE STRUCTURAL RELATIONSHIPS AMONG SELECTED VARIABLES IMPORTANT TO TRIP GENERATION

The interrelationships among several of the variables which have been found to be significant in explaining travel variation in the households have been discussed. In this chapter, a structural model is used to define a system of equations which corresponds to hypothesized causal processes. In the structural model one's interest is not restricted to studying the effect of changes in a single equation, but instead, the interest is to study a set of equations simultaneously to analyze how a change in the relationships of any one equation of the system might affect all other variables of the system. The purpose of the method of analysis is to determine whether the interpretations of a set of proposed causal equations relating significant trip generation variables is consistent throughout. Each equation of the system may not necessarily be the best predictive equation, but rather, its presence is important in explaining the structure of the variables which have been studied in trip generation analysis.

\section{An Introduction to Causal Analysis}

The discussion here is directed toward outling the basic assumptions and limitations of causal models. In addition, the basic principles of establishing the causal models and computing correlations which should be observed if the hypothesized model is correct, is discussed to familiarize the reader with the concepts of the structural model. For more detailed discussion of the computational procedures, the interested reader may refer to the articles by Land and Heise $(13,20)$. Also,Blalock offers extensive arguments 
pointing out the need for careful consideration in making causal inferences from the data and clarifies the conditions under which causal inferences may be possible (1).

The goal of causal modeling is to develop a set of relationships which correspond to actual causal processes in the real world. Analysis of a causal structure requires specification of a network of causal paths which exist between the variables of interest, and identification of the parameters of causation so one can measure the effects of each variable on the other variables in the model. The mathematical equations which make up the causal structure are a set of recursive equations such as the following, four variable recursive system:

$$
\begin{aligned}
& \mathrm{z}_{1}=\mathrm{P}_{1 \mathrm{a}} \mathrm{z}_{\mathrm{a}} \\
& \mathrm{z}_{2}=\mathrm{P}_{2 b} \mathrm{z}_{\mathrm{b}} \\
& \mathrm{z}_{3}=\mathrm{P}_{31} \mathrm{z}_{1}+\mathrm{P}_{3 c} \mathrm{z}_{\mathrm{c}} \\
& \mathrm{z}_{4}=\mathrm{P}_{41} \mathrm{z}_{1}+\mathrm{P}_{42} \mathrm{z}_{2}+\mathrm{P}_{43} \mathrm{z}_{3}+\mathrm{P}_{4 \mathrm{~d}} \mathrm{z}_{\mathrm{d}}
\end{aligned}
$$

This set of mathematical equations can be represented conveniently using the notion of the path diagram developed by Wright (45). Figure 7.1 is the pictorial representation of the above recursive system. There is a one to one correspondence between the structural equations and the path diagram. Further, some of the assumptions of causal modeling become more apparent when viewing the path diagram. The rules for constructing a path diagram will be given as each of the different types of variables are discussed.

A structural model is composed of three types of variables:

1. Exogenous variables are considered to be the inputs to the system. These variables are assumed to be completely determined by other variables outside of the system and neither the nature of their origin, nor the correlation which may exist between these inputs, is of concern for the model being 


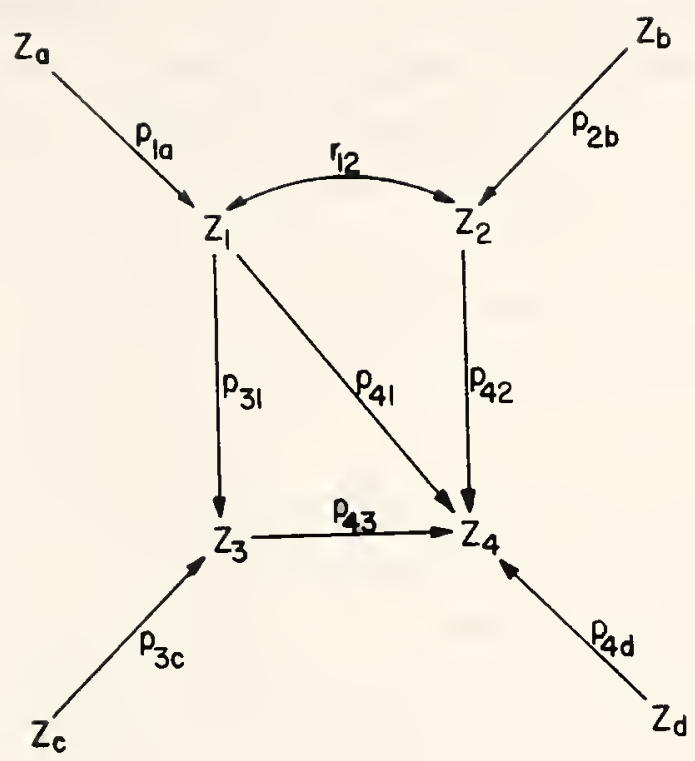

FIGURE 7.1 AN EXAMPLE OF A FOUR VARIABLE CAUSAL MODEL

considered. The paths between the exogenous variables are represented on the path diagram as twoheaded curvilinear arrows. These paths indicate only that some correlation may exist. No direction of causality is assumed. In the above model $\mathrm{Z}_{1}$ and $\mathrm{Z}_{2}$ are the exogenous variables of the system.

2. Measured variables within the structural model are referred to as endogenous variables. Unlike the exogenous variables, the total variation in the endogenous variables is of interest. The total variation in the endogenous variables is assumed to be completely determined by some linear combination of exogenous variables, other endogenous variables and some unmeasured residual or error variable. 
The postulated causal relations among the variables are represented on the path diagram by unidirectional arrows extending from each determining variable to each variable dependent on it. In the path models discussed here the assumption must be made that there is only one direction of causation, i.e., if $X$ causes $Y, Y$ cannot in turn be a cause of $\mathrm{X}$. Variable $\mathrm{Z}_{3}$ and $\mathrm{Z}_{4}$ are the endogenous variables in Figure 7.1.

3. Since it is unrealistic to assume that the variation of a variable in the systen will be completely determined by the other measured variables of the system, residual variables are introduced. The residual variable is assumed to be uncorrelated with the set of variables immediately determining the variable under consideration and it is assumed to have a mean value of zero.

Residual variables are represented on a path diagram by unidirectional arrows. Literal subscripts are attached to the residual variable paths to distinguish them from the paths of the measured variables which bear numerical subscripts. For the sake of clarity in presentation, the residual paths and the paths between the exogenous variables are often eliminated from the causal model in this dissertation. Variables $\mathrm{z}_{\mathrm{a}}, \mathrm{z}_{\mathrm{b}}, \mathrm{z}_{\mathrm{c}}$ and $\mathrm{z}_{\mathrm{d}}$ are the residual variables in Figure 7.1 .

The exogenous variables, $\mathrm{Z}_{1}$ and $\mathrm{Z}_{2}$, are assumed to be completely determined by outside forces $\mathrm{z}_{\mathrm{a}}$ and $\mathrm{z}_{\mathrm{b}}$ which are either unknown or just not of interest in the analysis. The path coefficients $P_{1 a}$ and $P_{2 b}$ would be equal to one ( 1 ) and are not normally included in the model or diagram.

The endogenous variables, $\mathrm{z}_{3}$ and $\mathrm{z}_{4}$, as has been noted, are determined by some linear combination of other exogenous and endogenous variables and an unknown residual or error 
term.

Estimation of the model parameters for each equation revolves around fitting a model to the data so as to minimize the amount of variation contributed by the residual variables. The parameters of the structural model are computed using the least squares criteria common to linear regression analysis, however, to facilitate the interpretation of the relative importance of the determining variables, standardized regression coefficients are used. This standardized parameter or path coefficient, $\mathrm{P}_{i j}$ ' is a measure of the fraction of the standard deviation of the dependent variable for which the independent variable is directly responsible. More definitely, it is the fraction which would be found if the factor varies to the same extent as in the observed data while all other variables in the equation are held constant.

The relationship between the regular regression coefficient, $b_{i j}$ ' and the path coefficient, $P_{i j}$ ' is:

$$
P_{i j}=b_{i j} \frac{\sigma_{j}}{\sigma_{i}}
$$

where $\sigma_{i}$ and $\sigma_{j}$ are the standard deviations of the dependent and independent variables, respectively. The path coefficients are also referred to as beta coefficients.

The standardized parameter facilitates the computations necessary to evaluate the consistency of the model in reproducing the interrelationships which exists in empirical data. Using standardized coefficients, it can be shown that, for the model given in Figure 7.1, the structural model would predict the linear correlation between variables $\mathrm{Z}_{4}$ and $Z_{1}$ to be:

$$
r_{41}^{\prime}=P_{41}+P_{43} r_{12}
$$


where

$r_{41}^{\prime}$ is a predicted correlation for the hypothesized model;

$r_{12}$ is the observed correlation between the exogenous variables; and

$\mathrm{P}_{41}, \mathrm{P}_{42}$ and $\mathrm{P}_{31}$ are the path coefficients estimated in regression analysis $(20)$.

The total correlation between $z_{4}$ and $z_{1}$ ' is composed of three elements. First, there is a direct effect between the variables indicated by the path coefficient, $\mathrm{P}_{42}$. Secondly, there is an indirect effect, $\mathrm{P}_{43}{ }^{\mathrm{P}} 3 I$, which is due to the influence which variable $z_{4}$ has on $z_{3}$, which in turn influences $z_{4}$. Finally, there is another indirect effect, $\mathrm{P}_{42} \mathrm{r}_{12}$, which encompasses the correlational effect of the exogenous variables. It must be cautioned that these direct and indirect effects can be interpreted only for the model under study. The direct effect is a true, isolated direct effect only if the other independent variables are orthogonal to the variable being considered and if the effects of all other variables are truly removed.

The entire correlation matrix could be reproduced in like manner using the additional relations derived for the model in Figure 7.1:

$$
\begin{aligned}
& r_{13}^{\prime}=P_{31} \\
& r_{23}^{\prime}=P_{31} r_{12} \\
& r_{24}^{\prime}=P_{42}+P_{41} r_{12}+P_{43} P_{31} r_{12} \\
& r_{34}^{\prime}=P_{43}+P_{41} P_{31}+P_{42} P_{31} r_{12}
\end{aligned}
$$

A variable which explains a significant portion of the variance in a dependent variable would exhibit a strong direct effect in the causal model and would logically be considered as an important element of the model. On the other hand, if a particular variable does not show a strong direct contribution in a given equation, the analyst would 
not immediately reject the variable from the entire structure. Instead the importance of the variable in the other equations of the system must be considered. If the variable is significant in other relationships it would be an important variable in the overall system being evaluated. The advantage of the structural model is that one may examine all relationships simultaneously and evaluate the faithfulness of that system in reproducing the empirical relationships in the data set.

\section{Evaluating the Adequacy of the Model}

The purpose in developing a causal model is to help the analyst understand the relationships among a set of variables which are important in some behavioral process. An objective in testing these relationships is to obtain a model which adequately reproduces the conditions which occur in empirical data and yet is as parsimonious as possible. For any postulated model, one can compute the correlation matrix. which would exist for the model and compare this with an observed correlation matrix. If one starts with the least parsimonious case in which all possible paths are included, there are no conditions imposed upon the model to test the adequacy of that model. It can be shown that any ordering of the variables would result in a reproduced correlation matrix which exactly equals the empirical correlations (19). In this case only the knowledge of the causal priorities would allow selection of one model over the other. The problem then is to make an initial determination of the significance of the paths in the model.

If sufficient data are available, analysis of variance models may serve as a starting point for evaluating the significance of variables which might be introduced in regression analysis. The analysis of variance provides a measure of significance, not only for the main effects of the variables, but also of possible interactions. Since interaction terms 
are not included in the simplified model, the analyst would be made immediately aware of possible incorrect interpretations from the structural model.

A second method for eliminating paths in the causal models would be to retain only those variables which are statistically significant according to the F-test criterion used in regression analysis. However, as the sample size becomes large, path coefficients which make very small contributions to the total variance may be judged statistically significant and retained in the model. For this situation, Land suggests that the analyst choose a minimum value below which a path coefficient is considered to be substantively insignificant.

Finally, when a model which is over identified has been structured, (i.e., a model in which one or more possible paths have been eliminated) additional constraints will be established. For a model to be judged as adequate, it must be able to reproduce correlations between the system variables in accordance with the imposed constraints. If these predicted correlations adequately represented the empirical correlations, the analyst might accept this as the best representation of the causal structure or he might check the possibility of eliminating other paths. If the model was not adequate, the analyst could either revert to the previously accepted model or test some other model in which a different link is eliminated.

A Summary of the Structural Model Assumptions

In this research, the method of path analysis to evaluate causal relationships is restricted to those models which meet the following methodological assumptions:

1. A change in the dependent variable always occurs as a linear function of changes in the determining variables, and the effects of all other variables are assumed to be held constant. 
2. The system contains no reciprocal causations, i.e., the model is strictly a recursive system. If two-way causation is allowed a problem in identification exists. Although methods of treating such models are available, the procedure is more complex and the interpretations are clouded.

3. The causal priorities are sufficiently well known so that the structure of the model can be established as the correct ordering of the variables. It is not necessary that all correct paths are known, but the order of causation should be clear.

4. The data should generally be measured on an interval or ratio scale, but as in regular regression analysis, the use of dumy variables is permissable if caution is exercised in the interpretation of the results.

5. The usual assumptions of multivariate regression analyses must be met. Of particular importance in the development of the path model is the assumption that the residuals be uncorrelated with the independent variables under consideration.

The path analysis model is a simplification of the real world system which allows the analyst to evaluate the relative direct and indirect effects of the variables within the system. The model is simplistic from the practical standpoint that obviously, not all determinants of travel could be included. The variables considered are those major determinants which have been studied in this dissertation. The model is simplistic from the statistical sense that only linear relationships are considered and no interaction terms are specifically introduced for consideration.

Interpretation of this simplified model is restricted by the degree to which the assumptions of the model have been met. The analysis technique assumes that the effects of all variables not in the model have been held constant. 
In non-experimental research such control cannot really be achieved. The variables considered in the causal models of this research were carefully evaluated before introducing them into the model. The ordering of the causal network was based on a priori knowledge of the variables under consideration and on previous research models (18). Where data permitted, several linear analysis of variance models were tested to determine significance of the main effects and the interaction terms (Tables 5.3, 6.3 and 6.4). The interaction terms were generally found to be insignificant. Finally, in this study, variations due to varying life styles of families living in different housing units were definitely controlled by selecting only single family, home-owners in the sample. It must be assumed that the variations in this data set are the same as would be exhibited if all other possible contributing factors had been held constant or did not vary. This condition is also imposed on the interpretation of regular regression models, but in the structural model the importance of this assumption is compounded in that the analyst is considering a system of relationships rather a single estimating relationship.

\section{An Evaluation of a Simplified Causal Model}

Initially a simplified causal model was constructed which considered only the interrelationships between family size, income, auto ownership, and household home based travel. As a first step it was hypothesized that family size and income were exogenous variables affecting auto ownership. These three variables were in turn linked to home based travel. The path model for this simplified structure is illustrated in Figure 7.2. For clarity, the residual paths to each of the variables are not shown. The estimated path coefficients, $p_{i j}$, developed from the 1964 and 1971 household data sets are shown. 
Except for the relationship between family size and auto ownership, the parameters of the model are consistent in magnitude for the two data sets indicating relative stability over the time period. It is felt that the changing relationship between family size and auto ownership is due to the maturation process which has occurred. As the families moved through the stages of the family life cycle and children from the larger families moved out of the household, the relationship between family size and auto ownership stabilized. As a result, the linear correlation between these variables increased substantially during the period, from 0.16 to 0.37 .

Considering the 1964 data, it is noted that the direct effect of income on home based travel, measured by the path coefficient, is 0.15 . The total indirect effect through other variables was found to be 0.14 ; a value nearly as large as the direct contribution. Since the prediction model developed earlier for home based travel, was effective in estimating household trips using only family size and auto ownership, a second causal model was evaluated in which income was not considered as a major, direct link to home based travel. This model is illustrated in Figure 7.3. The total indirect effect of income operating through other variables is greater than the direct effect observed initially. The indirect contribution of income through auto ownership alone is 0.13 . The results from the model indicate that, while income does influence travel behavior, this influence is due in large part to the influence which income has on auto ownership rates.

\section{An Evaluation of an Integrated Causal Model for Studying Travel Relationships}

A more complex model of travel behavior which allowed consideration of the other socioeconomic and accessibility measures was hypothesized and tested. The hypothesized 


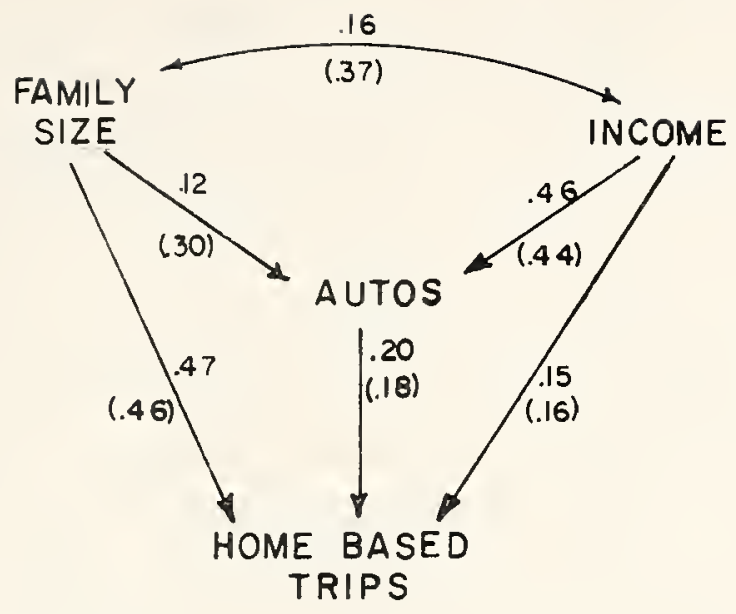

1971 PARAMETERS IN PARENTHESES

FIGURE 7.2 A SIMPLIFIED CAUSAL MODEL OF HOUSEHOLD TRIP GENERATION RELATIONSHIPS

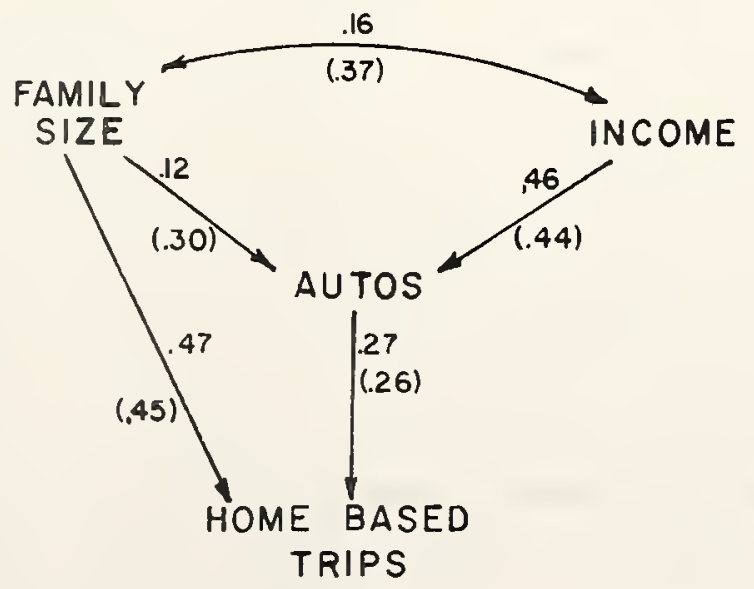

1971 PARAMETERS IN PARENTHESES

FIGURE 7.3 A REVISED, SIMPLIFIED CAUSAL MODEL OF HOUSEHOLD TRIP GENERATION RELATIONSHIPS 
formulation is a four stage recursive model. The model hypothesizes that a family chooses a residential location based on their desire for a certain life style, quality and style of housing, and preference or need for more or less space. Differences in preferred housing conditions may be shaped by several factors such as individual attitudes, age, stage in the family life cycle and family size. A family which has a greater need for space consumption would tend to locate in lower density areas which are relatively less accessible to other major activity centers. The ability to satisfy the desire for housing type and space consumption however, is controlled by the ability of the family to pay for the desired living style. Thus, one must consider the income level of the family. Income might be determined by several factors such as education, occupation, age, and number of working members in the household.

Having made the decision about housing requirements and residential location, the level of available transportation from that location influences the level of auto ownership. The families living in higher density neighborhoods with greater accessibility may have the opportunity to satisfy some of their transportation needs by use of public transportation. Further, due to greater accessibility, the need for vehicular travel may be decreased as more travel needs such as school or social-recreational trips are satisfied by walking mode. The level of auto ownership may also be affected by family size, labor force, household income, or social status of the family.

Finally, the trip production rate of the household may be affected by any of the variables mentioned previously. The task is to evaluate and understand the degree of influence a change in one variable might have on other variables in the model.

The causal ordering assumed in this study can be observed in Figure 7.4. Many of the possible linkages which 


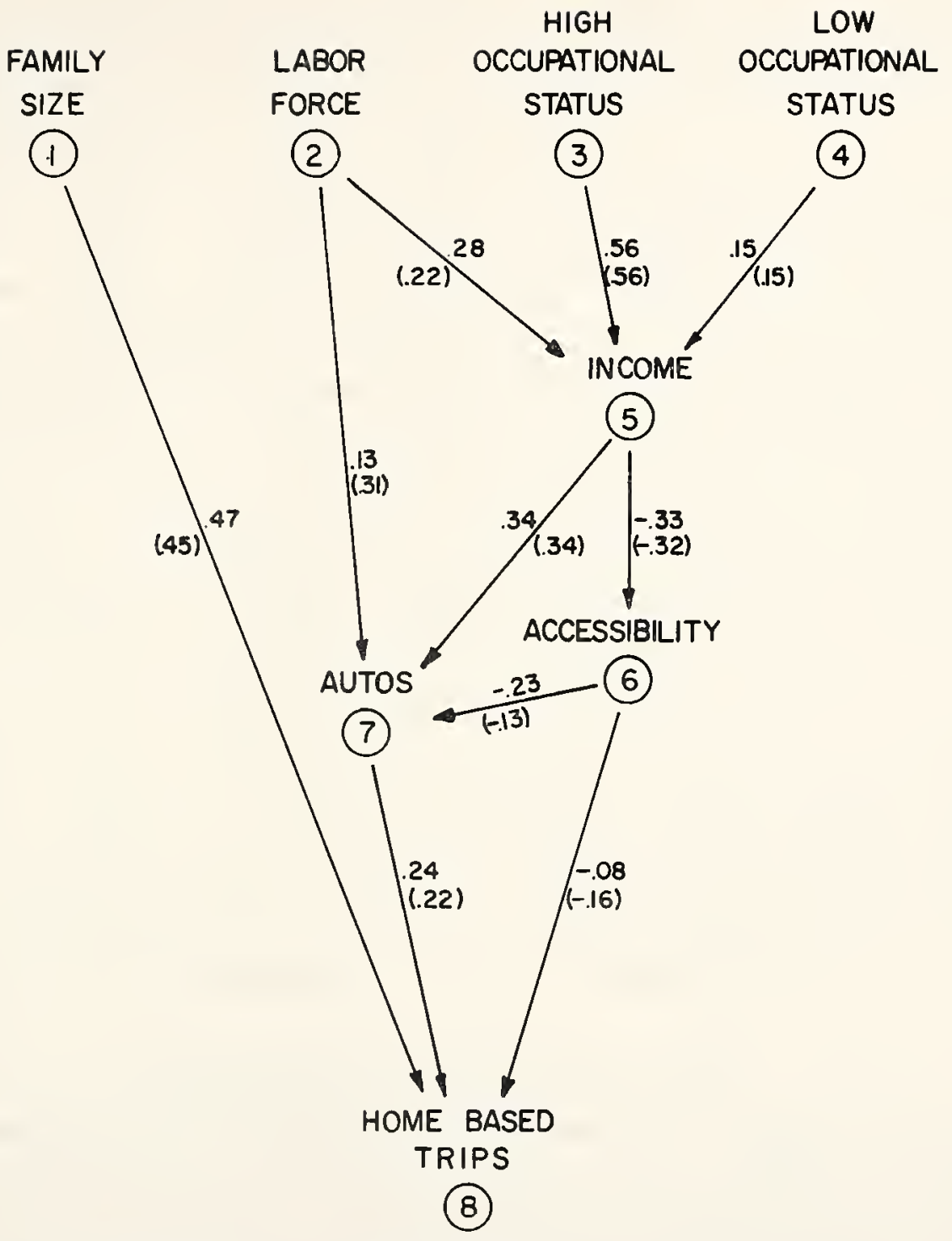

1971 PARAMETERS IN PARENTHESES

FIGURE 7.4 A DEVELOPED CAUSAL MODEL OF HOUSEHOLD TRAVEL RELATIONSHIPS, MODEL I 
could be included in the model have been eliminated since they were found to be of little importance as explanatory variables in the model. Only the final stages of the analysis are discussed in this dissertation.

The correlation matrix for the variables is given in Table 7.1. The variables which were taken as the exogenous variables were family size, labor force, and occupation of the head of household. Occupation of the head of household was stratified into three groups and used as dumy variables in the analysis. The groupings were non gainful, high status, and low status. The high status group was composed of professionals, managers and salesmen, while the low status group contained all other employed individuals. The nongainful dummy class was omitted from the analysis to allow solution of the least squares equations (37).

The models were tested using the data for both 1964 and 1971. Since it was not possible to obtain new estimates of the accessibility measure for 1971, the variable was assumed to be the same as in 1964. Based on the data presented previously, this assumption is not unrealistic.

\section{Analysis of the Causal Model}

Examination of Figure 7.4 shows that many of the path coefficients are very stable for the seven year period. The ability of the model to reproduce the correlations which exist among all of the variables can be evaluated by examining Table 7.2. If the model adequately represents all the existing relationships, these differences should approach zero. Although several of the possible links have been removed, the model does in fact reproduce the correlation matrix quite well. The major discrepancy occurs in the ability to reproduce the relationship between family size, and auto ownership in the 1971 data set. The calculated correlation was 0.20 whereas the observed correlation was 0.37 . The model was examined for other possible links which might be 

Table 7.1. Observed Correlation Matrix for Variables in
the Causal Models.a

\begin{tabular}{|c|c|c|c|c|c|c|c|c|}
\hline & 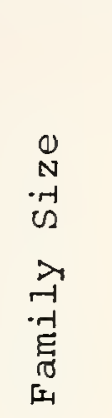 & $\begin{array}{c}0 \\
0 \\
\text { y-1 } \\
0 \\
5=1 \\
y \\
0 \\
0 \\
0 \\
0 \\
10\end{array}$ & 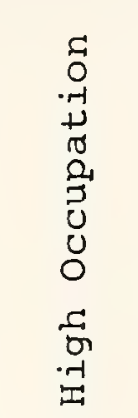 & $\begin{array}{c}5 \\
0 \\
.-1 \\
+1 \\
0 \\
0 \\
J \\
0 \\
0 \\
0 \\
0 \\
3 \\
0 \\
\mapsto \\
\mapsto\end{array}$ & 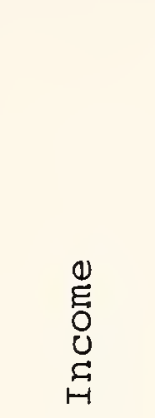 & 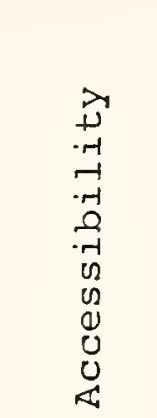 & 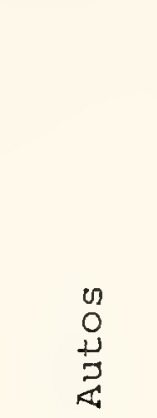 & 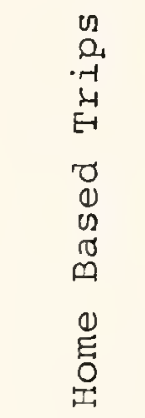 \\
\hline & 1 & 2 & 3 & 4 & 5 & 6 & 7 & 8 \\
\hline 1 & 1.00 & $\begin{array}{l}.24 \\
(.41)\end{array}$ & $\begin{array}{l}.01 \\
(.12)\end{array}$ & $\begin{array}{l}.10 \\
(.20)\end{array}$ & $\begin{array}{c}.08 \\
(.15)\end{array}$ & $\begin{array}{l}-.07 \\
(-.11)\end{array}$ & $\begin{array}{l}.16 \\
(.37)\end{array}$ & $\begin{array}{l}.52 \\
(.55)\end{array}$ \\
\hline 2 & & 1.00 & $\begin{array}{l}.07 \\
(.16)\end{array}$ & $(.14)$ & $\begin{array}{l}.34 \\
(.36)\end{array}$ & $\begin{array}{l}-.03 \\
(-.10)\end{array}$ & $\begin{array}{l}.26 \\
(.44)\end{array}$ & $\begin{array}{l}.31 \\
(.33)\end{array}$ \\
\hline 3 & & & 1.00 & $\begin{array}{c}-.83 \\
(-.65)\end{array}$ & $\begin{array}{l}.46 \\
(.50)\end{array}$ & $\begin{array}{c}-.23 \\
(-.27)\end{array}$ & $\begin{array}{l}.25 \\
(.25)\end{array}$ & $\begin{array}{l}.06 \\
(.24)\end{array}$ \\
\hline 4 & & & & 1.00 & $\begin{array}{l}-.28 \\
(-.15)\end{array}$ & $\begin{array}{l}.15 \\
(.10)\end{array}$ & $\begin{array}{r}-.18 \\
(.08)\end{array}$ & $\begin{array}{l}.05 \\
(.06)\end{array}$ \\
\hline 5 & & & & & 1.00 & $\begin{array}{l}-.33 \\
(-.32)\end{array}$ & $\begin{array}{l}.47 \\
(.49)\end{array}$ & $\begin{array}{l}.29 \\
(.31)\end{array}$ \\
\hline 6 & & & & & & 1.00 & $\begin{array}{l}-.35 \\
(-.27)\end{array}$ & $\begin{array}{l}-.20 \\
(-.27)\end{array}$ \\
\hline 7 & & & & & & & 1.00 & $\begin{array}{l}.35 \\
(.42)\end{array}$ \\
\hline 8 & & & & & & & & 1.00 \\
\hline
\end{tabular}

al971 Correlation in parentheses. 
Table 7.2. Differences Between Empirical and Reproduced Correlations - Model I.a

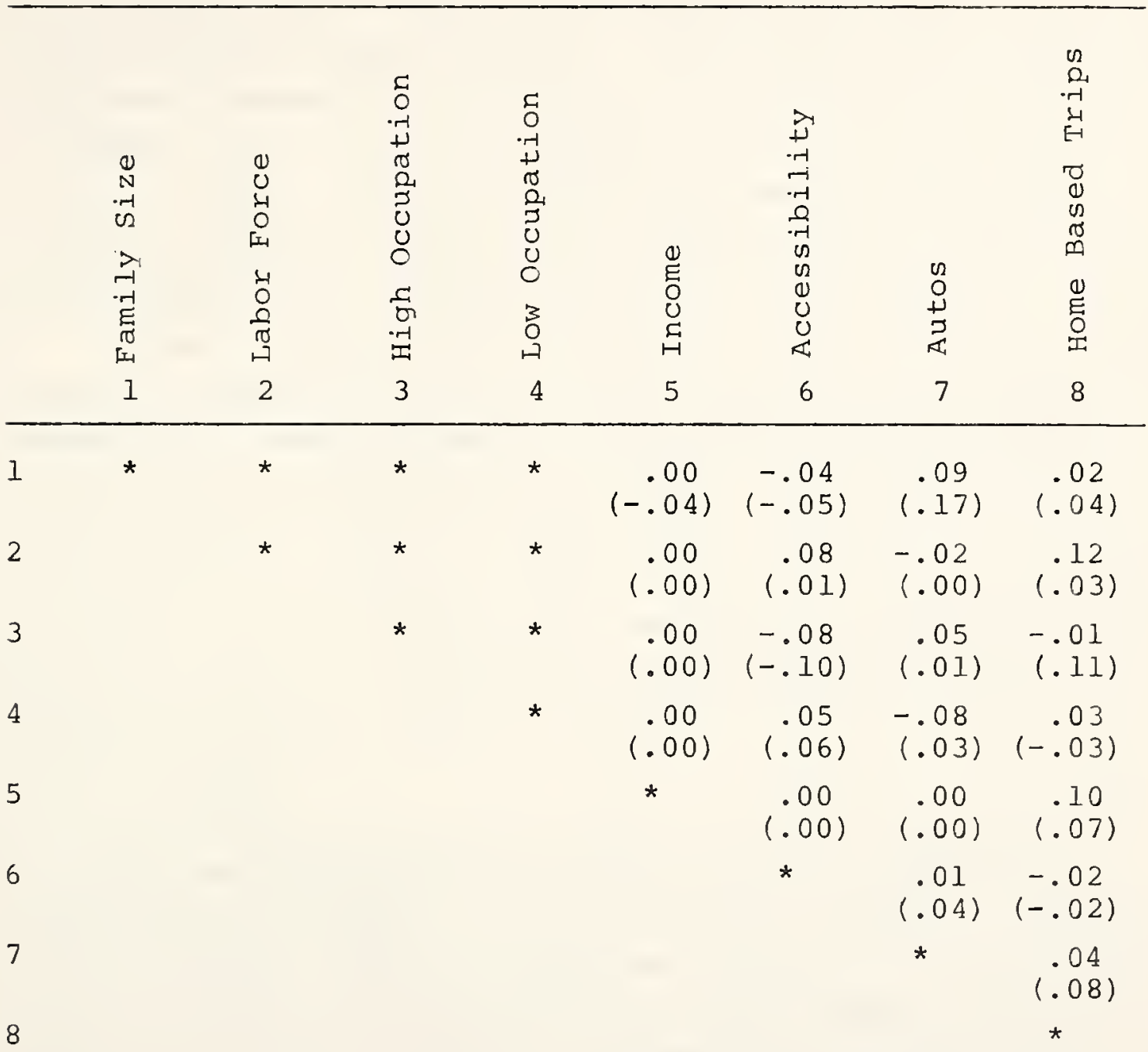

al971 differences in parentheses.

*These differences, by definition, must be zero. 
removed to make the model more parsimonious. Earlier analysis suggested that the effect of accessibility on home based travel may be more of an indirect effect due to its association with auto ownership. The ANOVA further indicated that when ownership and accessibility were tested, auto ownership was the only significant variable and no interaction was found. The path coefficient in the model also indicates that the direct path is substantively small and would explain only a small portion of the variance in travel.

It was also noted that, although income and labor force were the most significant variables for use in an estimation equation for auto ownership, the estimating equation may only require consideration of income. On the other hand, it was shown in Figure 6.8 that there is a degree of interaction between income and labor force which may be impossible to ignore. It was noted that a decrease in household income did not result in a decrease in auto ownership within the household when the number of people in the labor force was held constant.

The ability of the path model to continue to reproduce the observed correlation when labor force is removed is demonstrated in Table 7.3. The recursive system of equations for this model, Model II, would be identical to those of Model I except that the direct link from labor force to auto ownership has been removed. The reduced structural model exhibits only slightly less power in reproducing the correlations which exist in the data in 1964. However, when the controlling effect of labor force was not included in the model over time, the reproducibility of the model was greatly diminished. A large difference in the correlation between labor force and auto ownership is evident in 1971 (0.27). In addition, one can simultaneously note the effect on the relationship between other variables when the path is removed. Reproducibility of the relationship between trip production and the labor force and accessibility variabilities was also 
Table 7.3. Differences Between Empirical and Reproduced Correlations - Model II.a

\begin{tabular}{|c|c|c|c|c|c|c|c|c|}
\hline & 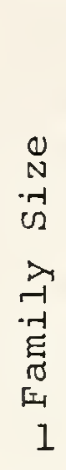 & $\begin{array}{l}0 \\
0 \\
. \\
0 \\
0=1 \\
4 \\
0 \\
0 \\
0 \\
0 \\
2 \\
2\end{array}$ & 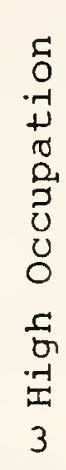 & 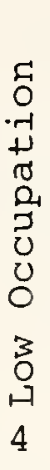 & 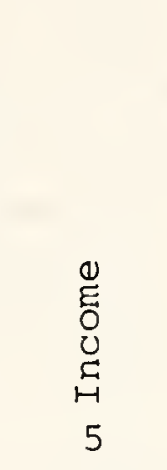 & $\begin{array}{l}\vec{H} \\
. \\
-7 \\
-7 \\
-7 \\
.7 \\
0 \\
0 \\
0 \\
0 \\
0 \\
0 \\
0 \\
6 \\
6\end{array}$ & $\begin{array}{l}0 \\
0 \\
\stackrel{0}{+} \\
z \\
Z \\
7 \\
7\end{array}$ & $\begin{array}{l}02 \\
2 \\
-1 \\
-1 \\
\text { E- } \\
0 \\
0 \\
0 \\
0 \\
0 \\
0 \\
0 \\
0 \\
0 \\
0 \\
8 \\
8\end{array}$ \\
\hline 1 & * & * & * & * & $\begin{array}{c}.00 \\
(-.04)\end{array}$ & $\begin{array}{l}-.04 \\
(-.05)\end{array}$ & $\begin{array}{l}.11 \\
(.28)\end{array}$ & $\begin{array}{l}.03 \\
(.07)\end{array}$ \\
\hline 2 & & * & * & * & $\begin{array}{l}.00 \\
.00\end{array}$ & $\begin{array}{l}.08 \\
(.01)\end{array}$ & $\begin{array}{l}.10 \\
(.27)\end{array}$ & $\begin{array}{l}.15 \\
(.10)\end{array}$ \\
\hline 3 & & & * & * & $\begin{array}{l}.00 \\
.00\end{array}$ & $\begin{array}{l}-.08 \\
(-.11)\end{array}$ & $\begin{array}{l}.04 \\
(.00)\end{array}$ & $\begin{array}{l}.00 \\
(.12)\end{array}$ \\
\hline 4 & & & & * & .00 & $\begin{array}{l}.05 \\
(.06)\end{array}$ & $\begin{array}{l}-.05 \\
(.15)\end{array}$ & $\begin{array}{r}.04 \\
-.01\end{array}$ \\
\hline 5 & & & & & * & $\begin{array}{l}.00 \\
(.00)\end{array}$ & $\begin{array}{l}.00 \\
(.00)\end{array}$ & $\begin{array}{l}.12 \\
(.10)\end{array}$ \\
\hline 6 & & & & & & * & $\begin{array}{l}.00 \\
.00\end{array}$ & $\begin{array}{l}-.09 \\
-.17\end{array}$ \\
\hline 7 & & & & & & & * & $\begin{array}{l}.05 \\
(.12)\end{array}$ \\
\hline
\end{tabular}

a 1971 differences in parentheses.

* These differences, by definition, must be zero. 
diminshed. In addition, removal of the link has produced large variations in the correlation between family size and auto ownership.

The inference to be drawn is that the labor force -auto ownership path is an important link in understanding the structure of the variables which have been related to home based travel. Understanding the causal relationships among the variables must go beyond the consideration of the single predictive equation which was used to estimate auto ownership.

The second reduced model mentioned earlier involved the removal of the direct link from accessibility to home based travel, Model III. The diagram for this structure is shown in Figure 7.5 and the differences in observed and empirical correlations are given in Table 7.4. The ability of the structural equations of Model III to reproduce the empirical correlation matrix is essentially the same as that of Model I. Only the relationship between trip production and accessibility is altered by removing this causal link. Since new measure of accessibility were not available in 1971, the author could not discern whether the difference in the correlation in 1971 was a function of "non-measurement" error or actual changes in the effect of accessibility over time. Considering that the analysis of variance for the 1964 data set found accessibility to be insignificant, the final structural model was taken as Model III. This model was accepted as the most plausible explanation of the causal relationships among the variables which have been considered in household trip generation analysis.

\section{Summary}

Structural models provide a simplified model which can be useful in studying the relationships among a set of variables in a causal system. The causal model allows the analyst to evaluate hypothesis of the causal structure of the set of 


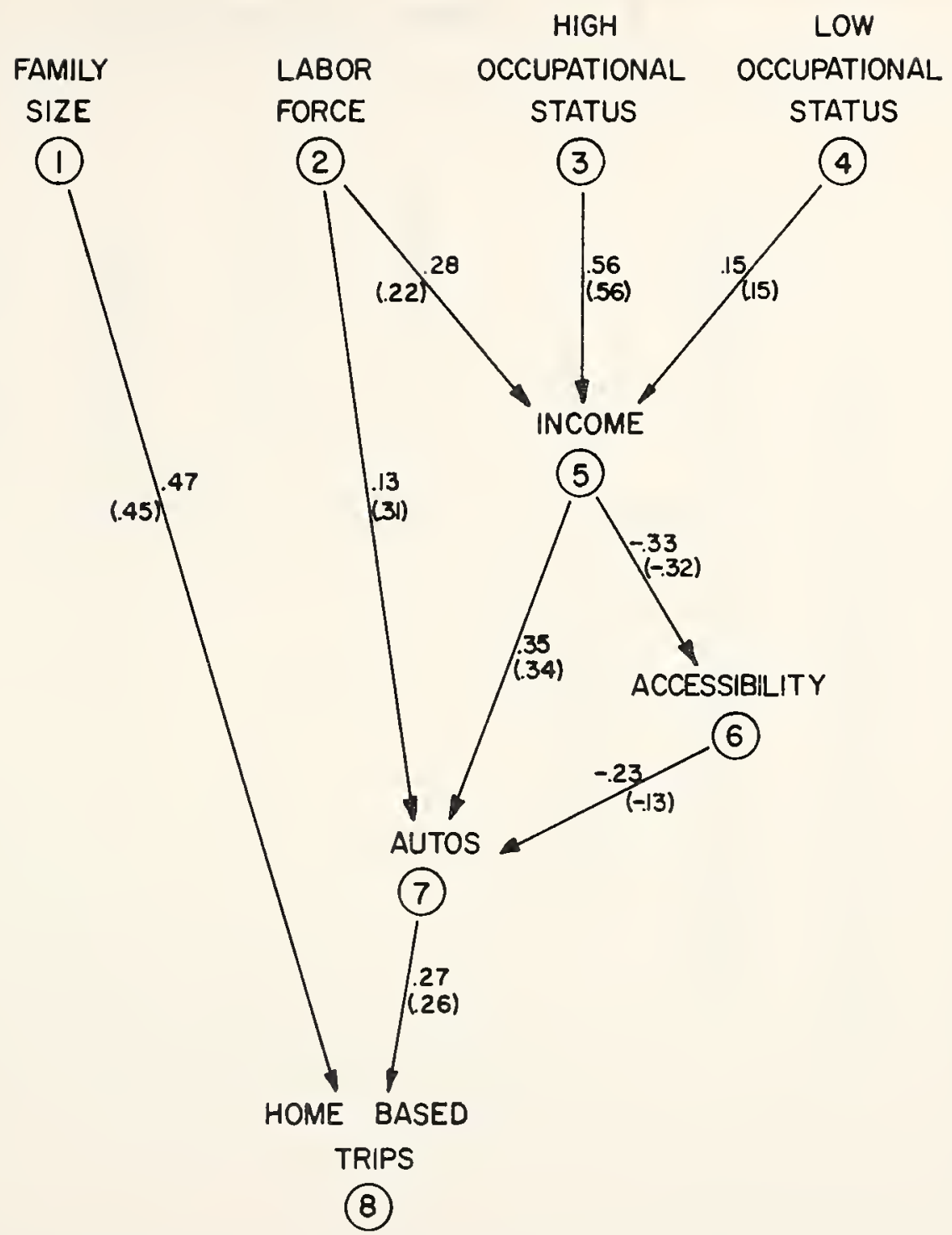

1971 PARAMETERS IN PARENTHESES

FIGURE 7.5 A DEVELOPED CAUSAL MODEL OF HOUSEHOLD TRAVEL RELATIONSHIPS, MODEL III 
Table 7.4. Differences Between Observed and Reproduced Correlations - Model III.a

\begin{tabular}{|c|c|c|c|c|c|c|c|}
\hline 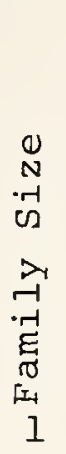 & 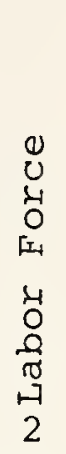 & 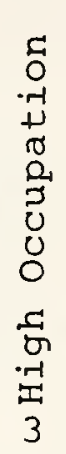 & $\begin{array}{l}5 \\
0 \\
-1 \\
+ \\
0 \\
0 \\
3 \\
0 \\
0 \\
0 \\
3 \\
0 \\
0 \\
4 \\
4\end{array}$ & 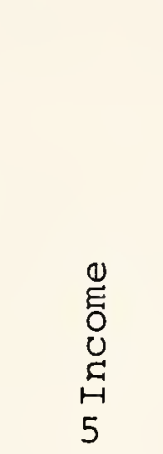 & $\begin{array}{l}\vec{H} \\
. \\
-7 \\
-7 \\
\cdot-1 \\
0 \\
-7 \\
0 \\
0 \\
0 \\
0 \\
0 \\
0 \\
0 \\
0 \\
6\end{array}$ & \begin{tabular}{l} 
n \\
0 \\
+ \\
3 \\
\multirow{4}{4}{} \\
7
\end{tabular} & $\begin{array}{l}0 \\
0 \\
-1 \\
-4 \\
E \\
00 \\
0 \\
0 \\
0 \\
0 \\
\infty \\
0 \\
0 \\
0 \\
0 \\
0 \\
8\end{array}$ \\
\hline \multirow[t]{8}{*}{ * } & * & $\star$ & * & $\begin{array}{c}.00 \\
(-.04)\end{array}$ & $\begin{array}{l}-.04 \\
(-.05)\end{array}$ & $\begin{array}{l}.09 \\
(.17)\end{array}$ & $\begin{array}{l}.02 \\
(.04)\end{array}$ \\
\hline & * & * & * & $\begin{array}{l}.00 \\
(.00)\end{array}$ & $\begin{array}{l}.08 \\
(.01)\end{array}$ & $\begin{array}{l}-.02 \\
(.00)\end{array}$ & $\begin{array}{l}.12 \\
(.03)\end{array}$ \\
\hline & & $\star$ & * & $\begin{array}{l}.00 \\
(.00)\end{array}$ & $\begin{array}{l}-.08 \\
-.11\end{array}$ & $\begin{array}{l}.05 \\
(.00)\end{array}$ & $\begin{array}{l}.00 \\
(.12)\end{array}$ \\
\hline & & & * & $\begin{array}{l}.00 \\
(.00)\end{array}$ & $\begin{array}{l}.05 \\
(.06)\end{array}$ & $\begin{array}{l}.08 \\
(.03)\end{array}$ & $\begin{array}{c}.03 \\
(-.04)\end{array}$ \\
\hline & & & & * & $\begin{array}{l}.00 \\
.00\end{array}$ & $\begin{array}{l}.00 \\
.00\end{array}$ & $\begin{array}{l}.12 \\
(.10)\end{array}$ \\
\hline & & & & & * & $\begin{array}{l}.01 \\
.00\end{array}$ & $\begin{array}{c}-.09 \\
(-.17)\end{array}$ \\
\hline & & & & & & * & $\begin{array}{l}.04 \\
(.08)\end{array}$ \\
\hline & & & & & & & * \\
\hline
\end{tabular}

a 1971 differences in parentheses

* For the model specified, these differences must be zero. 
variables to ascertain if the interpretation of the causal model is consistent throughout.

Variables which have been found significant in household trip generation analysis were subjected to evaluation in this chapter. The inferences obtained from the analysis indicate that auto ownership and family size variables have the most direct influence on trip generation rates. Income and level of accessibility of the household to activity centers in the urban area also have an impact on travel, but this influence is an indirect effect due to their influence on auto ownership. Households with larger family incomes and in less accessible residential locations exhibit higher auto ownership rates. The number of household members in the labor force also is a determinant of auto ownership rates, both directly and through its corresponding relationship with household income.

Finally, the effect of occupational status of the head of the household can best be understood by the extent to which it affects household income. Occupational status is an important variable for explaining variations in income but the direct effects on any other variables in the causal model are substantively negligible. 
CHAPTER 8. CONCLUSIONS

This dissertation has been directed toward evaluation of urban travel characteristics at a disaggregate level of analysis. In general, the research has evaluated the individual's perceptions of items which are important in travel decisions. In particular, the research has concentrated on analyzing trip generation relationships which exists at the household level of analysis as opposed to the standard aggregate analysis unit, the traffic zone. Whereas, analysis of aggregate data allows the planner to study only average characteristics of a group of households or individuals, analysis of travel at the household level allows one to obtain a better understanding of the relationships which occur at the decision level. Understanding of travel behavior at the decision level is necessary to identify the causal relationships. With knowledge of the basic decision variables, the planner can better judge the effects which future changes in the transportation system, the urban environment, or the social structure may have on individual travel.

In the first segment of this research the individual's perception of factors which are important in mode and route choice were evaluated. In addition, special characteristics of the shopping trip were considered to determine the individual's reason for selecting a particular trip destination. The purposes of these analyses were to help understand the nature of the individual's decision process and relate this information to the concepts which are used in traditional modal split, trip distribution, and trip assignment models. The second portion of the research concentrated on the analysis of home based trip generation relationships which exist at the household level of analysis. The stability of 
these relationships was examined by evaluating changes in the relationships over a seven year period. The ability of the household models to estimate total area travel was also evaluated. Finally, the entire structure of many of the variables which have been found significant in explaining trip production was analyzed and tested for internal consistency.

\section{Major Research Findings}

Attitudinal Measurements

Evaluation of the individual's attitudes and perceptions of the factors important in selection of a mode of travel indicated that the prime consideration was a concern for a reliable service. This service would ideally be able to serve the individual at a time that was desired; and then would arrive at the destination without delay due to accidents or repairs. Travel time and costs, which are typical variables used in modal split analysis, were not considered by the respondents of this study as important elements in selecting the mode of travel. Analysis of the attitudinal responses by subgroups of the population indicated that all groups held basically the same values in regards to mode selection. One major difference was that non-licensed drivers appeared to be more aware of the out-of-pocket costs for transportation; this group showed greater concern for the cost of the transportation than did those individuals who were licensed drivers. Less than three percent of all household trips were actually made by bus transportation, and the data indicated that much of this travel was by those who are not licensed drivers. The individuals responses to the mode choice factors were nearly independent of the purpose of this trip.

Evaluation of factors important in choice of route indicated that safety was of prime importance, followed closely 
by a preference for a route with less congestion and strain to driving. The third rated factor was preference for a route with a minimum driving time. Present network assignment procedures do, in fact, use these latter factors. In trip assignment modeling, time is considered as the primary decision variable with adjustments to the network loadings being made as the volumes reach the capacity of the streets. The route choice factors were rated basically the same by all subgroups of the sample and the relative importance of the factors for the work trip and shopping trip were likewise equivalent. Evaluation of the attitudinal items which were designed to indicate trip destination preferences for the shopping trip, showed that travel distance, time and cost, were not the predominant factors in selecting a shopping location. Of greater importance were characteristics of the commercial development itself and availability of parking. In free form responses, however, many respondents did indicate that at least one of the reasons for shopping at the selected destination was because the location was the closest opportunity to satisfy the needs of that particular trip. Thus, while time and distance were not considered as the most important variables in selecting a trip destination, per se, the ability to satisfy the trip at the nearest opportunity was important. This is in agreement with the basic concept of the Intervening Opportunity Model for trip distribution.

Household Trip Generation Analysis

Estimation of Zonal Travel from Disaggregate Models.

This research indicated that relationships which occur at the decision level of travel tend to be stable over time. Home based trip production models developed from household data from 357 single family households in 1964 exhibited model parameters similar to household models based on data from the same 357 households in 1971. After development of each 
of the models, the household equations were used to estimate zonal area trips reported by all single family households from which the survey data were drawn. The household models from 1964 and 1971 were equally effective in estimating the 1964 zonal trips.

Household models were also developed using all households interviewed in the 1964 IRTADS study. These models were used to estimate the total area home based trip productions which were developed by IRTADS. The expanded household equations were compared with the zonal based trip production models used by IRTADS and were found to be nearly comparable for estimating area wide travel data. The household model is preferred because the relationships are not tied to an artificial aggregation scheme. The household model evaluates relationships which occur at an analysis level which is a common unit over time, therefore the model parameters are more nearly independent of changes in density of development or size of an areal unit. Also, because the model parameters are not tied to an aggregation unit of a particular study area, the observed relationships were found to be similar for two different urban areas, Indianapolis and the Tri-state area including New York City. If further research indicates that travel relationships at the household analysis level are consistent for different geographic areas, the planner would be better able to use information from one study area to study behavior in a different study area.

Reduction in Data Requirements. The research also noted that because the survey data is used more completely, considerably less data would be necessary for estimating household trip productions. Whereas, IRTADs selected five percent of the households in Indianapolis for developing travel relationships, this research also developed models based on an effective one percent sampling rate. The trip estimates from the data set which was reduced by eighty percent were 
equivalent to the estimates obtained from the larger data set. In the continuing transportation study, it should be possible to monitor changes in travel characteristics with substantially smaller data sets than are used for the zonal models.

Causal Structure of Trip Generation Variables. The primary factors important in explaining variations in household travel were family size and auto ownership. Other variables which have been found significant in explaining travel behavior were also investigated. The variables given primary consideration were number of household members in the labor force, family income, occupation of the head of household, stage in the family life cycle and the relative accessibility of the household to activity centers in the urban area. A theory of the causal priorities of these variables was hypothesized and tested using analysis of variance and causal analysis modeling techniques. The research found that while the additional variables are important in understanding the relationships which affect travel behavior, the variables are not the direct causes of varying trip generation rates. Income, labor force, and level of accessibility are more important in defining variations in auto ownership rates. Labor force and occupation of the head of the household are important in defining the level of family income. Income, in turn, is an indicator of the type of housing or quality of living which the family is able to attain. As such, income was found to be the strongest indicator of the level of accessibility in which the family may choose to reside. The mathematical equations which represented the above relationships were simultaneously subjected to analysis in a structural model to test the consistency of the hypothesized causal structure. The causal structure was found to be faithful in representing the observed correlations in the data. 
Application and Recommendations for Future Research

Household trip generation relationships can be effectively expanded to estimate zonal home based travel. For the single family households in this study, the relationships were found to be relatively stable over time. Since a much smaller data set would be necessary to develop the model parameters, it is suggested that, in the continuing transportation study, the planner could monitor possible changes in the model parameters much more efficiently by examining household data rather than zonal average data. After analysis at the household level, the trip generation equations such as developed in this research, could be expanded to whatever aggregate level the planner desired.

Based on the analyses and results of this dissertation extensions of the research are recommended. First, this research has analyzed the stability of travel characteristics of a select group of families which have lived in the same single family household for a minimum of seven years. There is a need to determine if the general population would demonstrate the same degree of stability in the trip generation relationships and the same general response to the mode and route choice preferences. This general population would include families living in other dwelling unit types, and families having changed residential location within the urban area.

Secondly, the sampling variability of the household data set should be studied further to determine the extent to which the data set may be reasonably reduced. The eighty percent reduction of the sample in this study indicates that a substantial reduction would be possible for estimating trip production. A more thorough study of sampling variability should be conducted to determine the possible limits to sample size reduction. One should also determine the level of data needs in the continuing phase for the trip distribution, modal split and assignment models which are presently 
used in transportation planning.

Finally, compariscn of household trip generation relationships for different urban areas should be investigated to determining the degree of comparability of the model parameters in different areas. This research presented some indication that the model parameters may be similar across study areas. If this is the case, travel relationships developed in one area may have greater applicability in a second area than what has been noted when aggregate relationships are studied.

The household models examined in this research provide a means of studying travel characteristics at the behavioral level of analysis. The developed relationships can be used to obtain areal travel estimates which are necessary in other models used in the present state of the art of travel forecasting. Because of the potential benefits of reduced data requirements and better understanding of travel relationships in different urban areas, the disaggregate level research should be continued. 
LIST OF REFERENCES 


\section{LIST OF REFERENCES}

1. Blalock, H.M. Jr., Causal Inferences in Nonexperimental Research, University of North Carolina Press, 1964.

2. Botiny, W., "Trends in Automobile Ownership and Indicators of Saturation," Highway Research Record 106, Highway Research Board, Washington, D.C, 1966.

3. Box, G.E.P., "Some Theorms on Quadratic Forms Applied in the Study of Analysis of Variance Problems," Annals of Mathematical Statistics, Vol. 25, June, 1954.

4. Bureau of Public Roads, U.S. Department of Transportation, Guidelines for Trip Generation Analysis, U.S. Government Printing Office, 1967.

5. Deutschman, H.D., "Auto Ownership Revisited: A Review of Methods Used in Estimating and Distributing Auto Ownership," Highway Research Record 205, Highway Research Board, Washington, D.C., 1967.

6. Dixon, W.J., and F.J. Massey Jr., Introduction to Statistical Analysis, McGraw-Hill Book Company, New York, 1969 .

7. Domencich, T.A., G. Kraft, and J.P. Vallette, "Estimation of Urban Passenger Travel Behavior: An Economic Demand Model," Highway Research Record 238, Highway Research Board, Washington, D.C., 1968.

8. Draper, $N$. and H. Smith, Applied Regression Analysis, John Wiley and Sons, New York, 1966.

9. Duncan, O.D., "Path Analysis: Sociological Examples," American Journal of Sociology, Vol. 72, 1966.

10. Fleet, C.R., and S.R. Robertson, "Trip Generation in the Transportation Planning Process," Highway Research Record 240, Highway Research Board, Washington, D.C., 1968.

11. Guilford, J.P., Psychometric Methods, McGraw-Hill, Inc., New York, 1954.

12. Gulliksen, H., "A Least Squares Solution for Paired Comparison with Incomplete Data," Psychometrika, Vol. 21, 1956. 
13. Heise, D.R., "Problems in Path Analysis and Causal Inferences," Sociological Methodology, 1969, E.F. Borgatta, Ed., Jossey-Bass Inc., San Francisco, 1969.

14. Indianapolis Regional Transportation and Development Study, Home Interview Survey Manual, 1964.

15. , Origin-Destination Survey Coding Manual, $\overline{1964 .}$

16. "Trip Generation Analysis," Technical Work $\overline{\text { Paper, } 1966}$.

17. Paper, 1966.

"Travel Characteristics," Technical Work

18. Kain, J.F., "A Multiple Equation Model of Household Locational and Trip Making Behavior," RAND Memorandum 3086, RAND Corporation, Santa Monica, Cal., 1962.

19. Kassoff, H. and H. Deutschman, "Trip Generation: A Critical Appraisal," Highway Research Record 297, Highway Research Board, Washington, D.C., 1969.

20. Land, K., "Problems in Path Analysis and Causal Inferences," Sociological Methodology, 1969, E.F. Borgatta, Ed., Jossey-Bass, Inc., San Francisco, 1969.

21. Lansing, J.B., and G. Hendricks, Automobile Ownership and Residential Density, Institute for Social Research, University of Michigan, Ann Arbor, 1967.

22. MacGillivray, C.I., A Study of Billboards and Junkyards as Related to Some Aspects of the Aesthetics of the Highway Environment, Purdue University, M.S. Thesis, August, 1969 .

23. Manheim, M., "Practical Implications of Some Fundamental Properties of Travel Demand Models," Paper presented to Highway Research Board, January, 1972.

24. Martin, B.V., F.W. Memmot III, and A.J. Bone, principles and Techniques of Predicting Future Demand for Urban Transportation, M.I.T. Press, Cambridge, Massachusetts, 1966.

25. McCarthy, G.M., "Multiple Regression Analysis of Household Trip Generation - A Critique," Highway Research Record 297, Highway Research Board, Washington, D.C., 1969. 
26. McMillan, R., and H. Assael, "National Survey of Transportation Attitudes and Behavior," National Cooperative Highway Research Program Report Number 82, Washington, D.C., 1969 .

27. Michaels, R.M., "Attitudes of Drivers Determine Choice between Alternate Highways," Public Roads, Vol. 33, No. 11, December, 1965.

28. Nakkash, T., Activity-Accessibility Models of Trip Generation, Purdue University, Ph.D. Thesis, June, 1969.

29. Nash, A.N., and S.J. Hille, "Public Attitudes Toward Transport Modes: A Summary of Two Pilot Studies," Highway Research Record 233, Highway Research Board, Washington, D.C., 1968.

30. Oi, W. and P. Shuldiner, Analysis of Urban Travel Demand, Northwestern University Press, 1962.

31. Paine, F.T., et. al., "Consumer Conceived Attributes of Transportation: An Attitude Study," Maryland University, Department of Business Administration, 1967.

32. Quandt, R.E., and W. Baumol, "Abstract Mode Model: Theory and Measurement," Journal of Regional Science, Vol. 6, No. 2, 1966.

33. Robinson, W.S., "Ecological Correlations and the Behavior of Individuals," American Sociological Review, Vol. 15, June, 1950.

34. Siegel, S., Nonparametric Statistics for the Behavioral Sciences, McGraw-Hill Book Company, New York, 1956.

35. Simon, H., Models of Man, John Wiley and Sons, Inc., New York, 1957.

36. Stowers, J. and E. Kanwait, "The Use of Behavioral Surveys in Forecasting Transportation Requirements," Highway Research Record 106, Highway Research Board, Washington, D.C., 1966.

37. Suits, D., "The Use of Dummy-Variables in Regression Equations," American Statistical Association Journal, Vol. 52, December, 1957.

38. Torgeson, W.S., Theory and Methods of Scaling, John Wiley and Sons, Inc., New York, 1967.

39. U.S. Bureau of Census, "Income in 1970 of Families and Persons in the United States," Current Population Reports, Consumer Income, April, 1971. 
40. Wachs, M., Evaluation of Engineering Projects Using Perceptions and of Preferences for Project Characteristics, Northwestern University, Ph.D. Thesis, March, 1967 .

41. Walker, J.R., "Social Status of Head of Household and Trip Generation from Home," Highway Research Record 114, Highway Research Board, Washington, D.C., 1966.

42. Wheeler, J., "Some Effects of Occupational Status on Work Trips," Journal of Regional Science, Vol. 9, No. 1, 1968 .

43. Wold, H., and I. Jureen, Demand Analysis, John Wiley and Sons, New York, 1953.

44. Worrall, R.D., "The Urban Panel as a Longitudinal Data Source," Highway Research Record 194, Highway Research Board, washington, D.C., 1967.

45. Wright, S., "The Method of Path Coefficients," Annals of Mathematical Statistics, V, September, 1934.

46. Wright, S., "The Genetical Structure of Populations," Annals of Eugenics, XV, March, 1951.

\section{General References}

ABT Associates, Inc., Qualitative Aspects of Urban Personal Travel Demand, Cambridge, Massachusetts, 1968.

Brand, D., "Theory and Method in Land Use and Travel Forecasting," Presented at the Highway Research Board Meeting, January, 1972 .

Butler, E.W., et al., "Moving Behavior and Residential Choice - A National Survey," National Cooperative Highway Research Project, Report No. 81, Highway Research Board, Washington, D.C., 1969 .

Crespi, I., Attitude Research, American Marketing Association, Chicago, 1965.

Heathington, K.W., On the Development of a Freeway Driver Information system, Northwestern University, Ph.D. dissertation, June, 1969. 
Haney, D., "Consistency in Transportation Demand and Evaluation Models," Paper Prepared for Presentation at Annual Highway Research Board Meeting, 1972.

Hurst, M.E.E., "The Structure of Movement and Household Travel Behavior," Urban Studies, Vol. 6, No. 1, University of Glasgow, February, I969.

Kahn, R., and J. Cannell, The Dynamics of Interviewing, John Wiley and Sons, Inc., New York, 1957.

National Committee on Urban Transportation, Better Transportation for Your City, 1958.

Oppenheim, A., Questionnaire Design and Attitude Measurement, Basic Book, New York, 1966.

Ostle, B., Statistics in Research, The Iowa State University Press, Ames, Iowa, 1963.

Payne, S.I., The Art of Asking Questions, Princeton University Press, Princeton, New Jersey, 1957.

Reichman, S., and P. Stopher, "Disaggregate Stochastic Models of Travel-Mode Choice," Highway Research Record 369, Highway Research Board, Washington, D.C, 1971 .

Ruiter, E., "Improvements in Understanding, Calibrating, and Applying the Opportunity Model," Highway Research Record 165, Highway Research Board, Washington, D.C., I967.

Shaw, M., and J. Wright, Scales for the Measurement of Attitudes, McGraw-Hi1l, New York, 1967.

Stopher, P.R., and T. Lisco, "Modelling Travel Demand: A Disaggregate Behavioral Approach - Issues and Application," Proceedings Transportation Research Forum, Richard B. Cross Company, Oxford, Indiana, 1970.

Thurstone, L.L., The Measurement of Values, The University of Chicago Press, Chicago, 1929.

Vitt, J.E., et al., "Determining the Importance of User Related Attributes for a Demand-Responsive Transportation System," General Motors Research Publication, GMR-941, December, 1969. 
APPENDIX A

HOME INTERVIEW QUESTIONNAIRE AND RELATED MATERIALS 
APPENDIX A

HOME INTERVIEW QUESTIONNAIRE AND RELATED MATERIALS

The following questionnaire appears in the exact form as used in the 1971 survey. A copy of the letter sent to the households and a sample form used to record trips are attached. 


\section{INDIANAPOLIS AREA TRANSPORTATION STUDY}

Sample Name

Sample Address

Sample Number

Area Number

Travel Date

Principal Respondent

Interviewer's Name

Date of Interview

Time of start

Time of completion 
1. I would like to begin by getting some information about each person that lives here.

INTERVIEWER: Obtain the data in columns one (1) through six (6) at the beginning of the interview. At the completion of the interview, return to this section to obtain the information in columns seven (7) through nine (9).

\section{(1)}

\begin{tabular}{|c|c|c|c|c|c|c|c|c|}
\hline $\begin{array}{c}\text { Person } \\
\text { No. }\end{array}$ & $\begin{array}{c}\text { Relation } \\
\text { to } \\
\text { Head }\end{array}$ & Sex & $\begin{array}{c}\text { Licensed } \\
\text { Driver } \\
(\forall \text { if yes) }\end{array}$ & $\begin{array}{l}\text { Years } \\
\text { Driven }\end{array}$ & Occupation & Age & Education & $\begin{array}{c}\text { Marital } \\
\text { Status } \\
\end{array}$ \\
\hline 1 & & & & & & & & \\
\hline 2 & & & & & & & & \\
\hline 3 & & & & & & & & \\
\hline 4 & & & & & & & & \\
\hline 5 & & & & & & & & \\
\hline 6 & & & & & & & & \\
\hline 7 & & & & & & & & \\
\hline 8 & & & & & & & & \\
\hline
\end{tabular}

If more than 8 members live at this address, write in here the number of people who reside here but are not listed.

IN TER VIEWER:

Column 8, Education Codes

1. 8 th Grade or less

2. 2 yrs of High School or less

3. High School Graduate

4. 2 yrs. of College or less

5. College degree

6. Graduate Work

7. Business or Vocation School 
2. How many persons are regularly enrolled in primary or secondary school?

3. How many autos are owned here?

4. How many company-owed autos are garaged here?

5. How many miles or blocks is it to the nearest freeway or expressway? Miles or blocks

6. Is there a place near your home where you can walk to catch a city or suburban bus?

$$
\text { yes }
$$

no

7. How many blocks is it to the nearest bus stop?

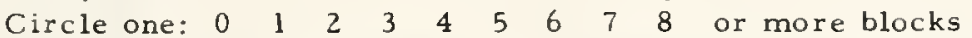
Don't know.

INTERVIEWER: If Respondent is unaware of Bus Service or if nearest bus stop is 8 or more blocks, skip to Q. 10 .

8. How often does a bus come by the bus stop at the time of day (Head) leaves for work? Every minutes

9. How of ten does a bus come by during the middle of the day, say at 1:00 P. M.? Every minutes

10. In the introductory letter which we sent to you, we asked that each member of the family keep a record of the numbers of trips he made on

(Travel Date). I would like to record that information now. Let's start with the head of the house.

INTERVIEWER: Fill in trip report information on next two pages, using additional forms $(\mathrm{HI}-4)$ if necessary. Also record trips made by anyone from out of the area who was visiting at this household on the TRAVEL DATE.

Record here the Number of Out-of-Area Visitors 


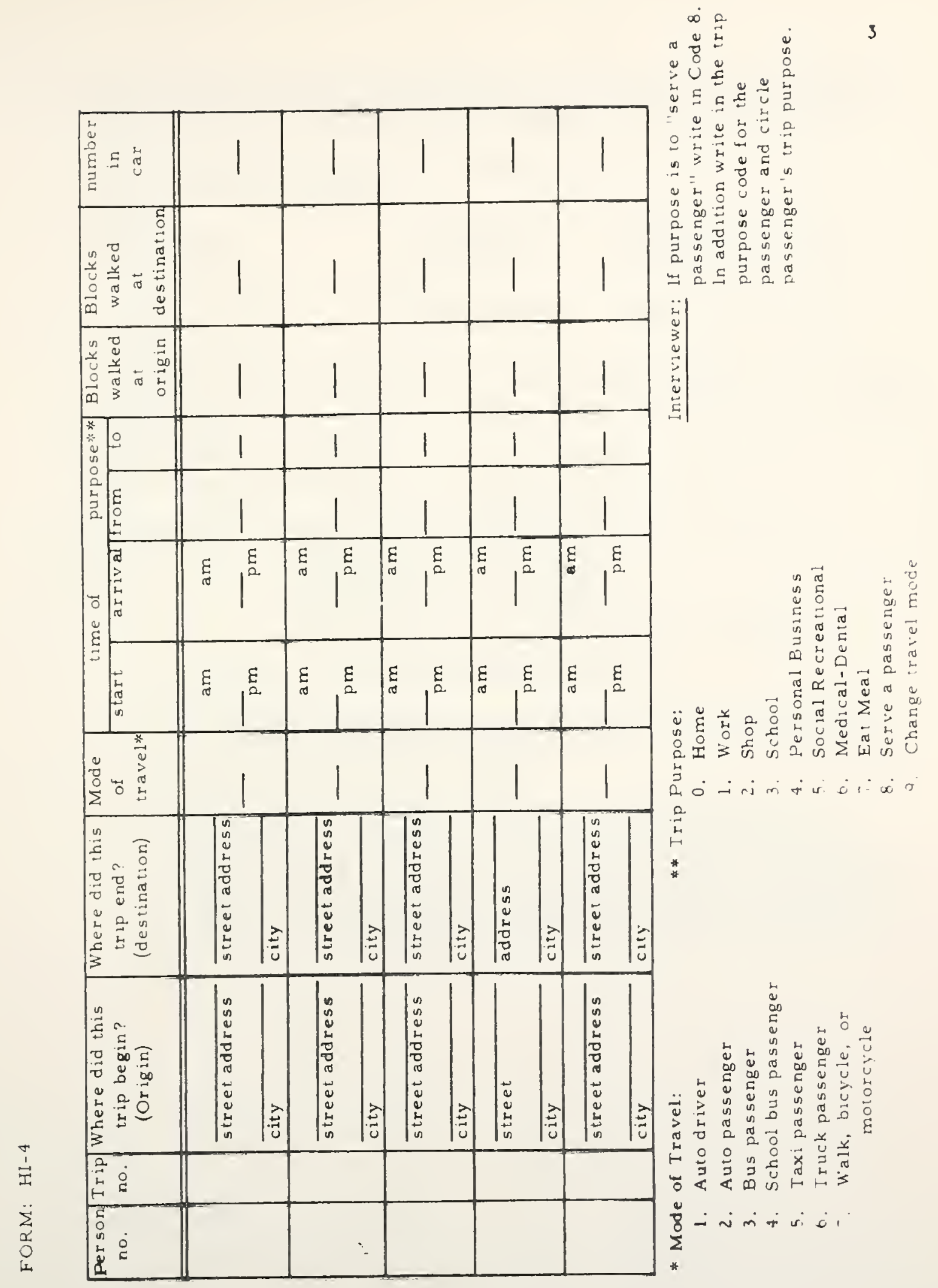


11. Now I would like to ask some questions about travel which you and other members of the household do within the area here. First I would like to ask some questions about means of transportation which members of your family use to get to work.

Which members of this household, 16 years old or older, make a regular trip to work two or more times a week?

Relation to Head

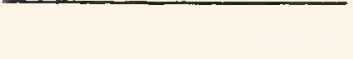

Person No. (from page 1 )
Check $(\Lambda$ it the person replies 1.0 Furm $1 \mathrm{~A}$

INTER VIEWER: If no one makes a regular work trip, skip to Question 47, page 13.

Request any of the other members of the household who are available and who make a regular work trip to $\mathrm{i} 11$ out Form $1 \mathrm{~A}$ of the survey form.

If respondent does not make a regular work trip and no other regular worker is available to answer form $1 \mathrm{~A}$, SKIP to Question 11c.

\section{HAND RESPONDENT (S) FORM IA}

11a. There are several characteristics of a transportation system such as cost, comfort, convenience and so forth, which seem to have diftercint degrees of importance to people when making a trip.

Assuming that you had a choice of ways to travel, I would like you lo letl me how important the factors in this list would be to you in chousing a means of transportation to get to work.

Choose a number somewhere on the scale which indicates how imporlarl you feel the particular item would be to you in chuosing a means of transportation to go to work. If an item is not at all important, you may circle the number 1 . If an item is of greatest importance, you may circle the number 7 . If your feelings lie somewhere in between you should circle a number on the scale which best describes how important that characteristic would be to you when choosing a way to go to work. 
Person No.

FORM IA

[2] is it:

When choosing a means of travel to get to work, how important

$\begin{array}{cc}\text { Not } & \text { Of } \\ \text { At All } & \text { Greatest } \\ \text { Important } & \text { Importance }\end{array}$

A. to be able to go whenever you want to?

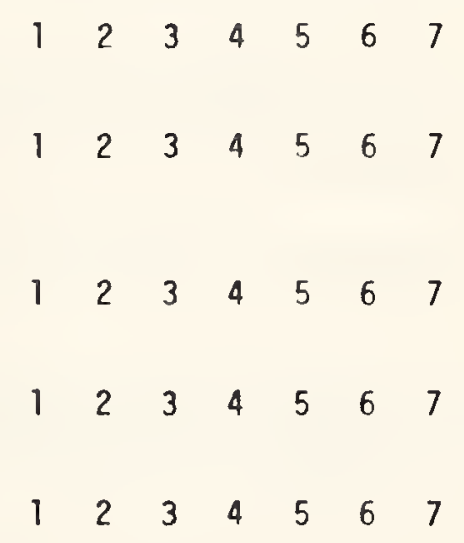

F. to feel confident the vehicle will not be stopped for repairs?

$\begin{array}{lllllll}1 & 2 & 3 & 4 & 5 & 6 & 7\end{array}$

G. to be independent of others for your transportation?

$\begin{array}{lllllll}1 & 2 & 3 & 4 & 5 & 6 & 7\end{array}$

H. to make the trip as fast as possible?

$\begin{array}{lllllll}1 & 2 & 3 & 4 & 5 & 6 & 7\end{array}$

I. to travel in an uncrowded vehicle?

1234567

J. to be able to ride with people you like?

1234567

$k$. to use a means of transportation which costs less?

$\begin{array}{lllllll}1 & 2 & 3 & 4 & 5 & 6 & 7\end{array}$

L. to be protected from the weather?

$12345 \quad 5 \quad 6 \quad 7$ 
Do any of you drive to work? Yes No Skip to Question $11 \mathrm{C}$

Interviewer: Hand Form $2 \mathrm{~A}$ to each person who drives to work.

On this sheet you will find several sets of items which might be important 1.1 you in choosing the route you take when going to work. For each pair, I would like you to circle the item which is more important to you when choosing your route to work.

Interviewer: Go through Form $2 \mathrm{~A}$ with respondent (s) and then return to question 1 lc Below.

Now for each member of the household which you listed before, I would like to ask some questions about their trip to work.

Interviewer: For each member of the Household who makes a regular work trip, repeat questions 12 through 46 . Use this questionnalre for Head of House or the firsl working member of household.

Use additional forms (3A) for other workers listed. 
Person No. FORH 2A-1

When choosing between two routes to go to work would you choose:

1. A. A route with a shorter driving time; or

B. A route with less congestion and strain to driving.

2. A. A route through more pleasant neighborhoods; or

B. A route with less congestion and strain to driving.

3. A. A route which you feel may be safer; or

B. A route with fower stop signs and signals.

4. A. A route with less congestion and strain to driving; or

B. A route with shorter distance.

5. A. A route with more stores, service stations and restaurants; or B. A route with shorter distance.

6. A. A route with a shorter distance; or

B. A route with a shorter driving time.

7. A. A route through more pleasant neighborhoods; or B. A route which you feel may be safer.

8. A. A route through more pleasant neighbohhoods; or

B. A route with more stores, service stations and restajrants.

9. A. A route with a shorter driving tiae; or

B. A route through more pleasant neighborhoods.

10. A. A route through more pleasant neighborhoods; or B. A route with a shorter distance.

11. A. A route with less congestion and strain to driving; or B. A route with fower stop signs and signals. 


\section{FORM 2A-2}

\section{2}

12. A. A route with fewer stop signs and signals; or

B. A route through more pleasant neighborhoods.

13. A. A route with a shorter driving time; or

B. A route which you feel may be safer.

14. A. A route with less congestion and stratn to driving; or

B. A route with more stores, service stations and restaurants.

15. A. A route with fewer stop signs and signals; or

B. A route with more stores, service stations and restaurants.

16. A. A route with shorter driving time; or

B. A route with fewer stop signs and signals.

17. A. A route with less congestion and strain to driving; or

B. A route which you feel may be safer.

18. A. A route with more stores, service stations and restaurants; or B. A route which you feel may be safer.

19. A. A route with shorter distance; or

B. A route which you feel may be safer.

20. A. A route with fewer stod signs and signals; or

B. A route with a shorter distance.

21. A. A route with more stores. service stations and restaurants; or B. A route with a shorter dpiving time. 
This trip report is for Person Number

12. How many miles is it to place where (worker) is employed?

13. How many days a week does (worker) go to work?

14. How many times a week does (worker) drive by himself (herself) to get to work?

15. How many times a week does (worker) ride or drive in a car pool to get to work?

16. How many times a week does (worker) ride a bus to get to work?

17. How many times a week does (worker) ride a taxi to get to work?

18. How many times a week does (worker) walk or bicycle to get to work?

Interviewer: Check the first box that applies to worker and go to ind cated question.

Worker never goes in private auto or bus go to Q. 19

Worker always goes by auto go to $Q .28$

Worker always goes by bus go to $Q .32$

Worker sometimes goes by auto go to $Q .25$

Worker sometimes goes by bus go to Q. 25

19. Why does worker choose the means of traneportation thet be uses to go to work?

20. Would (worker) prefer to make the trip by some otber means of transportation?
Yes
No
Go to Q. 21

20a. What way would he (bo) prefer?

20b. Why would that be better?

21. How long does it take (worker) to get from home to the place he (she) is employed" minutes 
22. How much does it cost (worker) to get to his (her) place of employment? \& Don't know

23. Is there a car available which worker could use to make this trıp? yes_ No_ Gu to Q. 24

23a. How long would it take (worker) to get to work if he (she) were to go by private auto? minutes Don't know

23b. How much would you say it would cost for gas oll and parking if he (she) were to go by private auto? Don't know

24. Could (worker) have used the bus to get to work?

Yes_G_ Go to Page 12 Q. 12 No_ Go to Page $13 \quad$ Q $\quad$ Q_ 47

These questions are for respondents who use either private auto or bus for some of the work trips.

25. Why does (worker) sometimes go one way and at other tımes he (she) uses a different means to get to work?

26. How would (worker) prefer to go to work?

27. Why do you feel (worker) would prefer going that way?

Interviewer: Check one and go to indicated question.

Worker sometimes goes by car Go to Q. 28

Worker never goes by car Go to Q. 32

28. How long does it take (worker) to get from home to his (her) place of employment when he (she) goes by car? minutes

29. How much of this time is spent looking for a parking space and walking to and from the car? minutes

30. Considering costs for gas, oil, and parking - - or the amount that (he, she) pays others to drive - - what would you say it costs (worker) each day to get to work? 
FORM 3A - 3

31. Does (worker) use the car in his (her) job? Yes

No

Interviewer: If worker does not make any work trips by crly or suburban hus, SKIP 10 Question 38.

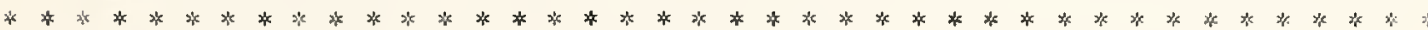

32. How long does it take (worker) to get from home to work when he (she) lakes the bus? minutes

33. How much of this time is spent walking to and from the bus? minules

34. How long does (worker) usually have to wait for a bus once he (she) is at the bus stop? minutes

35. Does (worker) have to transfer to get to his (her) place of tmpluyment?

$$
\text { Yes_ No_ Go to Q. } 36
$$

35a. How many times does worker transfer?

35b. How much lime does it take to make these translers? II) 1111110.5

36. How much does it cost (worker) when he (she) uses the bus:

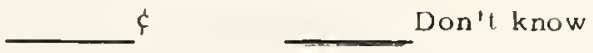

37. Would there have been a car available at home that (worker) could use un the days that he (she) rides the bus? Yes No

Interviewer: Check one box and go to indicated question. Worker makes some trips by car Go to Q. 47

Worker never goes by car Go to Q. 43 
For Respondents who never use the bus for work trips.

38. Does a city or suburban bus go to the area where (worker) is employed?

$$
\text { Yes_ No_ Skip to Q. } 47
$$

39. Could (worker) have used the bus to go to the area where (worker) is employed?

$$
\text { Yes_ No_ Skip to Q. } 47
$$

40. How often would (worker) have to transfer buses if he (she) were to take the bus?

41. Could you tell me how long it would take worker to get to work if he rode the bus?

minutes

42. How much would it cost to make the trip to work by bus Don't Know

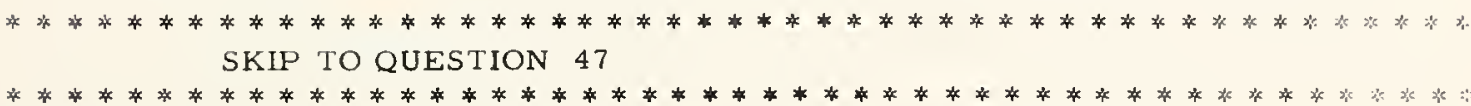

For Respondents who always use the bus.

43. Would (worker)prefer to go to work using a different means of transportatıon?

Yes_ No_ Skip to Q. 44

43a. What way would he prefer to go?

43b. Why would that be better?

44. Is there a car available for (worker) to use to go to work?

$$
\text { Yes_ No_ Skip to Q. } 47
$$

45. Why does (worker) take the bus rather than go by car?

46. Considering the cost for gas, oil and parking, how much would you say it would cost worker to go to work by car? Don't Know 
47. Now I would like to ask some questions about trips which your family makes for shopping. I would like you to consider a trip to shop for clothing.

INTERVIEWER: Request any other adult members of the family who are available to fill out Form $4 \mathrm{~A}$.

\section{HAND RESPONDENT(S) FORM 4A}

There are several characteristics of a transportation system such as cusl, comfort, convenience and so forth which seem to have different. degrees of importance to people when making a trip.

Assuming that you had a choice of ways to travel, I would like you to tell me how important the factors in this list would be to you in choosing a means of transportation to go shopping.

Choose a number somewhere on the scale which indicates how important you feel the particular item would be to you. If an item is not at all important, you may circle the number 1 . If an item is of greatest importance, you may circle the number 7 . If your feelings lie somewhere in between you shuuld circle the number on the scale which best describes how important lhal characteristic would be to you when choosing a way to go shopping.

INTERVIEWER: Go through Form $4 \mathrm{~A}$ with Respondent and then return to the section below.

INTERVIEWER: If the respondent is not a licensed driver and no licensed drivers are available to fill out form 5A, SKIP to $Q$. $\infty$

\section{HAND RESPONDENT(S) FORM 5A}

48. Here is another list of items which might be important to you in choosing the route you take to go shopping. For eecb pair, I would like you to circle the item which is most important to you when choosing a route to go shopping. 
Person No.

FORM 4A

[1] is it:

When choosing a means of travel to go shopping, how important

$\begin{array}{cc}\text { Not } & \text { Of } \\ \text { At All } & \text { Greatest } \\ \text { Important } & \text { Importance }\end{array}$

A. to feel confident vehicle

will get to destination

without an accident?

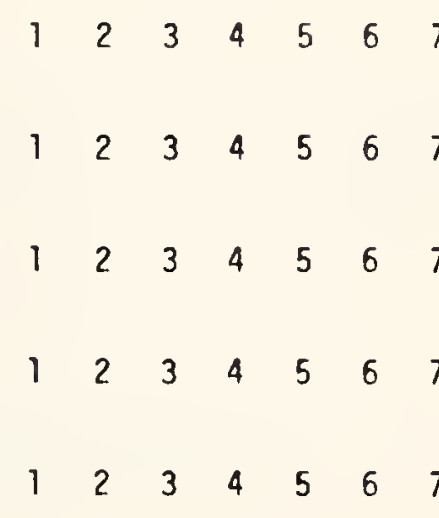

B. to make the trip as fast

as possible?

C. to be independent of others

for your transportation?

D. to travel in an uncrowded vehicle?

E. to use a means of transportation which costs less?

F to feel confident the vehicle will not be stopped for repairs?

$\begin{array}{lllllll}1 & 2 & 3 & 4 & 5 & 6 & 7\end{array}$

G. to be able to ride in areas which are familiar to you?

$H$. to be protected from the we a ther?

I. to be able to go whenever you want to?

J. to be able to ride with less strain and tension?

K. to be able to ride with people you like?

$\begin{array}{lllllll}1 & 2 & 3 & 4 & 5 & 6 & 7\end{array}$

$\begin{array}{lllllll}1 & 2 & 3 & 4 & 5 & 6 & 7\end{array}$

$\begin{array}{lllllll}1 & 2 & 3 & 4 & 5 & 6 & 7\end{array}$

$\begin{array}{lllllll}1 & 2 & 3 & 4 & 5 & 6 & 7\end{array}$

L. to have a comfortable vehicle to ride in? 
Person No.

FORM $5 A-1$

प]

When choosing between two routes to go shopping, would you choose

1. A. A route which you feel may be safer; or

B. A route through more pleasant neighborhoods.

2. A. A route with shorter driving time; or

B. A route with a shorter distance.

3. A. A route which you feel may be safer; or

B. A route with more stores, service stations and restaurants.

4. A. A route with fewer signals and stop signs; or

B. A route with shorter driving time.

5. A. A route through more pleasant neighborhoods; or

B. A route with less congestion and strain to driving.

6. A. A route which you feel may be safer; or

B. A route with a shorter distance.

7. A. A route which you feel may be safer; or

B. A route with less congestion and strain to driving.

8. A. A route with more stores, service stations and restaurants; or B. A route with a shorter driving time.

9. A. A route with more stores, service stations and restaurants; or B. A route with a shorter distance.

10. A. A route which you feel may he safer; or

B. A route with fewer stop signs and signals.

11. A. A route with less congestion and strain to Jriving; or

B. A route with more stores, service stations and restiurints.

$$
\text { (Please Continue un Next Page) }
$$


12. A. A route with a shorter distance; or

B. A route with less congestion and strain to driving.

13. A. A route with fewer signals and stop sians; or

B. A route with more stores, service stations and restaurants.

14. A. A route through more pleasant neiahborhoods; or

B. A route with a shorter distance.

15. A. A route with less congestion and strain to driving; or

B. A route with fewer stop signs and signals.

16. A. A route with a shorter driving time; or

B. A route through more pleasant nelahborhoods.

17. A. A route through more pleasant nelghborhoods; or

B. A route with more stores, service stations and restaurants.

18. A. A route with a shorter distance; or

B. A route with fewer stop signs and sianals.

19. A. A route with a shorter driving time; or

B. A route which you feel may be safer.

20. A. A route through more pleasant neiqhborhoods; or

$B$. A route with fewer stop signs and signals.

21. A. A route with less congestion and strain to driving; or

B. A route with shorter driving time. 
Next, I would like to get some information about a recent shopping trip which you made for such things as clothes, small household appliances, or other hous ehold needs.

49a. Have you used the bus to go shopping during the past week?

Yes___ go to question 51

49b. Have you taken a shopping trip in which you drove yoursell?

$$
\text { Yes___ go to question } 51
$$

Tell me then zbout your most recent shopping trip for clothes, small household appliances, or other household needs, in which you went in a private auto.

Who was driving:
Husband Wife Other Male Other Female

How many people a ltogether went on this trip?

What day was this trip made? (day and date)

What in general were you shopping for?

Where did you go to do your shopping? Check one. downtown lndianapolis

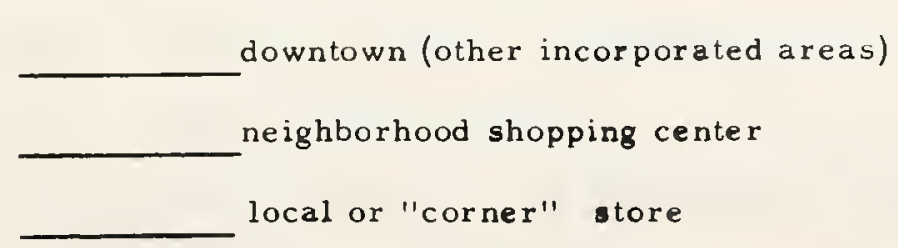

What are the names of the two streets which meet nearest the place where you did your shopping?

How many miles or blocks was it to the place where you did your shupping? miles or blocks 
How long did it take you to get to that location? min.

Considering such things as the time of day, the means of travel avalable io you, the weather, or other things which may influence you in deciding where you might shop, why would you say that you chose to gowhere you did, to do your shopping this time?

Probe: I see, is there anything else?

Did you actually shop at more than one store at this location?

Yes_ No

What time of the day did you start this trip? a. m. p $\mathrm{m}$.

Would you have preferred to go at a different time of day?

Yes No Skip to question 62

6la. What time would be better? a.m.

6 la. What time would be better? p. m.

61b. Why would that be better?

Would you consider shopping at any other places to obtain the items you wanted when you first decided to go shopping?

Yes No Skip to question 63

62a. Would any of these alternatives bave been closer to home? Yes How many? No

62b. How long would it have taken to get to the nearest place where you could have obtained the goods you were shopping for? minutes 
lnterviewer: if respondent is talking about a trip made by bus, skip to question 67

63. How long did it take you to find a place to park once you got to your destinaluon? Less than a minute $1-2$ minutes $2-3$ minutes

Less than a minute $\quad 1-2$ minutes
3 $^{3-5 \text { minutes }}$ More than 5 minutes

64. How much did it cost you to park?

65. Would you prefer to make your shopping trip by bus?

Yes_ No Go to 66

65a. Why is that?

66. Could you have made this trip by bus to the place where you shopped?

Yes_ No_ go to question 71

66a. How long do you think it would take you to get there if you went by bus? minutes

SK1P TO QUESTION 71

The following questions apply to those who used the bus for this trip.

67. At the time that you made this trip was there a car available which could have been used to go shopping? Yes_ No____ skip to question 68

67a. Why did you choose to use the bus instead of going by car?

68. Would you have used a different means of transportation if you had gone al a different time of day? Yes_ No_ skip to question 69

68a. What time of day would that have been? a. $\mathrm{m}$. 68 b. How would you go then?

$68 \mathrm{c}$. Would you have preferred to use that alternative?

$$
\text { Yes_ No }
$$


69. Would you have preferred to shop someplace else if you could have gine linere at the time of day you made this trip? Yes

No

70. Could you tell me please how long you think it would take to get. to the place where you shopped if you had gone by private auto? minutes

71. Now, I have another list of items which people might give as reasons which are important to them in choosing where they will go to do their shopping. Please indicate how important each of the items is to you when you decide where w shop? The range of values is the same as before. I indicales the llem is very unimportant, 7 indicates the item is very important. 
When you select a place to go shopping how important is it:

$\begin{array}{cc}\text { Not } & \text { Of } \\ \text { At All } & \text { Greatest } \\ \text { lmportant } & \text { Importance }\end{array}$

A. to go in an area of town you are familiar with?

$\begin{array}{lllllll}1 & 2 & 3 & 4 & 5 & 6 & 7 \\ 1 & 2 & 3 & 4 & 5 & 6 & 7 \\ 1 & 2 & 3 & 4 & 5 & 6 & 7 \\ 1 & 2 & 3 & 4 & 5 & 6 & 7 \\ 1 & 2 & 3 & 4 & 5 & 6 & 7 \\ 1 & 2 & 3 & 4 & 5 & 6 & 7 \\ 1 & 2 & 3 & 4 & 5 & 6 & 7\end{array}$

H. to go to places where the roads are not congested?

$\begin{array}{lllllll}1 & 2 & 3 & 4 & 5 & 6 & 7\end{array}$

I. to go where you don't have to walk far after you get off the bus or out of the car?

$\begin{array}{lllllll}1 & 2 & 3 & 4 & 5 & 6 & 7 \\ 1 & 2 & 3 & 4 & 5 & 6 & 7\end{array}$

K. to go where you can ride to several other stores at

different locations?

L. To go where you can quickly find a place to park? 


$$
\begin{gathered}
\text { Not } \\
\text { At AlI } \\
\text { Important }
\end{gathered}
$$

M. to go where the cost of travel

is less?

N. to shop as close to home

as possible?

O. to go where the stores and

surroundings have a pleasant

appearance?
Of

Greatest

Importance

$\begin{array}{lllllll}1 & 2 & 3 & 4 & 5 & 6 & 7\end{array}$

$\begin{array}{lllllll}1 & 2 & 3 & 4 & 5 & 6 & 7\end{array}$ 
72. The trips which we have been talking about indicate to us how much demand for transportation, families like yours have. Now I would like to know what changes might have occurred in your life and the area and how these changes affected your travel. I will read you a list of items which may be changes which have occurred in your household or in the community over the last seven years. Would you please tell me which of the following items are changes which you have experienced during this time.

\section{INTERVIEWER:}

1. Read through the list of items, ebecking those which respondent indicates have changed.

2. For each item checked in the list, ask the respondent, in your own words, how the change affected the amount the members of the household travel.

For example: "Would you say that because of the change in (Head's) job status, the amount the family travels by auto in the urban area has increased, decreased, or did not change.

3. Repeat the series of questions of (2) for changes in travel in the urban area by public transportation (bus).

73. Were there other changes which have occurred which affected the amount you travel?

Yes

No Skip to question 74

How is that? 


\begin{tabular}{|c|c|c|c|c|c|c|c|}
\hline Changes & & & Amou & nt of Tra & vel in Urba & in area by: & \\
\hline (Check if & & Auto & mobile & & Publ & ic Transpor & rtation \\
\hline $\begin{array}{c}\text { Change } \\
\text { occurred) }\end{array}$ & $(\checkmark)$ & Increased & Decreased & $\begin{array}{l}\text { Did Not } \\
\text { Change }\end{array}$ & Increased & Decreased & $\begin{array}{l}\text { Did not } \\
\text { Change }\end{array}$ \\
\hline Job Status of Head & & & & & & & \\
\hline Work Location of Head & & & & & & & \\
\hline $\begin{array}{l}\text { Number of autos owned } \\
\text { by Family changed }\end{array}$ & & & & & & & \\
\hline Marital Status & & & & & & & \\
\hline $\begin{array}{l}\text { Change in lncome of } \\
\text { family }\end{array}$ & & & & & & & \\
\hline Increased Family size & & & & & & & \\
\hline $\begin{array}{l}\text { Children becoming } \\
\text { scbool age }\end{array}$ & & & & & & & \\
\hline $\begin{array}{l}\text { Other members of family } \\
\text { becoming licensed drivers }\end{array}$ & & & & & & & \\
\hline Children leaving home & & & & & & & \\
\hline $\begin{array}{l}\text { New shopping centers } \\
\text { in area }\end{array}$ & & & & & & & \\
\hline $\begin{array}{l}\text { New Recreational } \\
\text { facilities }\end{array}$ & & & & & & & \\
\hline $\begin{array}{l}\text { Quality of public trans - } \\
\text { portation changed }\end{array}$ & & & & & & & \\
\hline New freeway facilities & & & & & & & \\
\hline $\begin{array}{l}\text { Quality of street } \\
\text { facilities chenged }\end{array}$ & & & & & & & \\
\hline
\end{tabular}


74. Finally we would like to get your opinions about how you feel about your travel in the area. For eacb statement circle the 1 if you strongly disagree and the 7 if you strongly agree witb the statement. If your feelings lie somewhere in between, circle the number which best describes your feelings.

$\begin{array}{lc}\text { Strongly } & \text { Strongly } \\ \text { Disagree } & \text { Agree }\end{array}$

Travel on urban streets is difficult

$\begin{array}{lllllll}1 & 2 & 3 & 4 & 5 & 6 & 7 \\ 1 & 2 & 3 & 4 & 5 & 6 & 7 \\ 1 & 2 & 3 & 4 & 5 & 6 & 7 \\ 1 & 2 & 3 & 4 & 5 & 6 & 7 \\ 1 & 2 & 3 & 4 & 5 & 6 & 7\end{array}$

I don't generally worry about bow much it costs me for travel when 1 decide to make a trip

$\begin{array}{lllllll}1 & 2 & 3 & 4 & 5 & 6 & 7\end{array}$

I would rather stay at bome than be in the crowd of people that are out on the road

$\begin{array}{lllllll}1 & 2 & 3 & 4 & 5 & 6 & 7\end{array}$


In order that we can tell how different families differ in their needs for transportation, and to determine some other information which we do not know from the 1964 study, I would like to ask you some final questions.

a. Was the head of the house hold married in 1964?

$$
\text { Yes_ No }
$$

b. How many children were there in this household in 1964 ?

c. How many licensed drivers were there?

HAND RESPONDENT FORM HI-5

d. Here is a card showing income ranges. Which code shows most closely what your family income is now before taxes?

\section{Code Number}

e. How many miles did the family drive last year? Miles

f. How many of these miles would you say (head) drove? Miles

INTERVIEWER: Return to Question Number 1 and complete the data in columns 7 through 9 . 
FORM HII-5 INCOME RANGE CARD

$\begin{array}{crrrr}\text { CODE } & \text { WEEKLY } & & \text { MONTHLY } & \text { YYARLY } \\ 1 & \$ 0-77 & \$ 0-333 & \$ & 0-3,999 \\ 2 & 77-96 & 333-417 & 4000-4,999 \\ 3 & 96-115 & 417-500 & 5000-5,999 \\ 4 & 115-135 & 500-583 & 6000-6,999 \\ 5 & 135-154 & 583-667 & 7000-7,999 \\ 6 & 154-192 & 667-833 & 8000-9,999 \\ 7 & 192-231 & 833-1000 & 10,000-11,999 \\ 8 & 231-289 & 1000-1250 & 12,000-14,999 \\ 9 & 289-341 & 1250-1500 & 15,000-17,999 \\ 10 & 341-455 & 1500-1999 & 18,000-23,999 \\ 11 & 455+ & 2000+ & 24,000+\end{array}$




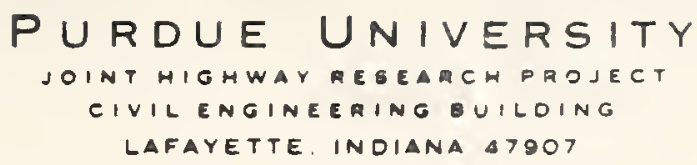

PURDUE UNIVERSITY

$A N D$

VDIANA STATE HIGHWAY COMMISSION

Dear Householder:

The Joint Highway Research Project of Purdue University is conducting survey in cooperation with the Indiana state Highway Comission. The purpose of this survey is to learn more about the travel needs and experience of the people in the Indianapolis area.

Your household has been selected from listing of households that were interviewed in sinilar survey in 1964. One of our representatives will call on you in few days. The facts that you give us will be used to plan for the future ransportstion needs of the people in the Indianapolis region. The information you glvo will be treated strictly confidential and will be usod for statistical purposes only.

In order to get the nost accurate information, each member of your family is asked to record on the enclosed forms all of the trips which he or she rakes on

Please follow the sample form on the beck of this letter.

Our interviewer will call you and errange a time to collect the information on your trip reports and ask some other questions about the trips you make in the area. We hope you will welcome the interviewer and the opportunity to provide inforation which will help plen for our transportation needs.

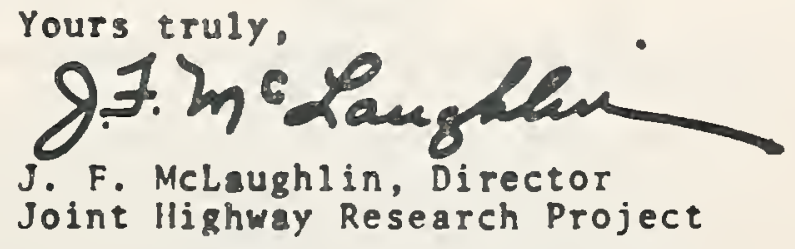




\section{YOUR TRIP REPORT}

NAME JOHN BAINES

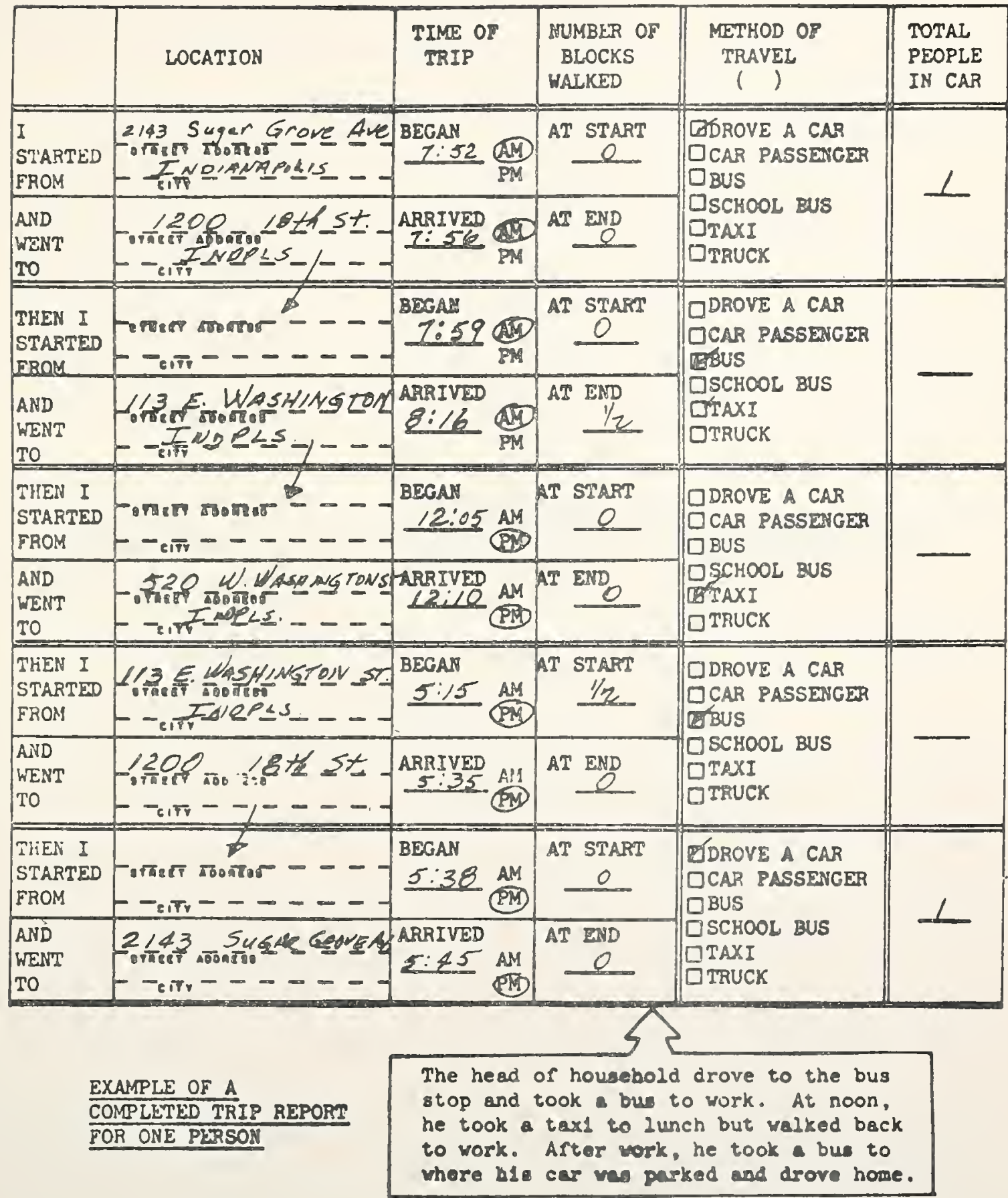


APPENDIX B

HOUSEHOLD CHARACTERISTICS AND TRIP PRODUCTION RATES 


\section{APPENDIX B \\ RESPONDENT CHARACTERISTICS AND \\ HOUSEHOLD TRIP PRODUCTION RATES}

The tables in this appendix give additional characteristics of the head of household and the average number of home based trips reported by the 357 households observed in this research. The trip reports are for 1964 and 1971 and are reported for family size, auto ownership, and income stratification. 


\begin{tabular}{cl} 
Number of & $\begin{array}{l}\text { Percent of } \\
\text { Respondents } \\
\text { in Group }\end{array}$ \\
\hline
\end{tabular}

1) Eigth grade or less

$\begin{array}{rr}43 & 12 \\ 48 & 14 \\ 139 & 39 \\ 59 & 17 \\ 33 & 9 \\ 22 & 6 \\ 12 & 3\end{array}$

TABLE B2 AGE DISTRIBUTION OF HEAD OF HOUSEHOLD, 1221

Number in

Age Group

Less than 35

35 to 44

45 to 54

55 to 64

65 and over
22

59

115

95

66
Percent in Age Group

TABLE B3 FAMILY STATUS OF HOUSEHOLDS IN 1964 AND 1971

Percent of Households in Group

1964

Married with school age children

54

43

Married without school age children

36

39

Not married

10

18




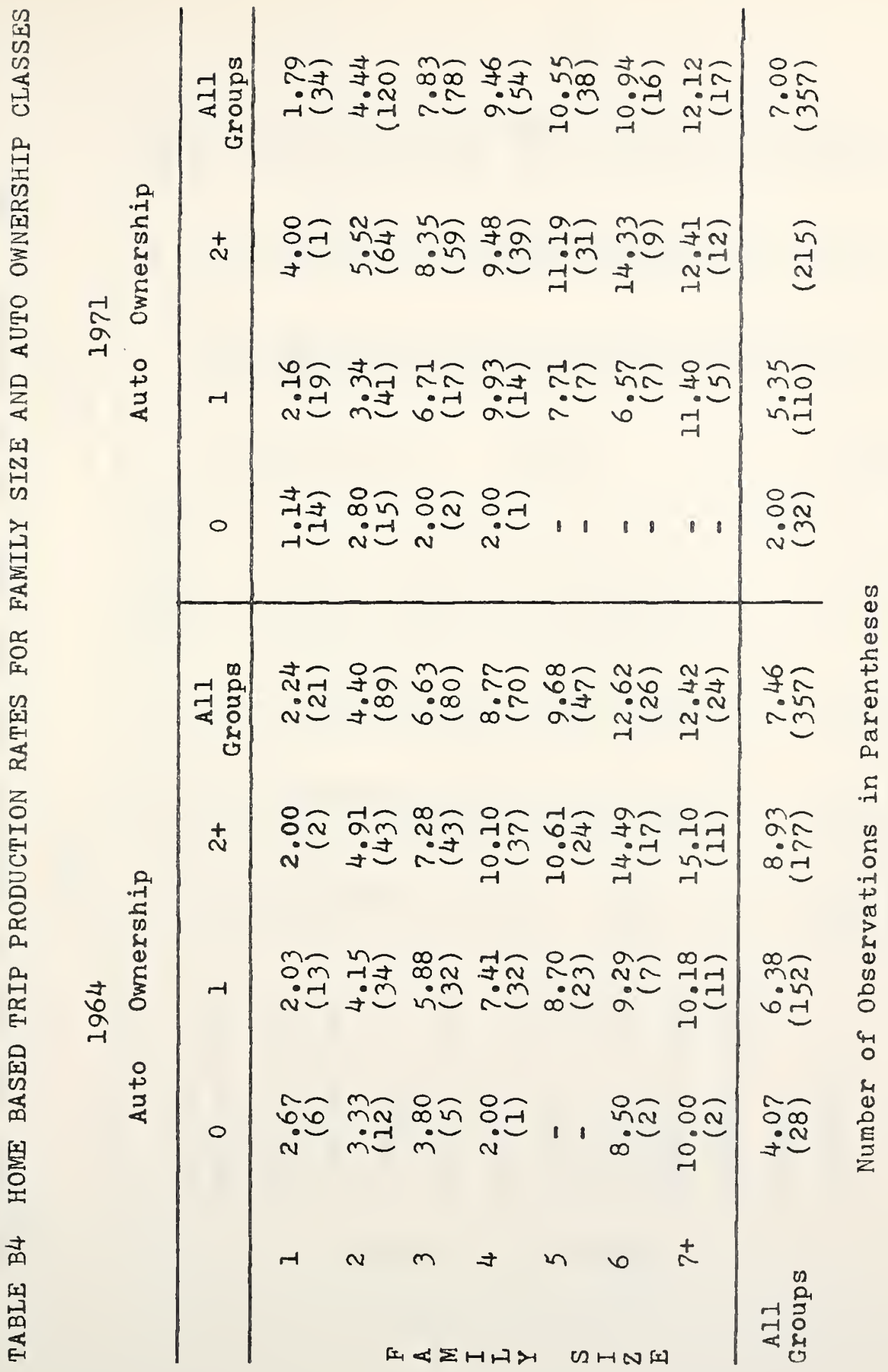




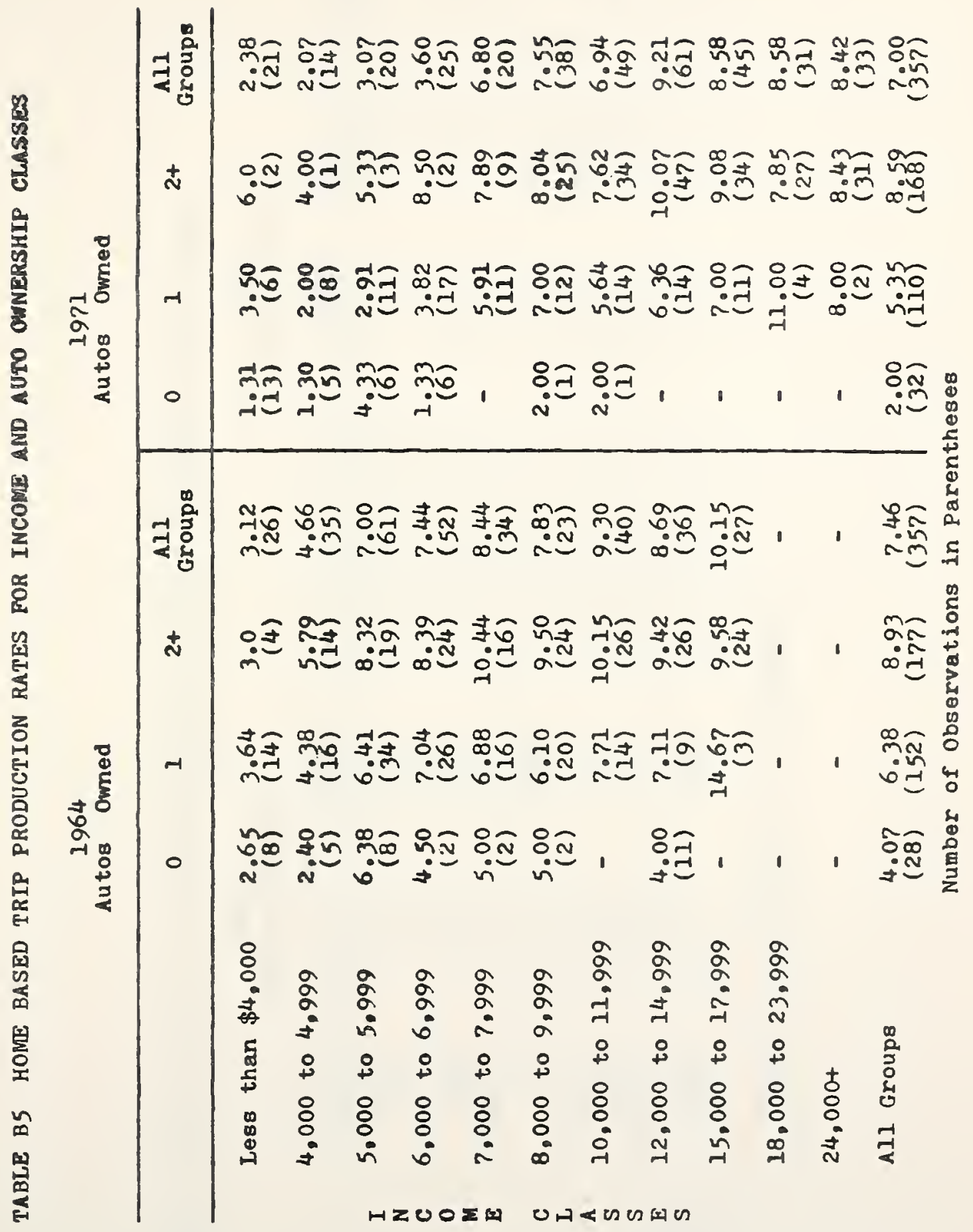




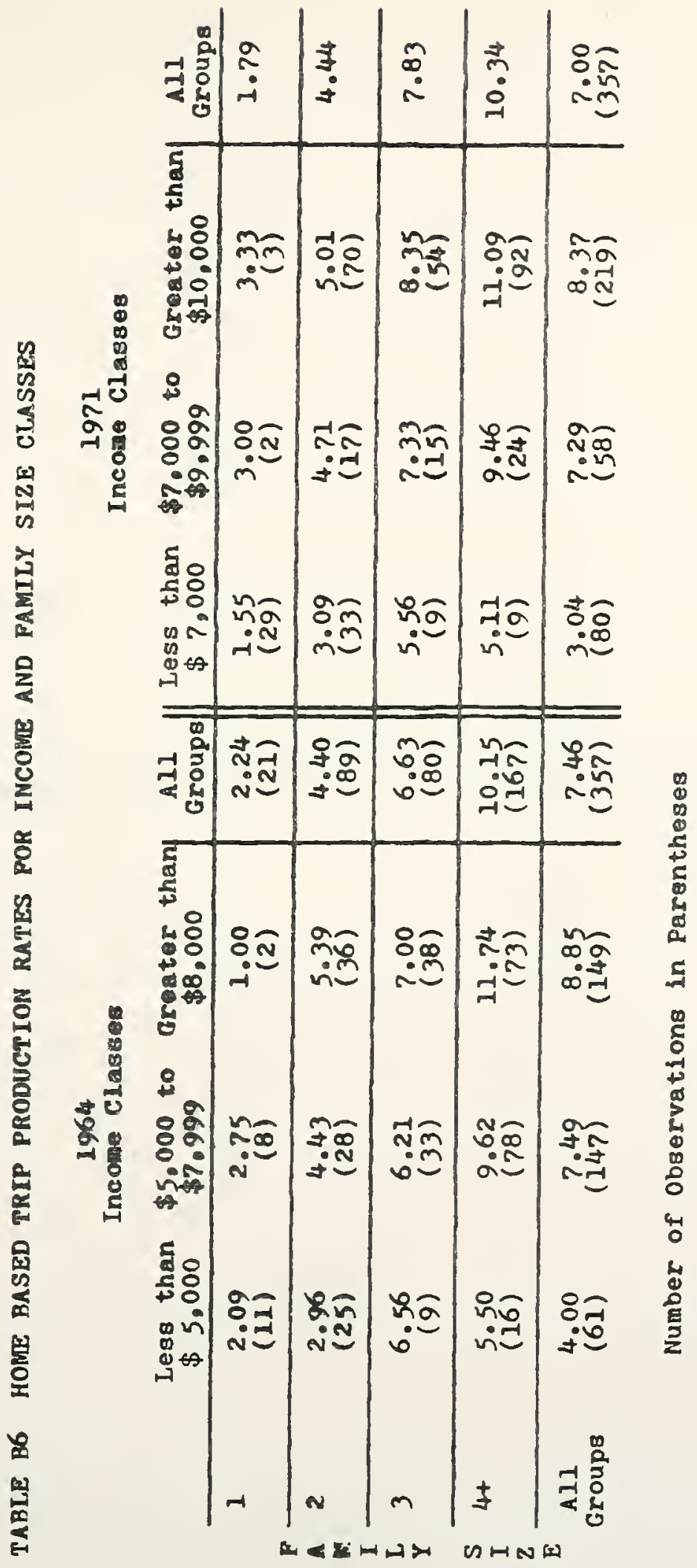


APPENDIX C

CHARACTERISTICS OF WORK TRIP AND SHOPPING TRIP 
APPENDIX C CHARACTERISTICS OF WORK TRIP AND SHOPPING TRIP

This appendix provides a summary of the data which was obtained in the unstructured section of the questionnaire. These questions were directed to differentiate between travel behavior of the respondents for the work trip and a shopping trip. In addition, the summated rating technique (Question 74) which was used to evaluate differences in trip production for individuals with different attitudes towards travel, is discussed.

The work trip questions were directed to determining modes of transportation, trip length and cost characteristics. The shopping trip was investigated in somewhat greater detail with an interest in obtaining information about the "why" of travel choice. Time of day, mode of travel, length of trip, and reasons for selecting the particular destination were given special consideration.

For each trip purpose there was an interest in distinguishing characteristics of respondents by mode of travel selected, however, the use of bus transportation by the respondents was too small to make anything other than general summarizations. The average number of reported vehicular trips per household was 9.31. About three percent of these trips, or 0.25 trips per household, were on the city or suburban bus lines. Moreover, these trips were generated from only 48 households of the 357 in the survey.

Lack of use of public transportation can not necessarily be attributed to lack of availability of the service in the areas in which these single family residences were located. Table Cl provides information which indicates the availability of public transportation service to the households 
of this survey in terms of distance to the bus line. Over $60 \%$ of the households are within three blocks of a city or suburban bus line. When the respondents were asked if there was a location where they could catch a bus, $81 \%$ indicated such an opportunity existed. However, of those indicating this opportunity, only fifty percent knew the frequency of service at the time the head of the household left for work. Thus, even though some service is available, a large percentage of the households in the study did not consider this transportation as a viable alternative: many were not even aware of the frequency of service provided.

TABLE CI DISTANCE TO BUS STOP FOR SURVEY HOUSEHOLDS

Number of Blocks ( $n$ ) to Bus Stop

8 or more

Unknown
Percent of all Respondents within ( $n$ ) Blocks

$\begin{array}{lr}1 & 29 \\ 3 & 20 \\ 4 & 14 \\ 5 & 8 \\ 6 & 5 \\ 7 \text { or more } & 0 \\ \text { Unknown } & 1 \\ & 14 \\ & 9\end{array}$

\section{Summary of Work Trip Characteristics}

A total of 362 completed forms were obtained with information about the trip to work (Form $3 \mathrm{~A}$ of Questionnaire.) The dominance of automobile usage is indicated here as only 13 workers always use the bus to get to work, while 8 others 
trade off between bus and private auto. Workers were generally satisfied with the mode of transportation used to get to work. Although about $25 \%$ of the bus users would prefer to go by car, this represents only a total of three workers. The length of the work trip varied according to the occupation and sex of the worker and the relative accessibility of the residential location of the worker. The joint affect of occupation and sex is exhibited by the data in Table C2. Managers, salesmen and craftsmen reported greater work trip lengths than the average of all occupation groups, while the trip length of the professionals was near the average of all groups. There was a degree of correlation between the trip length and the income range of the occupational groups. Each of the four groups whose journey to work is equal to a greater than the average, also report average incomes above the average of all groups. The remaining occupational groups report lower than average trip lengths and lower than average income. In all occupational levels, females consistently report a shorter journey to work.

Table C3 shows the effect of accessibility on work trip length. Since accessibility was originally defined as a relative accessibility to employment centers, one would expect that as the residential location becomes less accessible to employment centers the journey to work should increase in length. This was clearly the case for the households in the study.

\section{Characteristics of the Shopping Trip}

Table 04 provides a summary of the distribution of the shopping trip destinations for three modes of travel. By far the greatest percent of the trips were destined to neighborhood shopping centers. Only 13 percent were directed to the Central Business District of Indianapolis. Approximately fifty percent of the trips to the CBD were by bus 
TABIE C2 AVERAGE WORK TRIP IENGTH FOR OCCUPATION AND SEX GROUPS

\begin{tabular}{|c|c|}
\hline & 0 \\
\hline
\end{tabular}

\begin{tabular}{lccc}
\hline Professional & $\begin{array}{c}8.1^{a} \\
(39)^{b}\end{array}$ & $\begin{array}{l}6.1 \\
(15)\end{array}$ & $\begin{array}{l}7.5 \\
(54)\end{array}$ \\
\hline Managers & $\begin{array}{c}10.5 \\
(27)\end{array}$ & $\begin{array}{c}6.9 \\
(5)\end{array}$ & $\begin{array}{l}9.9 \\
(32)\end{array}$ \\
\hline Clerical & $\begin{array}{l}6.9 \\
(21)\end{array}$ & $\begin{array}{l}6.4 \\
(54)\end{array}$ & $\begin{array}{l}6.6 \\
(75)\end{array}$ \\
\hline Salesman & 8.3 & 4.6 & 7.7 \\
\hline Craftsman & $(31)$ & $(7)$ & $(38)$ \\
\hline Operatives & 9.6 & $\begin{array}{l}9.6 \\
(78)\end{array}$ & $(78)$ \\
\hline Service Personnel & 6.5 & 5.9 & 6.3 \\
& $(26)$ & $(12)$ & $(38)$ \\
\hline
\end{tabular}

${ }^{a}$ Distance in Miles

${ }^{b}$ Number of observations in parentheses

${ }^{c}$ Less than 5 observations 
TABLE C3 AVERAGE WORK TRIP IENGTH FOR VARYING LEVELS OF ACCESSIBILITY

Accessibility Levels

\begin{tabular}{rrrrrr}
\hline .010 & .070 & .140 & .210 & .280 & .350 \\
to & to & to & to & to & and \\
.069 & .139 & .209 & .279 & .349 & up \\
\hline
\end{tabular}

$\begin{array}{lllllll}\text { Length of work trip } & 12.67 & 10.69 & 8.67 & 7.08 & 5.15 & 5.0\end{array}$

$\begin{array}{lllllll}\text { Number of Observations } & 6 & 44 & 103 & 122 & 62 & 25\end{array}$

passengers. Twenty-two of the 27 bus trips, or 82 percent, were reported by females. In addition, only four of these trips were made by licensed drivers, indicating the high degree of captive ridership for the respondents using the transit system.

The average reported trip length of female shoppers was 3.7 miles, while males traveled 4.2 miles to shop.

\section{Reason for Selecting Shopping Iocation}

The respondents were asked to indicate the reason or reasons for selecting the shopping location which they chose for this particular trip (Question 58). Table C5 is a summary of these unstructured responses. The summary indicates the importance of shopping at a close and convenient shopping destination. Unfortunately, in the free response form, the meaning of convenience is not defined and, although the interviewer was asked to probe for other reasons for the selection, the respondent provided insufficient detail to determine the respondents definition of convenience. It would be impossible to state whether convenience was related to ease of travel to the location, ease in finding a parking location, or say, convenience of service provided by the commercial establishment. 
是

Z⿱

됭

D

总

$\underset{\text { 点 }}{\mathrm{B}}$

0

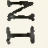

A

号

资

的

$z$ 这

喪

范

它

뫽

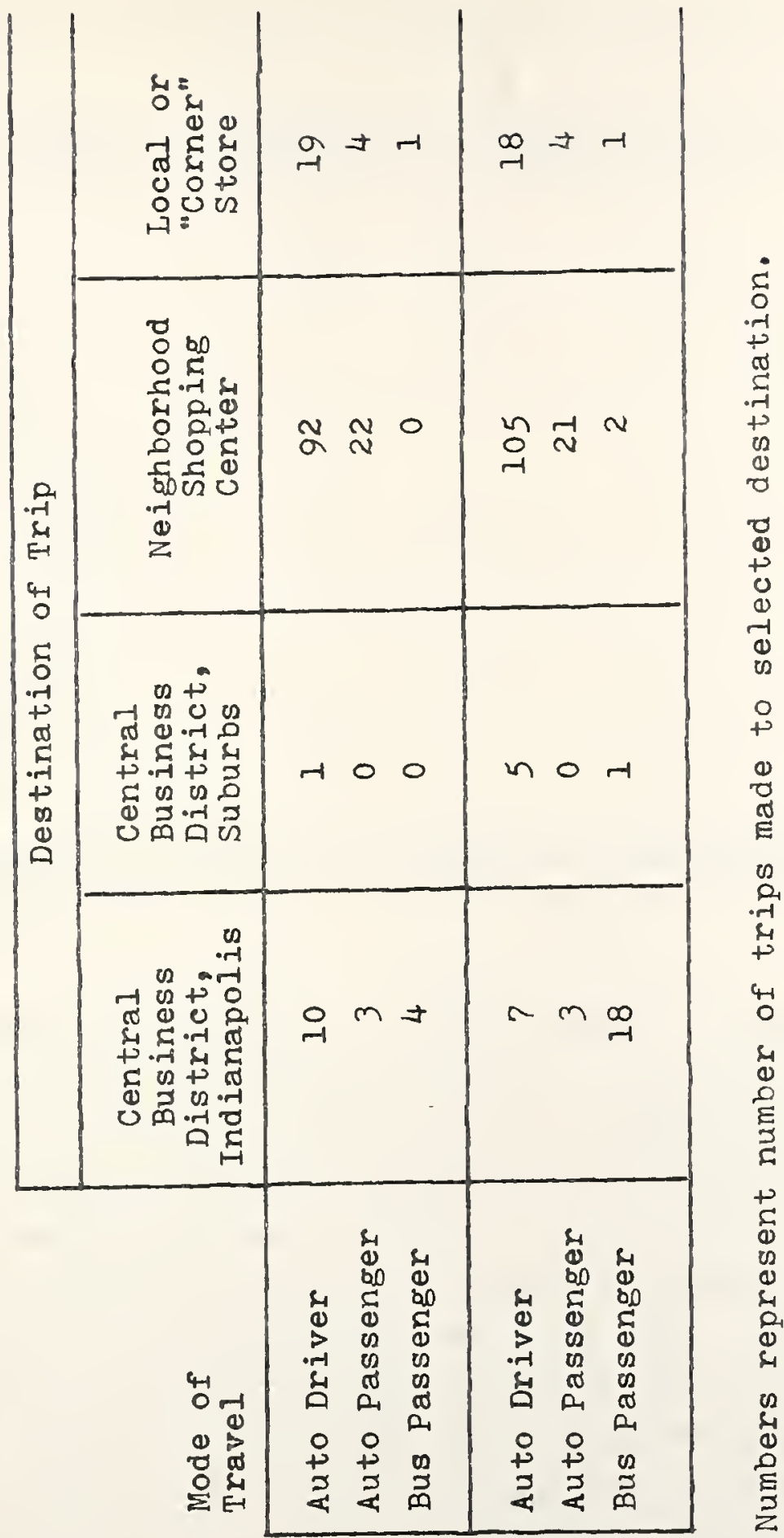


TABLE C5 REASONS FOR SELECTING SHOPPING TRIP DESTINATION

Reason for choice

of shopping location

Closest

Convenience

Selection

Price of goods

(or sale)

Had other business

in area

Could shop at several stores

Easiest to get to

Always go there

(traditional)

Miscellaneous
Number of

Responses

110

76

74

65

40

Percent of Respondents

Indicating this Factor*

32

22

22

19

12

26

8

13

4

11

3

47

14

* Since respondents could cite more than one reason for selecting their destination, the percentages do not add to 100 percent.

The respondents seldom directly stated a reason for their choice which was a direct factor of the quality of the transportation system or traffic flow. However, when the respondents were asked to consider whether a different time of the day would have been preferred for the trip, the effects of traffic become more prominent. Nearly twenty five percent of the respondents who would have preferred a different time to make the trip indicated they would prefer to make the trip at a time when there was less traffic. The conditions within the shopping development itself though, were more important as nearly one-third of the respondents indicated the stores would be less crowded if they could have gone at the preferred time. 
In general, the respondents were satisfied with the time of day for travel as only 15 percent would prefer an alternate time. Those starting their trips between 3:00 P.M. and 4:00 P.M. indicated the greatest desire to make the trip at an alternate time; forty percent of these individuals would have preferred another time of day. Irrespective of the actual time of start, 80 percent of those preferring an alternate time would like to have started the trip earlier in the day.

\section{A Summated Rating for Relating Individual's Attitudes to Rate of Trip Production}

A summated rating scale was used to obtain a measure of individual's psychologrical values which might be related to his inclination or desire to travel. It is felt that, in addition to economic considerations such as income and auto owership, the individual's attitudes towards travel would also help define variations in travel behavior. For example, respondents who agree with a statement that "it is relaxing to get away from the house and travel" may tend to make more trips than an individual who disagrees with the statement. The measures selected to describe the travel characteristics which might arise in an individual's psychological field are given in the questionnaire, (Appendix A, Question 74). These descriptors are repeated in Table $c 4$ along with the average response value for each statement. The scales were established such that a respondent more inclined to travel would have a higher socre than a respondent less inclined to travel. In the presentation of the statements, however, some of the statements (numbers one, three, and seven) were worded such that a low score would indicate higher travel inclinations. Then, during coding, the score values were reversed for these statements. The total score for all items is a composite measure of the individuals attitudes. 
TABLE C6 SUMMATED RATING SCALE ANALYSIS FOR RELATING

\section{INDIVIDUAL ATTITUDES TO TRIP PRODUCTION}

\section{Statement}

Travel on Urban Streets is Difficult.

I can leave to make a trip about any time I like.

It is difficult to get to the place I would really like to go.

I find it relaxing to get out and take a trip in the area. I don't worry too much about having an accident when I take a trip.

I don't generally worry about how much it costs me for travel when I decide to make a trip.

I would rather stay at home than be in the crowd of people that are out on the road.
Numerical rating indicating degree of agreement with statement a

$$
\begin{aligned}
& 3.62 * \\
& 5.09 \\
& 4.67 *
\end{aligned}
$$

4.28

4.50

4.82

$3.48 *$

Composite Score

30.46

a Maximum possible score is 7. A higher score is taken to represent a higher inclination to travel.

* These items were reversed scored before computing average (Average score $=8$ - Reported score) 
The average values were noted to be very close to a neutral opinion (scale value of 4 indicates the neutral position) for each of the individual statements and for the composite measures. The composite score of a persons attitude towards travel exhibited a linear correlation with the respondents trip production of 0.15 . This composite measure, as defined by the selection of statements in this study, was not considered a successful measure to differentiate travel behavior in an estimation model. 


\section{VITA}


VITA

Edward Joseph Kannel was born July 27, 1944 in Plum City, Wisconsin. He attended elementary school there and was graduated from Plum City High School in 1962.

He attended the University of Wisconsin - River Falls from 1962 to 1964 before transferring to the University of Wisconsin in Madison. He received the Bachelor of Science in Civil Engineering degree in 1966 and the Master of Science in Civil Engineering degree in 1967.

In 1967 he joined the staff of the University of Wisconsin - Platteville. In 1969 he returned to graduate studies at Purdue University.

He is an associate member of the American Society of Civil Engineers and the Society of Sigma $X i$. He is a member of the American Society of Engineering Education, Chi EpsiIon and Tau Beta $\mathrm{Pi}$. He is a student member of the Institute of Traffic Engineers and a supporting member of the Highway Research Board.

He is married and has two sons. 

